\title{
Cochrane
}

Library

Cochrane Database of Systematic Reviews

\section{Psychological interventions for symptomatic management of non- specific chest pain in patients with normal coronary anatomy} (Review)

Kisely SR, Campbell LA, Yelland MJ, Paydar A

Kisely SR, Campbell LA, Yelland MJ, Paydar A.

Psychological interventions for symptomatic management of non-specific chest pain in patients with normal coronary anatomy.

Cochrane Database of Systematic Reviews 2015, Issue 6. Art. No.: CD004101.

DOI: 10.1002/14651858.CD004101.pub5.

www.cochranelibrary.com

Psychological interventions for symptomatic management of non-specific chest pain in patients with normal 
TABLE OF CONTENTS

ABSTRACT

PLAIN LANGUAGE SUMMARY

BACKGROUND

OBJECTIVES

METHODS

RESULTS

Figure 1.

DISCUSSION

AUTHORS' CONCLUSIONS

ACKNOWLEDGEMENTS

REFERENCES

\section{CHARACTERISTICS OF STUDIES}

DATA AND ANALYSES

Analysis 1.1. Comparison 1: Psychological intervention versus no such therapy, Outcome 1: Any chest pain up to 3 months after intervention

Analysis 1.2. Comparison 1: Psychological intervention versus no such therapy, Outcome 2: Any chest pain from 3 to 12 months after intervention

Analysis 1.3. Comparison 1: Psychological intervention versus no such therapy, Outcome 3: Chest pain free days up to 3 months after intervention

Analysis 1.4. Comparison 1: Psychological intervention versus no such therapy, Outcome 4: Chest pain frequency up to 3 months after intervention

Analysis 1.5. Comparison 1: Psychological intervention versus no such therapy, Outcome 5: Chest pain frequency 3 to 12 months after intervention

Analysis 1.6. Comparison 1: Psychological intervention versus no such therapy, Outcome 6: Chest pain severity up to 3 months

Analysis 1.7. Comparison 1: Psychological intervention versus no such therapy, Outcome 7: Quality of life - physical functioning up to 3 months after intervention

Analysis 1.8. Comparison 1: Psychological intervention versus no such therapy, Outcome 8: Quality of life - physical functioning 3 to 12 months after intervention

Analysis 1.9. Comparison 1: Psychological intervention versus no such therapy, Outcome 9: Quality of life - role problems due to emotional limitations up to 3 months after intervention

Analysis 1.10. Comparison 1: Psychological intervention versus no such therapy, Outcome 10: Quality of life - role problems due to emotional limitations 3 to 12 months after intervention

Analysis 1.11. Comparison 1: Psychological intervention versus no such therapy, Outcome 11: Quality of life - social functioning up to 3 months after intervention

Analysis 1.12. Comparison 1: Psychological intervention versus no such therapy, Outcome 12: Quality of life - social functioning 3 to 12 months after intervention

Analysis 1.13. Comparison 1: Psychological intervention versus no such therapy, Outcome 13: Psychological symptoms up to 3 months after the intervention (depression \& overall)

Analysis 1.14. Comparison 1: Psychological intervention versus no such therapy, Outcome 14: Psychological symptoms up to 3 months after the intervention (anxiety and overall)

Analysis 1.15. Comparison 1: Psychological intervention versus no such therapy, Outcome 15: Psychological symptoms 3 to 12 months after the intervention

Analysis 1.16. Comparison 1: Psychological intervention versus no such therapy, Outcome 16: Cardiac anxiety fear up to 3 months

Analysis 1.17. Comparison 1: Psychological intervention versus no such therapy, Outcome 17: Cardiac anxiety fear 3 to 12 months

Analysis 1.18. Comparison 1: Psychological intervention versus no such therapy, Outcome 18: Cardiac anxiety avoidance up to 3 months

Analysis 1.19. Comparison 1: Psychological intervention versus no such therapy, Outcome 19: Cardiac anxiety avoidance 3 to 12 months

Analysis 1.20. Comparison 1: Psychological intervention versus no such therapy, Outcome 20: Cardiac anxiety attention up to 3 months

Analysis 1.21. Comparison 1: Psychological intervention versus no such therapy, Outcome 21: Cardiac anxiety attention 3 to 12 months 
[Intervention Review]

\section{Psychological interventions for symptomatic management of non- specific chest pain in patients with normal coronary anatomy}

Steve R Kisely ${ }^{1}$, Leslie A Campbell2 ${ }^{2}$, Michael J Yelland ${ }^{3}$, Anita Paydar ${ }^{4}$

1School of Medicine, The University of Queensland, Woolloongabba, Australia. 2Department of Community Health and Epidemiology, Dalhousie University, Halifax, Canada. ${ }^{3}$ School of Medicine, Logan Campus, Griffith University, Meadowbrook, Australia. ${ }^{4}$ School of Population Health, The University of Queensland, Brisbane, Australia

Contact: Steve R Kisely, s.kisely@uq.edu.au, steve.kisely@health.qld.gov.au.

Editorial group: Cochrane Heart Group.

Publication status and date: Stable (no update expected for reasons given in 'What's new'), published in Issue 4, 2021.

Citation: Kisely SR, Campbell LA, Yelland MJ, Paydar A. Psychological interventions for symptomatic management of non-specific chest pain in patients with normal coronary anatomy. Cochrane Database of Systematic Reviews 2015, Issue 6. Art. No.: CD004101. DOI: 10.1002/14651858.CD004101.pub5.

Copyright ( 2015 The Cochrane Collaboration. Published by John Wiley \& Sons, Ltd.

\section{A B S T R A C T}

\section{Background}

Recurrent chest pain in the absence of coronary artery disease is a common problem which sometimes leads to excess use of medical care. Although many studies have examined the causes of pain in these patients, few clinical trials have evaluated treatment. This is an update of a Cochrane review originally published in 2005 and last updated in 2010 . The studies reviewed in this paper provide an insight into the effectiveness of psychological interventions for this group of patients.

\section{Objectives}

To assess the effects of psychological interventions for chest pain, quality of life and psychological parameters in people with non-specific chest pain.

\section{Search methods}

We searched the Cochrane Library (CENTRAL, Issue 4 of 12, 2014 and DARE Issue 2 of 4, 2014), MEDLINE (OVID, 1966 to April week 4 2014), EMBASE (OVID, 1980 to week 18 2014), CINAHL (EBSCO, 1982 to April 2014), PsycINFO (OVID, 1887 to April week 5 2014) and BIOSIS Previews (Web of Knowledge, 1969 to 2 May 2014). We also searched citation lists and contacted study authors.

\section{Selection criteria}

Randomised controlled trials (RCTs) with standardised outcome methodology that tested any form of psychotherapy for chest pain with normal anatomy. Diagnoses included non-specific chest pain (NSCP), atypical chest pain, syndrome X or chest pain with normal coronary anatomy (as either inpatients or outpatients).

\section{Data collection and analysis}

Two review authors independently selected studies for inclusion, extracted data and assessed quality of studies. We contacted trial authors for further information about the included RCTs.

\section{Main results}

We included two new papers, one of which was an update of a previously included study. Therefore, a total of 17 RCTs with 1006 randomised participants met the inclusion criteria, with the one new study contributing an additional 113 participants. There was a significant reduction in reports of chest pain in the first three months following the intervention: random-effects relative risk $=0.70(95 \% \mathrm{Cl} 0.53$ to 0.92$)$. This was maintained from three to nine months afterwards: relative risk $0.59(95 \% \mathrm{Cl} 0.45$ to 0.76$)$. There was also a significant

Psychological interventions for symptomatic management of non-specific chest pain in patients with normal coronary anatomy (Review) 
increase in the number of chest pain-free days up to three months following the intervention: mean difference (MD) 3.00 (95\% $\mathrm{Cl} 0.23$ to 5.77). This was associated with reduced chest pain frequency (random-effects $\mathrm{MD}-2.26,95 \% \mathrm{Cl}-4.41$ to -0.12 ) but there was no evidence of effect of treatment on chest pain frequency from three to twelve months (random-effects MD $-0.81,95 \% \mathrm{Cl}-2.35$ to 0.74 ). There was no effect on severity (random-effects MD $-4.64(95 \% \mathrm{Cl}-12.18$ to 2.89$)$ up to three months after the intervention. Due to the nature of the main interventions of interest, it was impossible to blind the therapists as to whether the participant was in the intervention or control arm. In addition, in three studies the blinding of participants was expressly forbidden by the local ethics committee because of issues in obtaining fully informed consent. For this reason, all studies had a high risk of performance bias. In addition, three studies were thought to have a high risk of outcome bias. In general, there was a low risk of bias in the other domains. However, there was high heterogeneity and caution is required in interpreting these results. The wide variability in secondary outcome measures made it difficult to integrate findings from studies.

\section{Authors' conclusions}

This Cochrane review suggests a modest to moderate benefit for psychological interventions, particularly those using a cognitivebehavioural framework, which was largely restricted to the first three months after the intervention. Hypnotherapy is also a possible alternative. However, these conclusions are limited by high heterogeneity in many of the results and low numbers of participants in individual studies. The evidence for other brief interventions was less clear. Further RCTs of psychological interventions for NSCP with follow-up periods of at least 12 months are needed.

\section{PLAIN LANGUAGE SUMMARY}

\section{Cognitive-behavioural treatments for non-cardiac chest pain}

Recurrent chest pain in the absence of coronary artery disease is a common, difficult to treat problem that sometimes leads to excess use of medical care. A substantial number of patients are not reassured by negative medical assessment, reporting persistent pain and limitations. Psychological factors appear to be of importance for treatment. This Cochrane review included all studies of psychotherapy for non-cardiac chest pain. Seventeen trials met the inclusion criteria, and included a total of 1006 participants. The review found that cognitive-behavioural treatments are probably effective (in terms of reduced chest pain frequency) in the short term, for the treatment of non-cardiac related chest pain. No adverse effects of the psychotherapy were found. Hypnotherapy is also a possible alternative. A limitation of this review is the high variability of the studies included, reflected in a wide range of outcome measures, although there was an overall fairly low risk of bias. 


\section{B A C K G R O U N D}

Chest pain is one of the most frequent reasons for people's presentation to emergency services. Of patients admitted to the emergency department for chest pain, more than half are discharged with a diagnosis of noncardiac chest pain (NCCP) or chest pain of unknown cause (Capewell 2000; Knockaert 2002). Non-specific chest pain (NSCP) accounts for between $2 \%$ to $5 \%$ of all admissions to the emergency department (Eslick 2003; Knockaert 2002). Approximately 50\% of new referrals to outpatient cardiac clinics with the presenting complaint of chest pain are found to have a non-cardiac basis for their pain (Mayou 1997). The reported prevalence of NCCP in the community ranges from 23\% to 33\% (Eslick 2002; Eslick 2003). While various causes have been proposed, including microvascular coronary artery disease, coronary spasm, chest wall pain, oesophageal dysmotility or reflux, hyperventilation, panic disorder and general anxiety, many patients are given a non-specific diagnosis (Mayou 1997). In all groups of patients there is some association with psychiatric disorder, although the importance of this varies according to diagnosis.

Chest pain with normal coronary anatomy and no clear physical cause has been described by a number of terms including NSCP, NCCP, atypical chest pain, syndrome $X$ or chest pain with normal coronary anatomy. Syndrome $X$ refers to a triad of angina pectoris, positive exercise electrocardiogram (ECG) for myocardial ischaemia and angiographically smooth coronary arteries (Asbury 2005a). In this Cochrane review we will use the term NSCP. Most NSCP studies are concerned with outpatients with normal coronary angiograms whose chest pain is chronic. In one study, $61 \%$ of patients with NSCP had psychiatric symptoms on structured interview (the Clinical Interview Schedule), compared with $23 \%$ of patients with abnormal coronary arteries (Bass 1984). The respective figures for NSCP and coronary heart disease in another study using the Diagnostic Interview Schedule were $43 \%$ and $6.5 \%$ for panic disorder, $36 \%$ and $4 \%$ for major depression, and $36 \%$ and $15 \%$ for phobias (Katon 1988). These proportions are much higher than in patients with coronary heart disease, although a possible confounding factor may have been the chronic nature of the NSCP.

There have been similar findings in inpatients. In one study of consecutive admissions to a coronary intensive care unit, $55 \%$ of patients with NSCP $(n=27)$ had panic disorder compared with $11 \%$ of those with coronary heart disease (Carter 1992a). There was a similar but non-significant association between major depression and NSCP $(22 \%)$ as opposed to coronary heart disease (11\%).

The prognosis of patients with NSCP varies with the outcome measure. In contrast to patients with coronary disease, the incidence of myocardial infarction or death in patients with chest pain and normal cardiac arteriography is very low in most longterm studies (Chambers 1990). In terms of functional disability, approximately $75 \%$ of patients continue seeing a physician, $50 \%$ remain or become unemployed, and $50 \%$ regard their lives as significantly disabled. Fewer than $50 \%$ of NSCP patients appear reassured that they do not have serious heart disease. Most continue to report residual chest pain during follow-up (Chambers 1990).

A number of possible mechanisms for NSCP have been suggested. These include hyperventilation (DeGuire 1992; DeGuire 1996) or panic disorder (Mayou 1989b) and an association with alcohol and cigarette use (Kisely 1997), possibly mediated through changes in oesophageal motility (Kahrilas 1990; Matsuguchi 1984). Other potential mechanisms are less clear. There may be an interaction in which psychological factors affect the interpretation of physiological perceptions, which in turn worsen mental state (Chambers 1990). In addition, recent life events as measured by a structured interview or personality factors, such as an excess of Type A behaviour (hard driving and competitive behaviour, a potential for hostility, pronounced impatience and vigorous speech stylistics (Hemingway 1999)), have been identified as occurring more frequently in patients with NSCP compared with physically healthy controls matched for age and sex (Roll 1987). In addition, the presence of pain is associated with increased psychiatric morbidity, including psychophysiological symptoms other than pain, thus exacerbating the problem (Von Korff 1988). Chest pain forms part of the spectrum of medically unexplained symptoms, the exact presenting features varying by specialty. For instance, the equivalent for NCCP in cardiology would be irritable bowel syndrome in gastroenterology or fibromyalgia in rheumatology (Hatcher 2008).

Treatment is known to be difficult (Klimes 1990). Some patients are reassured by negative medical assessment, but a substantial number report persistent pain and limitations. A variety of drugs have been used including anti-secretory drugs, anxiolytics, antidepressants, nitrates and calcium channel blockers (Bennett 2001). As cognitions are of aetiological importance in NSCP and with high levels of psychiatric co-morbidity, psychological approaches have been suggested as appropriate interventions (Bass 1984; Klimes 1990; Ockene 1980) as early intervention might help prevent the pain becoming chronic. Such approaches generally use a behavioural framework and include an explanation of the nature of the pain, treatment of anxiety or depression, and cognitive behavioural psychotherapy.

The exact contributions to a successful outcome are unknown. Given the wide range of behavioural treatments in use, any systematic review would have to include a sensitivity analysis. The sensitivity analysis would identify any dilution of findings in the meta-analysis.

Both cognitive-behavioural therapy (CBT) and psychodynamic therapy are effective in treating anxiety and depressive disorders (Shapiro 1994). CBT is effective in the treatment of patients with unexplained physical symptoms (Speckens 1995; Hatcher 2008) and chronic fatigue syndrome (Price 2008; Sharpe 1996). Previous versions of this review indicated modest to moderate benefit for psychological interventions, particularly those using a cognitivebehavioural framework, which was largely restricted to the first three months after the intervention (Kisely 2005; Kisely 2010). This is consistent with findings for other types of medically unexplained symptoms (Kroenke 2000; Hatcher 2008).

Given the large number of people living with chest pain and the high prevalence of psychiatric co-morbidity, it is important to identify psychological interventions that may alleviate such symptoms. This is an update of a previously published Cochrane review (Kisely 2005; Kisely 2010). 


\section{O B JECTIVES}

To assess the effects of psychological interventions for chest pain, quality of life and psychological parameters in people with NSCP. We included the psychological interventions of:

1. CBT;

2. Relaxation therapy;

3. Hyperventilation control;

4. Hypnotherapy;

5. Other psychotherapy/talking/counselling therapy;

6. Standard care, 'attention' placebo, waiting list controls or no intervention as the control conditions.

\section{METHODS}

\section{Criteria for considering studies for this review}

\section{Types of studies}

Randomised controlled trials (RCTs).

\section{Types of participants}

People presenting with chest pain who have normal anatomy as assessed on clinical history, cardiac enzymes, ECGs, exercise ECGs or coronary angiography. Diagnoses included NSCP, atypical chest pain, syndrome $X$, or chest pain with normal coronary anatomy (as either inpatients or outpatients). We included psychiatric comorbidity, although we excluded patients who were receiving drug therapy for psychiatric disorders.

\section{Types of interventions}

\section{Cognitive behavioural therapy}

For the purposes of this Cochrane review, we based CBT on Jones 2004's definition. In order to be classified as 'well defined' the intervention must clearly demonstrate the following components:

1. The intervention involves the recipient establishing links between their thoughts, feelings and actions with respect to the target symptom;

2. The intervention involves the correction of the person's misperceptions, irrational beliefs and reasoning biases related to the target symptom;

3. The intervention should involve either or both of the following:

- the recipient monitoring his or her own thoughts, feelings and behaviours with respect to the target symptom;

- the promotion of alternative ways of coping with the target symptom.

All therapies that did not meet these inclusion criteria and were described as 'CBT' or 'cognitive therapy' were labelled as 'less-well defined' CBT. We established the exact nature of 'less-well defined' therapies by contacting study authors.

We conducted a sensitivity analysis on the primary outcomes (see Types of outcome measures) of this Cochrane review to determine whether there was a difference based on the 'well-defined' or 'lesswell defined' classification of CBT.

\section{Relaxation therapy}

Relaxation therapy consists of alternating tension and relaxation of various muscle groups (Woolfolk 1983). Some studies have added imagery to the relaxation (Borkovec 1982).

\section{Hyperventilation control}

Hyperventilation control techniques consist of an explanation of how hyperventilation can contribute to symptoms (DeGuire 1992). Control of hyperventilation can be achieved by holding the breath for 20 seconds and then breathing on a six-second cycle (10 breaths per minute). Breathing should be as light as possible and preferably diaphragmatic. Additional relief can be obtained from either breathing into cupped hands or into a re-breathing bag for one to two minutes every five minutes until symptoms abate (QAP 1982).

\section{Hypnotherapy}

Hypnosis can be induced by eye closure, followed by progressive muscular relaxation and standard deepening techniques. Suggestions for normalisation of function and sensitivity are made using both imagery and conditioning techniques (Jones 2006).

\section{Other psychotherapy/talking/counselling therapy}

Any psychological intervention described as behavioural therapy such as psychosocial interventions such as non-directive counselling and supportive therapy and other 'talking therapies'.

\section{Control interventions}

Any of the above interventions compared with:

\section{Standard care}

The care that a person would normally receive had they not been included in the research trial. We considered standard care to include no change to normal daily activities, and no care in the context of the study, but patients were free to use any health agencies (such as their general practitioner (GP) or medical specialist) on their own initiative. The category 'standard care' also incorporates 'waiting list control groups' where participants receive drug or other interventions.

\section{'Attention' placebo}

Interventions where participants are involved in education.

\section{No intervention}

Untreated control group.

\section{Types of outcome measures}

\section{Primary outcomes}

A significant reduction in chest pain (as defined in the individual studies) following the intervention.

1. Pain intensity measured by categorical scales or visual analogue scales (VAS);

2. Pain diaries (mean difference (MD) in pain scores or recorded frequency of exacerbation of pain). 


\section{Secondary outcomes}

1. Psychological symptoms as defined by standardised psychiatric instruments or criteria such as the General Health Questionnaire, Beck Depression Inventory (BDI), Zung Depression Scale, Hamilton Anxiety and Depression Scales, Hospital Anxiety and Depression Scales (HADS), Present State Examination (PSE), Clinical Global Impression Severity, and Composite International Diagnostic Interview;

2. Quality of life e.g. Short Form-36 (SF-36) scores;

3. Health service use e.g. hospital re-admission for chest pain, outpatient contacts, visits to primary care;

4. Non-fatal cardiovascular events (stroke, myocardial infarction, angina pectoris, pulmonary embolism or peripheral arterial embolism);

5. Cardiac behavioural risk factors reduction (e.g. smoking, exercise and alcohol consumption);

6. Death (cardiovascular and all-cause mortality);

7. Health beliefs.

We grouped outcomes into short-term (within 12 weeks of the start of therapy), medium-term (between 13 to 24 weeks after the beginning of therapy) and long-term (> 24 weeks after the start of therapy).

\section{Search methods for identification of studies}

\section{Electronic searches}

We searched the following sources up to 6 May 2014 to identify potentially eligible studies and review articles: the Cochrane Library (CENTRAL, Issue 4 of 12, 2014 and DARE Issue 2 of 4, 2014), MEDLINE (OVID, 1966 to April week 4 2014), EMBASE (OVID, 1980 to week 182014), CINAHL (EBSCO, 1982 to April 2014), PsycINFO (OVID, 1887 to April week 52014 ) and BIOSIS Previews (Web of Knowledge, 1969 to 2 May 2014). We used methodological filters to identify RCTs in MEDLINE and EMBASE (Lefebvre 2011).

We have listed the search details in Appendix 1 (initial search up to 2002), Appendix 2 (from 2002 to 2008), Appendix 3 (2011 updated searches) and Appendix 4 (2014 updated searches).

\section{Searching other resources}

We checked the reference lists of all references that were retrieved as full-text articles and were potentially relevant, as well as relevant systematic reviews and literature reviews to identify other potentially relevant articles. We retrieved these articles and assessed them for possible inclusion in the review.

We wrote to the lead authors of all relevant references to ascertain if they knew of any additional published or unpublished studies that might be relevant to the review.

We scrutinised abstracts from national and international cardiology, psychiatry and psychology conferences to identify unpublished studies. These included meetings organised by national and international medical colleges, specialty societies and professional organisations.

We did not apply any language restrictions and we translated all relevant foreign language papers.

\section{Data collection and analysis}

\section{Selection of studies for inclusion/exclusion}

Two review authors (SK, LAC) independently selected suitable studies for inclusion in the original review (Kisely 2005), as detailed below. For the review updates, SK and AP performed this. Where the two review authors disagreed about the inclusion of a study, we resolved disagreements by consensus of opinion, and consulted a third review author if disagreements could not be resolved. Where resolution was not possible we contacted the trial authors to obtain more information and clarification.

We assessed titles and abstracts of studies identified by searching electronic databases to determine whether each article met the eligibility criteria. In order to prevent any bias, we printed a list of all titles and abstracts and excluded the author names, institutions and journal title. If the title and abstract contained sufficient information to determine that the article did not meet the inclusion criteria, then it was rejected. We recorded all rejected papers and the reasons for rejection. We scanned the reference lists of all relevant papers for published reports, conference abstracts and citations of unpublished research.

We retrieved the full papers of all remaining titles and abstracts deemed relevant. Also we reviewed all other potentially relevant articles identified by the various search strategies (reference checking, personal communications etc). Two review authors independently assessed all articles, who completed a form for each study and scored the quality of the research as defined below. We documented the reasons for exclusion. Where the same study had more than one article written about the outcomes, we treated all articles as one study and presented the results only once.

\section{Risk of bias}

We prepared a 'Risk of bias' table for any new articles included in this update. The 'Risk of bias' table included random sequence generation (selection bias), allocation concealment (selection bias), blinding of participants and personnel (performance bias), blinding of outcome assessment (detection bias), incomplete outcome data (attrition bias) and selective reporting (reporting bias) using the methodology described in the Cochrane Handbook for Systematic Reviews of Interventions (Higgins 2011).

\section{Losses to follow-up}

Ideally, included papers should have given an adequate description of the loss of its participants in terms of the number of withdrawals, dropouts and protocol deviations. In the protocol for this review we stated that we would only include RCTs where $<20 \%$ of participants originally randomised were lost to follow-up. In view of the limited number of trials, we relaxed these criteria to include studies that combined RCT and cross-over designs, and those that had greater losses to follow-up. In each case, we performed sensitivity analyses to assess the effect of the inclusion of these studies.

\section{Addressing publication bias}

Where there were more than 10 studies in an analysis, we entered data into a funnel plot (size of study versus effect size) (Egger 1997), to detect the possibility of publication bias. 


\section{Data extraction}

Two review authors (SK and LAC or AP) completed a data extraction form for each included study to elicit the following information:

- General: published/unpublished, title, authors, source, contact address, country, language of publication, year of publication, duplicate publications, sponsoring, setting (hospital inpatients or outpatients, primary care, community);

- Trial characteristics: design, duration, randomisation and method, allocation concealment and method, blinding of outcome assessors, check of blinding;

- Interventions (frequency, timing), comparison interventions, co-medications;

- Patient characteristics - sampling, exclusion criteria number of participants, age, sex, ethnicity, marital status, educational status, duration of symptoms, number of complications, mode of referral (e.g. self-referral or via psychiatrists, psychologists, or other clinicians), similarity of groups at baseline (including any co-morbidity), withdrawals/losses to follow-up (reasons/ descriptions), history of myocardial infarction (MI);

- Type of intervention - CBT, psychotherapy, 'talking/ counselling' therapy, no intervention versus psychological intervention; usual care versus psychological intervention; and 'attention' placebo versus psychological intervention; timing of intervention (early vs late);

- Type of outcomes - level of chest pain at baseline, and at subsequent follow-ups, psychiatric symptoms, quality of life, number of hospital re-admissions, non-fatal cardiovascular events, reduction of cardiovascular behavioural risk factors, death (cardiovascular and all-cause mortality), and health beliefs;

- Type of psychiatric outcome - clinical diagnosis or symptomatology assessed by questionnaire;

- Type of assessment tool used to assess psychiatric outcome e.g. BDI, Zung Depression Scale, HADS, Structured interview, DSM-IV criteria;Cut-off used on psychiatric scale, percentage of people defined as psychiatric cases on this basis; mean (SD) symptom score;

- Duration of follow-up and point from which follow-up was calculated start or end of intervention.

We stated that we would group outcomes into short term (within 12 weeks of the start of therapy), medium term (between 13 to 24 weeks after the beginning of therapy) and long-term (more than 24 weeks after the start of therapy). As interventions varied in length from one session to treatment lasting three months, we used time from the end of intervention to ensure that comparison between treatments were appropriate (i.e. an assessment made six months after baseline assessment and a three month course of treatment is the equivalent of three months after initial assessment for an intervention lasting a few days). Using this methodology, it was only possible to divide outcomes into those within three months of the end of the intervention (or the equivalent time for controls), and those from three to 12 months after the intervention (or the equivalent time for controls). Only one study reported data on ten participants at 36 month follow-up (DeGuire 1996).

\section{Data analysis}

\section{Data entry}

Two review authors (SK and LAC or AP) independently entered data into RevMan 2014. We reported a summary of data extracted from included studies. If studies were available that were sufficiently similar and of sufficient quality we pooled those that could be grouped together and meta-analysed the data. We synthesised the data using MetaView within RevMan 2014.

\section{Data types}

We assessed outcomes using continuous (e.g. changes on depression scales), categorical (e.g. one of three categories on a quality of life scale, such as 'better', 'worse' or 'no change') or dichotomous (e.g. either depressed or not-depressed) measures.

\section{Continuous data}

Many rating scales are available to measure outcomes in psychological trials. These scales vary in the quality of their validation and reliability. Therefore, if validation of a rating scale was not published in a peer-reviewed journal, then we did not include the data in this Cochrane review. In addition, the rating scale should either be self-reported or completed by an independent observer or relative. Trials that used the same instrument to measure specific outcomes were used in direct comparisons where possible. Where continuous data were presented from different scales rating the same effect, we presented both sets of data and inspected the general direction of the effect. We reported the mean and standard deviation (SD). Where SDs were not reported in the paper, we attempted to obtain them from the trial authors or to calculate them using other reported measures of variation, such as the confidence intervals (Cls). We pooled data from different scales rating the same outcome using the standardised mean difference (SMD).

\section{Dichotomous data}

We converted continuous outcome measures to dichotomous data where it was necessary to combine these with dichotomous outcomes. If the trial authors used a designated cut-off point for determining clinical effectiveness we used this where appropriate. Otherwise, we identified cut-offs on rating scales and divided participants on the basis of whether they were 'clinically improved' or 'not clinically improved'. For dichotomous outcomes, we estimated a risk ratio with its associated $95 \% \mathrm{Cls}$. As a summary measure of effectiveness, where possible we calculated the number needed to treat statistic (NNT).

Initially we compared any psychological intervention to any control. Depending on the number of included studies, we compared each intervention category with any control, and also subgroup according to type of control. We investigated the effect of different approaches using sensitivity analyses (see below).

\section{Heterogeneity}

When we inspected graphical representations of the data, if the $\mathrm{Cls}$ of the study results did not overlap, we deemed the differences were likely to be statistically significant (Walker 1988). In addition, we checked the differences between the results of each included trial using a test of heterogeneity. As these tests usually have low statistical power, we used a type I error level of 0.10 rather than the customary 0.05 for rejecting the null hypothesis of homogeneity.

Psychological interventions for symptomatic management of non-specific chest pain in patients with normal coronary anatomy (Review) $\mathbf{6}$

Copyright (c) 2015 The Cochrane Collaboration. Published by John Wiley \& Sons, Ltd. 
We analysed the results using both fixed-effect and random-effects methods. However, where there was significant heterogeneity (12 statistic > 50\%), we only used a random-effects model. We attempted to explore the reasons for this heterogeneity in post hoc analyses of omitting each study in turn where there were more than two studies. However, we reported both fixed-effect and randomeffects models when there was no statistical heterogeneity.

\section{Sensitivity analyses}

We investigated factors which may have led to differences between the results of individual studies by using sensitivity analyses. In this Cochrane review we investigated differences between:

- Trials which defined psychiatric symptoms operationally (e.g. clinician diagnosis or validated questionnaire and whether the questionnaire had been validated in this specific population or in other groups);

- Types of psychological interventions and types of controls;

- Route of referral for intervention (e.g. referred to psychiatrists, clinical psychologists, other mental health professionals or other clinicians for management);

- Participants with and without a family history of heart disease;
- Studies that used subject reported pain or assessments by clinicians or carers;

- Well-defined and less-well defined psychological interventions;

- Analyses involving all studies and excluding trials of low methodological quality;

- Analyses involving all studies and those that excluded comorbid psychiatric disorder;

- Participants with and without a history of myocardial infarction;

- Participants with and without coronary angiography; and

- Self referral and referral from a clinician.

\section{RE S U L T S}

\section{Description of studies}

\section{Results of the search}

In the literature search in 2014 we identified 81 unique references in addition to the 369 articles we identified in 2011, 2008 and 2002. From these, and the original searches, we considered 81 papers in detail for inclusion. Of these, we excluded 58 papers from 55 studies, and included 23 papers from 17 studies (Figure 1).

Figure 1. Study flow diagram.

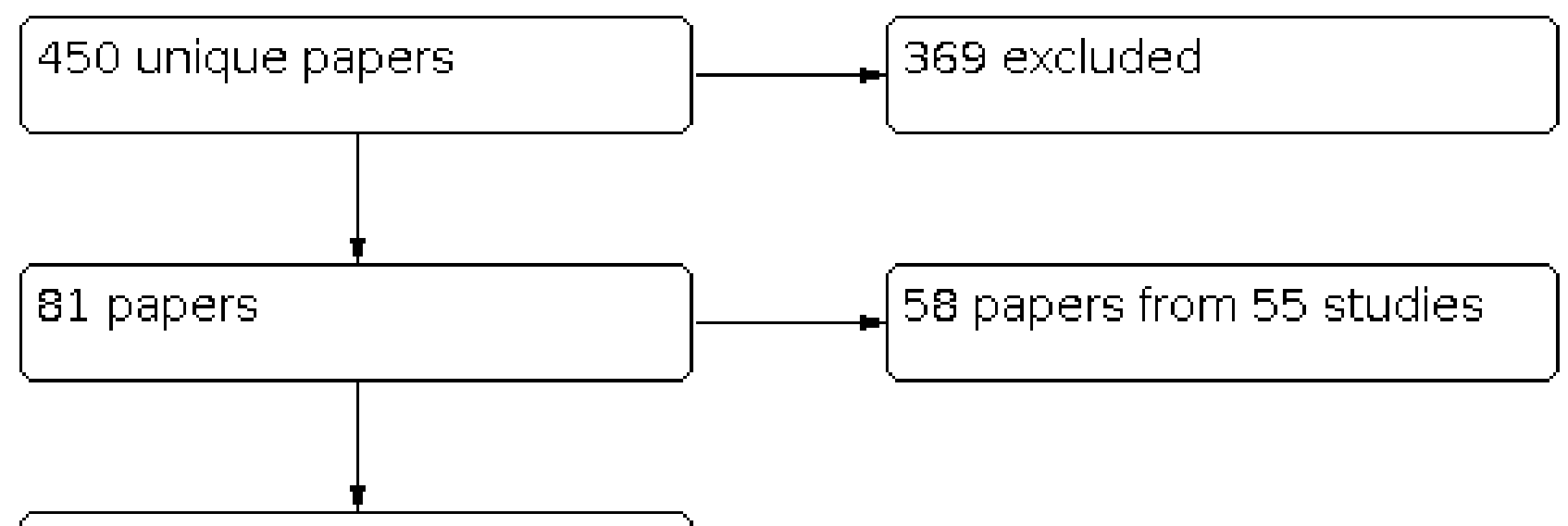

23 papers from 17 studies

\section{Included studies}

We included 17 RCTs (1006 participants) (Asbury 2007; Asbury 2008; Asbury 2011; DeGuire 1996; Esler 2003; Jonsbu 2011; Keefe 2011; Klimes 1990; Lahmann 2008; Jones 2006; Mayou 1997; Potts 1999; Sanders 1997; Spinhoven 2010; Tyni-Lenne 2002; van Beek 2013; Van Peski-Oosterbaan 1999). Of these, one was new to this update $(n=113)$ (van Beek 2013). See Characteristics of included studies for further details of each included trial.

\section{Data reporting}

Two studies combined the results of the RCT and crossover designs (Klimes 1990; Potts 1999). Three studies did not report SDs (Klimes 1990; Potts 1999; Tyni-Lenne 2002). The authors of Potts 1999 kindly provided the missing SDs for the RCT component of their study, including pain episodes and pain-free days.

\section{Interventions and analysis}

Comparisons of psychological interventions included CBT, hypnotherapy, autogenic training, group support, brief intervention by a nurse, relaxation training and breathing retraining. Only two studies evaluated a group intervention (Asbury 2011; Potts 1999). Two studies used a combined randomised controlled and crossover design where participants in the control groups were offered the active treatment after the initial controlled trial (Klimes 1990; Potts 1999). In one trial, control participants were given an initial behavioural explanation of their symptoms before being placed on the wait-list. Although both studies reported some data of the RCT component, many of the reported outcomes combined the results of the RCT and crossover designs. Where it was not possible to find data of the RCT alone, we conducted sensitivity analyses including and excluding combined data. In the other studies, control participants were offered assessment only combined with either usual care (Tyni-Lenne 2002; Van Peski-

Psychological interventions for symptomatic management of non-specific chest pain in patients with normal coronary anatomy (Review) 7 Copyright $\odot 2015$ The Cochrane Collaboration. Published by John Wiley \& Sons, Ltd. 
Oosterbaan 1999) or no care (DeGuire 1996; Mayou 1997). In the case of the former, no information was reported on details of usual care the controls received. Where studies had more than two arms (DeGuire 1996; Keefe 2011; Tyni-Lenne 2002), we used the control treatment that most readily allowed comparison with other studies. For DeGuire 1996 we used guided re-breathing training without physiological monitoring of diaphragmatic breathing or end-tidal $\mathrm{CO}_{2}$. For Tyni-Lenne 2002, we used relaxation as opposed to physical training. It was not possible to examine differences in the timing of the interventions. In the case of Keefe 2011, there were four study arms: 1) placebo; 2) psychological treatment and placebo; 3) sertraline and placebo; and 4) sertraline plus psychological treatment. We used the results of the first two arms. Six of the 15 studies did not described timing of the intervention (early vs. late). One study examined the differences between "immediate" and "delayed" interventions, but as per the inclusion criteria, participants may have had an angiogram within the past year (Potts 1999). Similarly, Esler 2003 conducted the intervention while the patient was in the emergency room, but did not provide information regarding a history of chest pain. Therefore, it is unclear whether the patients were presenting for the first time or not. Therapist training was not noted in four of the studies. Nine studies described adherence to a treatment manual or plan. Keefe 2011 also assessed fidelity. Therapists met weekly for supervision with a senior psychologist who reviewed audiotapes of the sessions and provided feedback regarding treatment quality and adherence to the study protocol.

\section{Participants}

Four studies was restricted to females (Asbury 2007; Asbury 2008; Asbury 2011; Tyni-Lenne 2002). All studies were of outpatients who were either referred by treating physicians or GPs, or undergoing coronary angiography. One study, DeGuire 1996, included participants who responded to a newspaper advertisement. A sensitivity analysis excluding this study made no difference to the results. All included participants whose main symptom was chest pain and who had been investigated to some degree to exclude cardiac explanations for their pain. Only one study excluded participants who had other co-morbid medical conditions, such as diabetes (Tyni-Lenne 2002). Only three studies excluded participants who had comorbid psychiatric disorder, such as major depression (Klimes 1990; Mayou 1997; Van PeskiOosterbaan 1999). We conducted sensitivity analyses of studies that used such exclusion criteria and those that did not.

\section{Completion rates}

Completion rates varied widely. Only ten studies reported the number of subjects eligible for inclusion who agreed to participate (Jones 2006; Jonsbu 2011; Keefe 2011; Klimes 1990; Lahmann 2008; Mayou 1997; Sanders 1997; Spinhoven 2010; van Beek 2013; Van Peski-Oosterbaan 1999). In most cases, only $40 \%$ to $60 \%$ agreed to participate. Lahmann 2008 and van Beek 2013 were the only exceptions, where $90 \%$ of eligible subjects participated. Completion rates following randomisation were generally acceptable (approximately $80 \%$ ), although in three trials over 35\% were lost to follow-up (DeGuire 1996; Mayou 1997; van Beek 2013). We conducted sensitivity analyses of studies where completion rates were less than $80 \%$.

\section{Outcomes}

All included studies reported change in frequency and severity of chest pain except one (van Beek 2013). Some also included the number of days when participants were free of chest pain. Studies reported a wide range of other outcomes covering psychological morbidity, quality of life, health beliefs and service use. Both observer-rated and self-report measures were included.

\section{Duration of follow-up}

Follow-up periods varied from three to 36 months. Studies generally dated follow-up from baseline intervention rather than the end of the intervention. Duration of interventions varied from a single session, to a few days or several months. We calculated duration from follow-up from the end of the intervention. For example, we classified a trial in which participants were followed up for six months dated from baseline intervention, with an intervention duration of three months as followed up for three months.

\section{Excluded studies}

We excluded 58 papers from 55 studies (see Characteristics of excluded studies). Most were reviews that did not contain primary data or were not intervention studies. Eight intervention studies were excluded; three were trials of antidepressant medication (Cox 1998; Handa 1999; Wulsin 2002) and another was an uncontrolled trial of behavioural therapy (Hegel 1989). The fifth trial pooled data from 90 patients with mitral valve prolapse with 14 participants with NSCP (Cott 1992). We tried to contact the study authors to determine whether there were any data restricted to patients with NSCP. The sixth trial was an evaluation of a chest pain unit where patients received up to six hours of observation and biochemical testing followed by an exercise treadmill test (Goodacre 2004). The seventh was a quasi-experimental evaluation of brief CBT in an emergency department (Lessard 2012). We excluded a final study, (Mayou 1999), because it reported on a consecutive sample of 133 outpatients referred to cardiac outpatient clinics, and was not a RCT.

\section{Risk of bias in included studies}

We created a 'Risk of bias' table for the new trial identified in this update, as well as those added in previous revisions. In ten studies there was a low risk of random sequence generation and/or selection bias (Asbury 2007; Asbury 2008; Asbury 2011; Esler 2003; Jones 2006; Jonsbu 2011; Keefe 2011; Mayou 1997; Spinhoven 2010; van Beek 2013). In seven, there was unclear risk for both of these biases (DeGuire 1996; Klimes 1990; Potts 1999; Sanders 1997; TyniLenne 2002; Lahmann 2008; Van Peski-Oosterbaan 1999). In studies where there was a medical aspect to the intervention, the patients were blinded to medication or placebo (Keefe 2011; Spinhoven 2010). However, due to the nature of the main interventions of interest (normally counselling or $\mathrm{CBT}$ ), it was impossible to blind the people delivering the treatment as to whether the participant was in the intervention or control arm. In addition, in three studies the blinding of participants was expressly forbidden by the local ethics committee because of issues in obtaining fully informed consent (Asbury 2007; Asbury 2008; Asbury 2011). For this reason, we considered all studies to be at high risk of performance bias. As outcomes were largely assessed by self-reports, and the patients were at least in part not blinded to the intervention, we judged most studies at high risk of outcome assessment bias. One exception was 
van Beek 2013, which assessed disease severity with the Clinical Global Inventory (CGI) rated by a blinded independent rater. Most studies did not discuss intention-to-treat (ITT) analysis, but most studies appeared to have analysed data based on ITT analysis. We considered three studies to be at high risk of outcome bias because of a high loss or differential loss from baseline to follow-up (Asbury 2011; Spinhoven 2010; van Beek 2013). The other trials were at low risk of bias for this domain. Two studies had unclear risk of selective reporting because they did not clearly state the outcomes of interest (Lahmann 2008; Spinhoven 2010).

We did not include funnel plots as all the outcomes had fewer than 10 studies.

\section{Effects of interventions}

The 17 included studies used very different ways of assessing outcomes. For this reason, we analysed some separately without attempting a quantitative integration of data (meta-analysis).

\section{Primary outcome measures}

\section{Absence of chest pain}

Studies reported either the absence of chest pain over a week (Klimes 1990; Van Peski-Oosterbaan 1999) or a month (Sanders 1997), or the number of chest-pain free days over a week (Mayou 1997). All showed significant improvements following intervention, apart from brief CBT where the improvement failed to reach statistical significance. For Klimes 1990, the results were of the combined RCT and crossover trial. Klimes 1990 also reported the number of chest-pain free days over a week at the end of the RCT stage before the crossover trial, but did not include SDs. Therefore we were only able to combine the studies of CBT that reported the absence of chest pain over a certain period of time (Klimes 1990; Van Peski-Oosterbaan 1999) or that included SDs when reporting the number of chest-pain free days (Mayou 1997; Potts 1999). In the case of absence of chest pain (Klimes 1990; Van Peski-Oosterbaan 1999), there was a significant reduction in reports of chest pain in the first three months following the intervention. The random-effects model gave a relative risk of $0.70(95 \% \mathrm{Cl} 0.53$ to 0.92 ; three studies, 172 participants; $\mathrm{I}^{2}$ statistic $=59 \%$; Analysis 1.1). This was maintained from three to 12 months afterwards, the relative risk being 0.59 (95\% $\mathrm{Cl} 0.45$ to 0.76 ; two studies; 111 participants; I $^{2}$ statistic $=0 \%$; Analysis 1.2 ) for both fixed or randomeffects models. Exclusion of Sanders 1997, which reported the absence of chest pain over a month following brief CBT, made no significant difference to the results. Exclusion of the combined RCT and crossover trial (Klimes 1990) also made no significant difference to the results. There was also a significant increase in the number of chest pain free days up to three months following intervention; the MD was $3.00(95 \% \mathrm{Cl} 0.23$ to 5.77 ; two studies, 81 participants; $I^{2}$ statistic $=69 \%$; Analysis 1.3$)$. However, this was largely attributable to Potts 1999, which reported the results of a group intervention.

\section{Chest pain frequency and severity}

Where stated, studies reported the frequency of chest pain episodes over a week (Van Peski-Oosterbaan 1999), two weeks (DeGuire 1996; Potts 1999) or a month (Esler 2003; Mayou 1997). All studies reported reduced chest pain frequency, except Esler 2003. However, in Esler 2003 the baseline scores in the treatment group were much higher than in the controls. At one month follow-up, chest pain frequency had fallen by 7.9 per month in the treatment group as opposed to 4.8 in the controls, with a significant Group $\times$ Time interaction effect. Jonsbu 2011 reported frequency of symptoms of chest pain or palpitations on a scale rated as 1 ("daily"), 2 ("weekly or more often"), 3 ("rare but sometimes") and 4 ("no symptoms for the last 6 months"). Therefore we could not include this in the metaanalysis. There was a reduction in participants receiving either CBT or guided re-breathing compared with controls within the first three months of follow-up on the random-effects model; the MD was -2.26 $\left(-4.41\right.$ to -0.12 ; seven studies, 294 participants; $I^{2}$ statistic $=94 \%$; Analysis 1.4). However, this was not maintained at three to nine months follow-up (MD - 0.81 (95\% Cl -2.35, 0.74; four studies, 164 participants; $\mathrm{I}^{2}$ statistic $=75 \%$; Analysis 1.5 ). Restricting the analyses to only those studies that reported the results of CBT made little difference to any of these results.

Jones 2006, a study of hypnotherapy, reported rates of overall improvement in chest pain; $80 \%$ of the hypnotherapy group improved compared with only $23 \%$ of controls $(P=0.008)$ at 17 weeks follow-up. This improvement was maintained approximately two years later with 14 of the 15 patients (93\%) who received hypnotherapy now classified as responders compared with only $3 / 13(23 \%)$ controls $(P=0.001)$.

Four studies reported chest pain severity (Asbury 2007; Jones 2006; Keefe 2011; Spinhoven 2010). Spinhoven 2010 calculated a daily chest pain index $(\mathrm{PI})$ score in which duration of chest pain activity was weighed by the intensity of the chest pain. At three months follow-up, there was no significant difference between intervention and control groups in the random-effects model (MD $=-4.64(95 \%$ $\mathrm{Cl}-12.18$ to 2.89; four studies, 180 participants; $\mathrm{I}^{2}$ statistic $=65 \%$; Analysis 1.6). It is important to note that Spinhoven 2010 reported outcomes at two intervals; mid-treatment and post-treatment. The scores included in Analysis 1.6, are post-treatment outcomes.One study reported frequency of GP visits over 12 months (Asbury 2011): $29 \%$ of support patients made one or more GP visits over the duration of the study, compared with $54 \%$ of the control group (P $=0.06$ ).

\section{Secondary outcome measures \\ Quality of life}

Studies reported very different measures of quality of life, making quantitative integration of data difficult. Two trials showed significant improvements in global quality of life following intervention using a standardised and validated instrument (the Sickness Impact Profile (SIP)) compared to controls, but reported medians and ranges instead of means and SDs (Potts 1999; TyniLenne 2002). Another study, Jones 2006, gave the percentage of subjects reporting an improvement in global quality of life: $73 \%$ of the hypnotherapy group improved compared with only $23 \%$ of controls $(P=0.02)$ at 17 weeks follow-up. This improvement was maintained approximately two years later with 11 of the 15 patients $(73 \%)$ who received hypnotherapy now classified as responders compared to only $3 / 13(23 \%)$ controls $(P=0.02)$. Five studies reported results using some or all of the scales of the SF-36 including physical functioning, work problems, social functioning, and problems with role due to emotional limitations (Asbury 2008; Esler 2003; Jonsbu 2011; Sanders 1997; Van Peski-Oosterbaan 1999), but Sanders 1997 did not report SDs. In addition to reporting the overall percentage of patients reporting improvement in global Quality of Life (QoL), Jones 2006 gave MacNew scores for QoL 
derived from emotional, physical and social domains (Jones 2006). As with the SF-36, an increase in scores indicates improvement. However, the trial authors did not report the subscores. Asbury 2007 reported QoL using the Ferrans and Powers Quality of Life Index. This covers four domains (health and functioning, psychological/spiritual domain, social and economic domain, and family). Again, an increase in scores indicates improvement. We were, therefore, only able to combine data from Esler 2003, Van Peski-Oosterbaan 1999 and Asbury 2007 for the following three areas: physical functioning, social functioning, and problems with role due to emotional limitations. In each case we combined these results with the global MacNew scores that incorporated emotional, physical and social domains. In the case of social functioning, we also attempted to integrate measures of social functioning and social disability by inverting the social impairment scale used by Mayou 1997. There were significant differences between intervention and control groups in some of the domains at short or long term follow-up (Analysis 1.8; Analysis 1.9; Analysis 1.12) except in the cases of physical or social functioning up to three months after the intervention (Analysis 1.7; Analysis 1.11) and role problems due to emotional limitations three to 12 months after the intervention (Analysis 1.10). Using the random-effects or fixedeffect model made no difference to any of these results.

\section{Psychological measures}

Again, a wide variety of measures were used that measured global outcome or the presence of depression or anxiety. Klimes 1990, a combined RCT and crossover trial, reported a significant reduction in psychiatric cases compared with controls as determined by a standardised psychiatric interview following intervention; the relative risk was $0.42(95 \% \mathrm{Cl} 0.22$ to 0.8$)$. We quantitatively analysed seven studies of self-reported depression using standardised instruments (Asbury 2007; Asbury 2008; Jonsbu 2011; Keefe 2011; Lahmann 2008; Potts 1999; Van Peski-Oosterbaan 1999), combined with a further study that reported overall morbidity including depression (Mayou 1997). There was no significant difference between intervention and control groups up to three months after the intervention (Analysis 1.13). Notably, Asbury 2008 reported outcomes at two intervals within the three month time-frame. Using one or the other made no difference in the results of Analysis 1.13. We also quantitatively analysed seven studies of self-reported anxiety using standardised instruments (Asbury 2007; Asbury 2008; Keefe 2011; Lahmann 2008; Potts 1999; Spinhoven 2010; Van Peski-Oosterbaan 1999), combined with a further study that reported overall morbidity including anxiety (Mayou 1997). A ninth study reported medians and ranges rather than means and SDs (Jones 2006). This precluded inclusion in quantitative analyses. Asbury 2011 reported $P$ values but no actual scores. For the eight studies that we were able to combine data from, there was a significant difference between intervention and controls up to three months after the intervention; the SMD was -0.24 ( $95 \% \mathrm{Cl}-0.47$ to -0.01 ; eight studies, 383 participants; Analysis 1.14). Again, Asbury 2008 reported outcomes at two intervals within the three month time-frame. Using one or the other made no difference in the results of this analysis. There was no significant difference between intervention and control groups in overall psychological symptoms measured by either the Brief Symptom Inventory (BSI) or HADS from three to 12 months afterwards, with the SMD being $-0.14(95 \% \mathrm{Cl}-0.39$ to 0.11 ; four studies, 246 participants; Analysis 1.15). One study, van Beek 2013, only gave the results of the anxiety and depression subscales of the
HADS but using either made no difference to these results. Four studies reported three subscores of a scale specific to cardiac anxiety including fear, avoidance and attention to symptoms rather than generalised anxiety (Asbury 2007; Asbury 2008; Esler 2003; Spinhoven 2010). There were no significant differences in any of the domains at any time period (Analysis 1.16; Analysis 1.17; Analysis 1.18; Analysis 1.19; Analysis 1.20; Analysis 1.21). Using the random-effects model or fixed-effect model made no difference to any of these results. Spinhoven 2010 reported outcomes at two intervals; mid-treatment and post-treatment. The scores included in Analysis 1.14 and Analysis 1.16 are post-treatment outcomes. One study, van Beek 2013, assessed disease severity with the CGI by a blinded independent rater. An analysis of covariance (ANCOVA) in the ITT and completer sample showed that CBT was superior to treatment as usual (TAU) after 24 weeks in reducing disease severity as measured by the CGI $(P<0.001)$.

\section{Health beliefs}

Studies used very different measures of changes in health beliefs, making quantitative integration of data difficult. Of the seven studies examining CBT, two did not report change in health beliefs as an outcome (Esler 2003; Van Peski-Oosterbaan 1999). Klimes 1990 reported that prior to the intervention, all study patients believed their chest pain was due to a physical cause, while afterwards $69 \%$ attributed their pain to stress. They did not report the difference between intervention and control groups. A further study reported that Illness perceptions mediated the short and long term treatment effects of a three-session CBT programme for patients with NCCP (Jonsbu 2011). Asbury 2011, a study of support groups, reported that patients randomised to support showed a trend towards improved health beliefs total score $(P=0.068)$ and threat perception $(P=0.062)$ compared with the controls. Two studies reported non significant differences in health beliefs after the intervention (Mayou 1997; Sanders 1997). Only Potts 1999 reported that participants were significantly less likely to believe they had heart disease after the intervention $(11 / 56,20 \%)$ than before $(25 / 56,45 \%, P<0.05)$.

\section{Heterogeneity}

Many of our analyses had a high level of statistical heterogeneity. We explored possible reasons for this heterogeneity in post hoc analyses, omitting each study in turn where there were more than two studies. This did not alter heterogeneity apart from the following two comparisons: Analysis 1.1: Any chest pain up to three months after intervention, and Analysis 1.5: Chest pain frequency three to 12 months after intervention. In each case, exclusion of Van Peski-Oosterbaan 1999 reduced heterogeneity to non-significant levels. The reasons for this heterogeneity are unclear and as a consequence, we have presented the results of random effects models in all the tables to take heterogeneity into account. We did this even where there was no evidence of statistical heterogeneity as we could not definitely exclude other sources of between-study variation, such as clinical heterogeneity, given the increase in studies since the first version of this review (Kisely 2005). However, when there was no evidence of statistical heterogeneity, we reported the results of both the fixed-effect and random-effects models in the text. 


\section{Sensitivity analyses}

Due to the small number of included trials in each analysis, these results are limited and should be interpreted with caution. Issues concerning the proposed sensitivity analyses are as follows:

- Differences between studies that define psychiatric symptoms operationally (clinician diagnosis or validated questionnaire (and whether validated in this specific population or in other groups): all studies included in the meta-analysis used standardised instruments;

- Differences between types of psychological interventions and types of controls: there was little change to the results when analyses were restricted to CBT or hypnotherapy only. All but two studies used individual therapy;

- Differences between routes of referral for intervention (referred to psychiatrists, clinical psychologists, other mental health professionals, or other clinicians for management): most studies did not report route of referral. There was no difference to the results when studies were excluded by route of referral;

- Differences between participants with and without a family history of heart disease: there were no studies in which this information was included;

- Differences between studies that use subject reported pain or assessments by clinicians or carers: there were no studies that used assessments by clinicians or carers;

- Differences between well defined and less-well defined psychological interventions: there was little change to the results when analyses were restricted to CBT or hypnotherapy only;

- Differences between analyses involving all studies and excluding trials of lower methodological quality: two studies combined the results of the RCT and crossover designs (Klimes 1990; Potts 1999). There was no difference in the results when we excluded studies that combined results of a RCT and crossover trial;

- Differences between analyses involving all studies and those that excluded co-morbid psychiatric disorder: all but two studies included in the meta-analysis excluded co-morbid psychiatric disorder (DeGuire 1996; Jones 2006). There was no difference to the results when we excluded these studies from the analysis;

- Differences between participants with and without a history of myocardial infarction: a history of myocardial infarction was excluded from three studies, and not captured in the remainder. This made little change to the results;

- Differences between participants with and without coronary angiography: there was no difference to the results with this analysis;

- Differences between self referrals and referral from a clinician: one study, DeGuire 1996, included participants who responded to a newspaper advertisement. Exclusion of this study made no difference to the results.

\section{DISCUSSION}

Recurrent chest pain in the absence of coronary artery disease is a common problem that sometimes leads to excess use of medical care. Although many studies have examined the causes of pain in these patients, few clinical trials have evaluated treatment. The studies included in this updated Cochrane review provide an insight into the effectiveness of psychological interventions for this group of patients. We have attempted to draw modest conclusions based on available evidence, and to highlight areas requiring further study, rather than draw conclusions that may not be based on evidence of high quality.

This Cochrane review revealed limited evidence for the effective psychological treatment of NSCP. We identified only a small number of RCTs, and two combined data from RCTs and crossover trials. The identified studies were heterogeneous in terms of design, types of and implementation of interventions, outcome measurement and follow-up periods. All had small numbers of participants and questions concerning methodological quality. For example, where participants were waiting-list controls, especially in combined RCT and crossover designs, it is not possible for the subject to be unaware of which group they are in, and many studies relied on participants' self-report assessments of outcome. In addition, due to the nature of the main interventions of interest, it was impossible to blind the therapists as to whether the participant was in the intervention or control arm. Furthermore, in three studies the blinding of participants was expressly forbidden by the local ethics committee because of issues in obtaining fully informed consent (Asbury 2007; Asbury 2008; Asbury 2011). For this reason, all studies had a high risk of performance bias. Finally, three studies were thought to have a high risk of outcome bias. Although there was a low risk of bias in other domains, the results showed heterogeneity and caution is therefore required in their interpretation. Given the clinical and statistical heterogeneity, we have stressed the random effects results.

Despite these problems, it was possible to aggregate some data for short and long-term outcomes and the aggregated data support a modest to moderate benefit for psychological interventions, especially those using a cognitive-behavioural framework or hypnotherapy. These results are consistent with findings for other types of medically unexplained symptoms (Hatcher 2008; Kroenke 2000). The evidence for other interventions, such as brief nurse-led counselling, is less clear.

There are several practical difficulties concerning the delivery of psychological interventions for NSCP. One is that participation rates in many studies were low ( $40 \%$ to $60 \%)$. It has been suggested that this is because many studies of approaches such as CBT use the Attribution Model (Esler 2004). This requires patients to complete a cardiological work up, such as stress testing, to definitely establish that the pain is noncardiac in origin before therapy can begin, thus marking one obstacle to treatment. Furthermore the Attribution Model may be incompatible with the patient's view of their symptoms. Even if patients can be convinced, this psychological attribution may still be controversial with their family and friends, and many physicians. If patients are accustomed to thinking of chest pain as a medical illness they may not be ready to attribute their symptoms to having a psychological cause. By contrast, the Biopsychosocial Model accepts that most illness, whether physical or psychiatric, is influenced and determined by biological, psychological and social phenomena. This model assumes that better patient outcomes are achieved when therapeutic interventions are based on evaluation of the relationship between biological, psychological and social variables. This approach may be more in tune with the patient's perception of their problems and does not require physical investigations to be completed before therapy can begin (Esler 2004). 
Another difficulty is access to psychotherapists, as cardiologists or gastroenterologists have neither the time nor training necessary to provide the treatment. Furthermore, there is considerable variation in presenting physical symptomatology, concerns, needs, beliefs and outcomes among patients. A 'stepped' approach to the implementation of psychological interventions has therefore been suggested (Mayou 1997; Sanders 1997). Such an approach would include a fuller explanation of the possibility and meaning of a negative outcome of angiography as preparation for the procedure and more opportunity for discussion with cardiologists prior to discharge. There should also be follow-up for review of the findings, reinforcement of the plan for symptomatic treatment and encouragement for a return to fuller activities.

One of our objectives was to compare different psychological treatments. However, due to the small number of included studies, we can only draw conclusions about CBT and possibly hypnotherapy. We also wished to assess the association between treatment effect sizes and methodological features. We were unable to do so because of the small number of included participants and methodological characteristics.

Only 17 studies met the inclusion criteria. The lack of research in this area and standardisation of outcomes may mean this is a relatively new field. Alternatively, researchers may be uncomfortable with randomisation and the use of controls. A further possibility is that participants with NSCP are reluctant to accept psychological explanations and interventions for their symptoms, making this a difficult group with which to conduct such studies. The high rates of attrition in many of the studies lends support for this final explanation.

\section{AUTHORS' CONCLUSIONS}

\section{Implications for practice}

Psychological treatments, especially CBT therapy and hypnotherapy, may be effective in the short-term for the treatment of patients with NSCP. However, the evidence is limited to small trials of questionable quality.

Evidence suggests that if untreated, patients with NSCP have levels of health service use comparable to patients with chest pain of organic causes (Kisely 1997). It may be useful to detect NCCP early, identify individual treatment needs and intervene before it becomes chronic. Patients in emergency departments or with recent onset of chest pain should be prepared for the possibility and meaning of negative findings. Those patients with chronic NSCP may benefit from specialist psychological intervention.

\section{Implications for research}

Further RCTs of psychological interventions for NSCP are needed. These should:

- Include a larger number of participants and be informed by explicit sample size and power analysis;

- Have follow-up periods of at least 12 months and preferably longer;

- Have adequate concealment of allocation, ITT analyses and at least single blind assessments of outcome;

- Use meaningful standardised outcome measurements;

- Use interventions that are explicitly described, manualised and monitored for treatment fidelity.

\section{ACKNOWLEDGEMENTS}

We thank Paul Skerritt for helpful discussions and reviewing earlier manuscript versions. SK and AP are employed by the University of Queensland, and LAC by Capital District Health Authority, Halifax, Canada. 


\section{R E F E R E N C E S}

\section{References to studies included in this review}

Asbury 2007 \{published data only\}

* Asbury EA, Kanji N, Ernst E, Barbir M, Collins P. Autogenic training to manage chest pain in women with angina and normal coronary arteries. Circulation 2007;116(16, Suppl. S):677.

Asbury EA, Kanji N, Ernst E, Barbir M, Collins P. Autogenic training to manage symptomology in women with chest pain and normal coronary arteries. Menopause 2009;16(1):60-5.

Asbury 2008 \{published data only\}

Asbury EA, Slattery C, Grant A, Evans L, Barbir M, Collins P. Cardiac rehabilitation for the treatment of women with chest pain and normal coronary arteries. Menopause 2008;15(3):454-60.

Asbury 2011 \{published data only\}

Asbury EA, Webb CM, Collins P. Group support to improve psychosocial well-being and primary-care demands among women with cardiac syndrome X. Climacteric 2011;14(1):100-4

\section{DeGuire 1996 \{published data only\}}

DeGuire S, Gevirtz R, Hawkinson D, Dixon K. Breathing retraining: a three year follow-up study of treatment for hyperventilation syndrome and associated functional cardiac symptoms. Biofeedback and Self-Regulation 1996;21(2):191-8.

\section{Esler 2003 \{published data only\}}

* Esler JL, Barlow DH, Woolard RH, Nicholson RA, Nash JM, Erogul MH. A brief cognitive-behavioral intervention for patients with noncardiac chest pain. Behavior Therapy 2003;34(2):129-48

Esler JL. A Brief Cognitive-Behavioural Intervention for Patients with Non-Cardiac Chest Pain [PhD thesis]. New York: State University of New York, 2000.

\section{Jones 2006 \{published data only\}}

* Jones H, Cooper P, Miller V, Brooks N, Whorwell PJ. Treatment of non-cardiac chest pain: a controlled trial of hypnotherapy. Gut 2006;55(10):1403-8.

Miller V, Jones $\mathrm{H}$, Whorwell PJ. Hypnotherapy for non-cardiac chest pain: long-term follow-up. Gut 2007;56(11):1643.

\section{Jonsbu 2011 \{published data only\}}

* Jonsbu E, Dammen T, Morken G, Moum T, Martinsen EW. Short-term cognitive behavioral therapy for non-cardiac chest pain and benign palpitations: a randomized controlled trial. Journal of Psychosomatic Research 2011;70(2):117-23.

Jonsbu E, Martinsen EW, Morken G, Moum T, Dammen T. Change and impact of illness perceptions among patients with noncardiac chest pain or benign palpitations following three sessions of CBT. Behavioural and Cognitive Psychotherapy 2013;41(4):398-407.
Keefe 2011 \{published data only\}

Keefe FJ, Shelby RA, Somers TJ, Varia I, Blazing M, Waters SJ, et al. Effects of coping skills training and sertraline in patients with non-cardiac chest pain: a randomized controlled study. Pain 2011;152(4):730-41.

Klimes 1990 \{published data only\}

Klimes I, Mayou RA, Pearce MJ, Coles L, Fagg JR. Psychological treatment for atypical non-cardiac chest pain: a controlled evaluation. Psychological Medicine 1990;20(3):605-11.

\section{Lahmann 2008 \{published data only\}}

Lahmann C, Loew TH, Tritt K, Nickel M. Efficacy of functional relaxation and patient education in the treatment of somatoform heart disorders: a randomized, controlled clinical investigation. Psychosomatics 2008;49(5):378-85.

\section{Mayou 1997 \{published data only\}}

Mayou R, Bass CM, Bryant BM. Management of noncardiac chest pain: from research to clinical practice. Heart 1999;81(4):387-92.

* Mayou R, Bryant BM, Sanders D, Bass C, Klimes I, Forfar C. A controlled trial of cognitive-behavioural therapy for non-cardiac chest pain. Psychological Medicine 1997;27(5):1021-31.

\section{Potts 1999 \{published data only\}}

Potts SG, Lewin R, Fox KAA, Johnstone EC. Group psychological treatment for chest pain with normal coronary arteries. Quarterly Journal of Medicine 1999;92(2):81-6.

\section{Sanders 1997 \{published data only\}}

Sanders D, Bass C, Mayou RA, Goodwin S, Bryant BM, Tyndel S. Non-cardic chest pain: why was a brief intervention apparently ineffective? Psychological Medicine 1997;27(5):1033-40.

\section{Spinhoven 2010 \{published data only\}}

Spinhoven P, Van der Does AJ, Van Dijk E, Van Rood YR. Heart-focused anxiety as a mediating variable in the treatment of noncardiac chest pain by cognitive-behavioral therapy and paroxetine. Journal of Psychosomatic Research 2010;69(3):227-35.

Tyni-Lenne 2002 \{published data only\}

Tyni-Lenne R, Stryjan S, Eriksson B, Berglund M, Sylven C. Beneficial therapeutic effects of physical training and relaxation therapy in women with coronary syndrome X. Physiotherapy Research International 2002;7(1):35-43.

van Beek 2013 \{published data only\}

van Beek MH, Oude Voshaar RC, Beek AM, van Zijderveld GA, Visser S, Speckens AE, et al. A brief cognitive-behavioral intervention for treating depression and panic disorder in patients with noncardiac chest pain: a 24-week randomized controlled trial. Depression and Anxiety 2013;30(7):670-8.

Van Peski-Oosterbaan 1999 \{published data only\}

* Van Peski-Oosterbaan AS, Spinhoven P, van Rood Y, Van der Does W, Brushke AJV, Rooijmans HG. Cognitive-behavioural 
therapy for non-cardiac chest pain: a randomised trial. American Journal of Medicine 1999;106(4):424-9.

Van Peski-Oosterbaan AS, Spinhoven P, van Rood Y, Van der Does W, Brushke AJV, Rooijmans HG. Cognitive change following cognitive-behavioural therapy for non-cardiac chest pain. Psychotherapy and Psychosomatics 1999;68(4):214-20.

\section{References to studies excluded from this review}

Achem 2008 \{published data only\}

Achem SR. Treatment of non-cardiac chest pain. Disease- $a$ Month 2008;54(9):642-70.

\section{Adler 2001 \{published data only\}}

Adler DG, Romero Y. Primary esophageal motility disorders. Mayo Clinic Proceedings 2001;76(2):195-200.

\section{Asbury 2005a \{published data only\}}

Asbury EA, Collins P. Psychosocial factors associated with noncardiac chest pain and cardiac syndrome X. Herz 2005;30(1):55-60.

\section{Asbury 2005b \{published data only\}}

Asbury EA, Collins P. Cardiac syndrome X. International Journal of Clinical Practice 2005;59(9):1063-9.

\section{Barker 2013 \{published data only\}}

Barker NJ, Jones M, O'Connell NE, Everard ML. Breathing exercises for dysfunctional breathing/hyperventilation syndrome in children. Cochrane Database of Systematic Reviews 2013, Issue 12. Art. No: CD010376. [DOI: 10.1002/14651858.CD010376.pub2]

\section{Carter 1992a \{published data only\}}

Carter CS, Maddock RJ. Chest pain in generalized anxiety disorder. International Journal of Psychiatry in Medicine 1992;22(3):291-8.

\section{Carter 1992b \{published data only\}}

Carter C, Maddock R, Amsterdam E, McCormick S, Waters C, Billett J. Panic disorder and chest pain in the coronary care unit. Psychosomatics 1992;33(3):302-9.

\section{Chambers 1998 \{published data only\}}

Chambers J, Bass C. Atypical chest pain; looking beyond the heart. Quarterly Journal of Medicine 1998;91(3):239-44.

Chen 2010 \{published data only\}

Chen X, Yan J, Wang W, Chen H, Zheng J, Xue Z. Behavior intervention therapy in patients with gastroesophageal reflux disease [[Chinese]]. Chinese Journal of Gastroenterology 2010;15:99-101.

\section{Coss-Adame 2014 \{published data only\}}

Coss-Adame E, Erdogan A, Rao SSC. Treatment of esophageal (noncardiac) chest pain: an expert review. Clinical Gastroenterology and Hepatology 2014;12(8):1224-45.
Cott 1992 \{published data only\}

Cott A, McCully J, Goldberg WM, Tanser PH, Parkinson W. Interdisciplinary treatment of morbidity in benign chest pain. Angiology 1992;43(3 Pt 1):195-202.

\section{Cox 1998 \{published data only\}}

Cox ID, Hann CM, Kaski JC. Low dose imipramine improves chest pain but not quality of life in patients with angina and normal coronary angiograms. European Heart Journal 1998;19(2):250-4.

\section{Elkins 2012 \{published data only\}}

Elkins G, Johnson A, Fisher W. Cognitive hypnotherapy for pain management. American Journal of Clinical Hypnosis 2012;54(4):294-310.

\section{Esler 2004 \{published data only\}}

Esler JL, Bock BC. Psychological treatments for noncardiac chest pain - recommendations for a new approach. Journal of Psychosomatic Research 2004;56(3):263-9.

\section{Eslick 2004 \{published data only\}}

Eslick GD. Noncardiac chest pain: epidemiology, natural history, health care seeking, and quality of life. Gastroenterology Clinics of North America 2004;33(1):1-23.

\section{Eslick 2005 \{published data only\}}

Eslick GD, Coulshed DS, Talley NJ. Diagnosis and treatment of noncardiac chest pain. Nature Clinical Practice. Gastroenterology \& Hepatology 2005;2(10):463-72.

Faybush 2004 \{published data only\}

Faybush EM, Fass R. Gastroesophageal reflux disease in noncardiac chest pain. Gastroenterology Clinics of North America 2004;33(1):41-54.

\section{Fleet 1998 \{published data only\}}

Fleet RP, Dupuis G, Marchand A, Kaczorowski J, Burelle D, Arsenhault A, et al. Panic disorder in coronary artery disease patients with noncardiac chest pain. Journal of Psychosomatic Research 1998;44(1):81-90.

\section{Goodacre 2001 \{published data only\}}

Goodacre S, Mason S, Arnold J, Angelini K. Psychologic morbidity and health related quality of life of patients assessed in a chest pain observation unit. Annals of Emergency Medicine 2001;38(4):369-76.

\section{Goodacre 2004 \{published data only\}}

Goodacre S, Nicholl J. A randomised controlled trial to measure the effect of chest pain unit care upon anxiety, depression, and health-related quality of life [ISRCTN85078221]. Health and Quality of Life Outcomes 2004;2:39.

\section{Handa 1999 \{published data only\}}

Handa M, Mine K, Yamamato H, Hayashi H, Tsuchida O, Kanazawa F, et al. Antidepressant treatment of patients with diffuse esophageal spasm: a psychosomatic approach. Journal of Clinical Gastroenterology 1999;28(3):228-32. 
Hegel 1989 \{published data only\}

Hegel MT, Abel GG, Etscheidt M, Cohen-Cole S, Wilmer Cl. Behavioural treatment of angina-like chest pain in patients hyperventilation syndrome. Journal of Behavioural Therapy and Experimental Psychiatry 1989;20(1):31-9.

Hershcovici 2012 \{published data only\}

Hershcovici T, Achem SR, Jha LK, Fass R. Systematic review: the treatment of noncardiac chest pain. Alimentary Pharmacology \& Therapeutics 2012;35(1):5-14.

\section{Jackson 2006 \{published data only\}}

Jackson JL, O'Malley PG, Kroenke K. Antidepressants and cognitive-behavioral therapy for symptom syndromes. CNS Spectrums 2006;11(3):212-22.

\section{Jeejeebhoy 2000 \{published data only\}}

Jeejeebhoy FM, Dorian P, Newman DM. Panic disorder and the heart: a cardiology perspective. Journal of Psychosomatic Research 2000;48(4-5):393-403.

Kaski 2001 \{published data only\}

Kaski JC, Valenzuela Garcia LF. Therapeutic options for the management of patients with cardiac syndrome X. European Heart Journal 2001;22(4):283-93.

\section{Katz 2000 \{published data only\}}

Katz PO. Chest pain of esophageal origin. Current Opinion in Gastroenterology 2000;16(4):369-73.

\section{Kroenke 2000 \{published data only\}}

Kroenke K, Swindle R. Cognitive-behavioral therapy for somatization and symptom syndromes: a critical review of controlled clinical trials. Psychotherapy and Psychosomatics 2000;69(4):205-15.

\section{Lahmann 2010 \{published data only\}}

Lahmann C, Henningsen P, Loew T. Functional relaxation in psychosomatic medicine - results from randomized-controlled trials. European Psychiatry 2010;25(Supplement 1):1018.

\section{Lessard 2012 \{published data only\}}

Lessard MJ, Marchand A, Lavoie KL. Interventions in the emergency department for chest pain with or without noncardiac panic-like anxiety. Canadian Psychology/Psychologie Canadienne 2012;53(3):178-91.

Lessard MJ, Marchand A, Pelland MÈ, Belleville G, Vadeboncoeur A, Chauny JM, et al. Comparing two brief psychological interventions to usual care in panic disorder patients presenting to the emergency department with chest pain. Behavioural \& Cognitive Psychotherapy 2012;40(2):129-47.

Pelland, ME, Marchand A, Lessard MJ, Belleville G, Chauny JM, Vadeboncoeur A, et al. Efficacy of 2 interventions for panic disorder in patients presenting to the ED with chest pain. American Journal of Emergency Medicine 2011;29(9):1051-61.

Poirier-Bisson J, Marchand A, Pelland ME, Lessard MJ, Dupuis $G$, Fleet R, et al. Incremental cost-effectiveness of pharmacotherapy and two brief cognitive-behavioral therapies compared with usual care for panic disorder and noncardiac chest pain. Journal of Nervous and Mental Disease 2013;201(9):753-9.

Looper 2002 \{published data only\}

Looper KJ, Kirmayer LJ. Behavioural medicine approaches to somatoform disorders. Journal of Consulting and Clinical Psychology 2002;70(3):810-27.

Masanga 2011 \{published data only\}

Masanga L, Fernandez L. Additive effects of high-intensity inspiratory muscle training in pulmonary rehabilitation among COPD patients in the philippines. Respirology 2011;16:119.

Mayou 1989 \{published data only\}

Mayou R, Klimes I, Pearce J. An evaluation of a psychological treatment of persistent atypical chest pain [meeting report]. Quarterly Journal of Medicine 1989;73:970-1.

Mayou 1994 \{published data only\}

Mayou R, Bryant B, Forfar C, Clark D. Non-cardiac chest pain and benign palpitations in the cardiac clinic. British Heart Journal 1994;72(6):548-53.

Mayou 1999 \{published data only\}

Mayou RA, Bass CM, Bryant BM. Management of non-cardiac chest pain: from research to clinical practice. Heart (British Cardiac Society) 1999;81(4):387-92. [PMID: 10092565]

Nanke 2004 \{published data only\}

Nanke A, Rief W. Biofeedback in somatoform disorders and related syndromes. Current Opinion in Psychiatry 2004;17(2):133-8.

Nezu 2001 \{published data only\}

Nezu AM, Nezu CM, Roessler E. Cognitive-behaviour therapy for medically unexplained symptoms. A critical review of the treatment literature. Behavior Therapy 2001;32:537-84.

Olden 2004 \{published data only\}

Olden KW. The psychological aspects of noncardiac chest pain. Gastroenterology Clinics of North America 2004;33(1):61-7.

Olden 2006 \{published data only\}

Olden KW. Treatment of noncardiac chest pain of psychological origin. Current Treatment Options in Gastroenterology 2006;9(1):51-8.

Otte 2011 \{published data only\}

Otte C. Cognitive behavioral therapy in anxiety disorders: current state of the evidence. Dialogues in Clinical Neuroscience 2011;13(4):413-21.

Palsson 2006 \{published data only\}

Palsson OS, Whitehead WE. Hypnosis for non-cardiac chest pain. Gut 2006;55(10):1381-4

Petrie 2007 \{published data only\}

Petrie KJ, Müller JT, Schirmbeck F, Donkin L, Broadbent E, Ellis CJ, et al. Effect of providing information about normal test results on patients' reassurance: randomised controlled trial. BMJ 2007;334(7589):352.

Psychological interventions for symptomatic management of non-specific chest pain in patients with normal coronary anatomy (Review) 
Ringel 1999 \{published data only\}

Ringel Y, Drossman DA. Treatment of patients with functional esophageal symptoms: is there a role for a psychotherapeutic approach? Journal of Clinical Gastroenterology 1999;28(3):189-93.

\section{Romeo 1993 \{published data only\}}

Romeo F, Rosano GM, Martuscelli E, Lombardo L, Valente A. Long term follow-up of patients initially diagnosed with syndrome X. American Journal of Cardiology 1993;71(8):669-73.

\section{Ryan 2004 \{published data only\}}

Ryan M, Gevirtz R. Biofeedback-based psychophysiological treatment in a primary care setting: an initial feasibility study. Applied Psychophysiology and Biofeedback 2004;29(2):79-93.

\section{Schey 2007 \{published data only\}}

Schey R, Villarreal A, Fass R. Noncardiac chest pain: Current treatment. Gastroenterology and Hepatology 2007;3(4):255-62.

\section{Schmulson 2004 \{published data only\}}

Schmulson MJ, Valdovinos MA. Current and future treatment of chest pain of presumed esophageal origin. Gastroenterology Clinics of North America 2004;33(1):93-105.

\section{Serlie 1995 \{published data only\}}

Serlie AW, Erdman RAM, Passchler J, Trijsburg RW, ten Cate FJ. Psychological aspects of non-cardiac chest pain. Psychotherapy and Psychosomatics 1995;64(2):62-73.

\section{Sert 2013 \{published data only\}}

Sert A, Aypar E, Odabas D, Gokcen C. Clinical characteristics and causes of chest pain in 380 children referred to a paediatric cardiology unit. Cardiology in the Young 2013;23(3):361-7.

Van Peski-Oosterbaan 1997 \{published data only\}

Van Peski-Oosterbaan AS, Spinhoven P, van Rood Y, Van der Does W, Brushke AJV. Cognitive-behavioural therapy for unexplained non-cardiac chest pain: a pilot study. Behavioural and Cognitive Psychotherapy 1997;25:339-50.

Wang 2012 \{published data only\}

Wang W, Sun YH, Wang YY, Wang YT, Wang W, Li YQ, et al. Treatment of functional chest pain with antidepressants: a meta-analysis. Pain Physician 2012;15(2):E131-42.

\section{Wertli 2013 \{published data only\}}

Wertli MM, Ruchti KB, Steurer J, Held U. Diagnostic indicators of non-cardiovascular chest pain: a systematic review and metaanalysis. BMC Medicine 2013;11:239. [PMID: 24207111]

Wu 2002 \{published data only\} Wu EB, Lau CP. Atypical chest pain - a review of latest research. Hong Kong Practitioner 2002;24:331-6.

\section{Wulsin 2002 \{published data only\}}

Wulsin L, Liu T, Storrow A, Evans S, Dewan N, Hamilton C. A randomized, controlled trial of panic disorder treatment initiation in an emergency department chest pain center. Annals of Emergency Medicine 2002;39(2):139-43.

\section{Zachariae 2001 \{published data only\}}

Zachariae R, Melchiorsen H, Frøbert O, Bjerring P, Bagger JP. Experimental pain and psychologic status of patients with chest pain with normal coronary arteries or ischemic heart disease. American Heart Journal 2001;142(1):63-71.

Zaubler 1998 \{published data only\}

Zaubler T, Katon W. Panic disorder in the general medical setting. Journal of Psychososmatic Research 1998;44(1):25-42.

\section{Additional references}

\section{Bass 1984}

Bass C, Wade C. Chest pain with normal coronary arteries: a comparative study of psychiatric and social morbidity. Psychological Medicine 1984;14(1):51-61.

\section{Bennett 2001}

Bennett J. ABC of the upper gastrointestinal tract: Oesophagus: Atypical chest pain and motility disorders. BMJ 2001;323(7316):791-4.

\section{Borkovec 1982}

Borkovec TD. Insomnia. Journal of Consulting and Clinical Psychology 1982;50(6):880-95.

\section{Capewell 2000}

Capewell S, McMurray J. "Chest pain-please admit": is there an alternative? A rapid cardiological assessment service may prevent unnecessary admissions. BMJ 2000;320(7240):951-2.

\section{Chambers 1990}

Chambers J, Bass C. Chest pain with normal coronary anatomy: a review of natural history and possible etiologic factors. Progress in Cardiovascular Diseases 1990;33(3):161-84.

\section{DeGuire 1992}

DeGuire S, Gevirtz R, Kawahara Y, Maguire W. Hyperventilation syndrome and the assessment of treatment for functional cardiac symptoms. American Journal of Cardiology 1992;70(6):673-7.

\section{Egger 1997}

Egger M, Davey Smith G, Schneider M, Minder CE. Bias in meta-analysis detected by a simple, graphical test. BMJ 1997;315(7109):629-34.

\section{Eslick 2002}

Eslick GD, Coulshed DS, Talley NJ. Review article: the burden of illness of non-cardiac chest pain. Alimentary Pharmacology \& Therapeutics 2002;16(7):1217-23.

\section{Eslick 2003}

Eslick GD, Fass R. Noncardiac chest pain: evaluation and treatment. Gastroenterology Clinics 2003;32(2):531-52.

\section{Hatcher 2008}

Hatcher S, Arroll B. Assessment and management of medically unexplained symptoms. BMJ (Clinical research ed.) 2008;336(7653):1124-8. [PMID: 18483055] 


\section{Hemingway 1999}

Hemingway $\mathrm{H}$, Marmot M. Evidence based cardiology: psychosocial factors in the aetiology and prognosis of coronary heart disease. Systematic review of prospective cohort studies. BMJ 1999;318(7196):1460-7.

\section{Higgins 2011}

Higgins JPT, Green S (editors). Cochrane Handbook for Systematic Reviews of Interventions Version 5.1 [updated March 2011]. The Cochrane Collaboration, 2011. Available from www.cochrane-handbook.org.

\section{Jones 2004}

Jones C, Cormac I, Silveira da Mota Neto Jl, Campbell C. Cognitive behaviour therapy for schizophrenia. Cochrane Database of Systematic Reviews 2004, Issue 4. Art. No: CD000524. [DOI: 10.1002/14651858.CD000524.pub2]

\section{Kahrilas 1990}

Kahrilas PJ, Gupta RR. Mechanisms of acid reflux associated with cigarette smoking. Gut 1990;31(1):4-10.

\section{Katon 1988}

Katon W, Hall ML, Russo J, Cormier L, Hollifield M, Vitaliano PP, et al. Chest pain: relationship of psychiatric illness to coronary arteriographic results. American Journal of Medicine 1988;84(1):1-9.

\section{Kisely 1997}

Kisely S, Guthrie E, Creed FH, Tew R. Predictors of mortality and morbidity following admission with chest pain. Journal of the Royal College of Physicians of London 1997;31(2):177-83.

\section{Knockaert 2002}

Knockaert DC, Buntinx F, Stoens N, Bruyninckx R, Delooz H. Chest pain in the emergency department: the broad spectrum of cases. European Journal of Emergency Medicine 2002;9(1):25-30.

\section{Lefebvre 2011}

Lefebvre C, Manheimer E, Glanville J. Chapter 6: Searching for studies. In: Higgins JPT, Green S, editor(s). Cochrane Handbook for Systematics Reviews of Interventions Version 5.1.0 [updated March 2011]. The Cochrane Collaboration, 2011. Available from www.cochrane-handbook.org.

\section{Matsuguchi 1984}

Matsuguchi T, Araki H, Anan T, Hayata N, Nakaguki O, Takeshita A, et al. Provocation of variant angina by alcohol ingestion. European Heart Journal 1984;5(11):906-12.

\section{Mayou 1989b}

Mayou R. Invited review: atypical chest pain. Journal of Psychosomatic Research 1989;33(4):393-406.

\section{Ockene 1980}

Ockene IS, Shay M, Alpert J, Weiner BH, Dalen JE. Unexplained chest pain in patients with normal coronary angiograms: a follow-up study of functional status. New England Journal of Medicine 1980;303(22):1249-52.

\section{Price 2008}

Price JR, Mitchell E, Tidy E, Hunot V. Cognitive behaviour therapy for chronic fatigue syndrome in adults. Cochrane Database of Systematic Reviews 2008, Issue 3. Art. No: CD001027. [DOI: 10.1002/14651858.CD001027.pub2]

\section{QAP 1982}

Quality Assurance Project. A treatment outline for agoraphobia. Australian and New Zealand Journal of Psychiatry 1982;16(1):25-33.

\section{RevMan 2014 [Computer program]}

The Nordic Cochrane Centre, The Cochrane Collaboration Review Manager (RevMan). Version 5.3. Copenhagen: The Nordic Cochrane Centre, The Cochrane Collaboration, 2014.

\section{Roll 1987}

Roll M, Theorell T. Acute pain without obvious organic cause before age 40 - personality and recent life events. Journal of Psychosomatic Research 1987;31(2):215-21.

\section{Shapiro 1994}

Shapiro DA, Rees A, Barkham M, Hardy G, Reynolds S, Startup M. Effects of treatment duration and severity of depression on the maintenance of gains after cognitive-behavioral and psychodynamic-interpersonal psychotherapy. Journal of Consulting and Clinical Psychology 1994;63(3):378-87.

\section{Sharpe 1996}

Sharpe M, Hawton K, Simkin S, Surawy C, Hackmann A, Klimes I, et al. Cognitive behaviour therapy for the chronic fatigue syndrome: a randomised controlled trial. $B M J$ 1996;312(7022):22-6.

\section{Speckens 1995}

Speckens A, van Hemert AM, Spinhoven P, Hawton, K Bolk JH, Rooijmans $\mathrm{H}$. Cognitive behavioural therapy for medically unexplained physical symptoms: a randomised controlled trial. BMJ 1995;311(7016):1328-32.

\section{Von Korff 1988}

Von Korff M, Dworkin SF, Le Resche L, Kruger A. An epidemiologic comparison of pain complaints. Pain 1988;32(2):173-83.

\section{Walker 1988}

Walker AM, Martin-Moreno JM, Artalejo FR. Odd man out: a graphical approach to meta-analysis. American Journal of Public Health 1988;78(8):961-6.

\section{Woolfolk 1983}

Woolfolk RL, McNulty TF. Relaxation treatment for insomnia: a component analysis. Journal of Consulting and Clinical Psychology 1983;51(4):495-503.

\section{References to other published versions of this review Kisely 2005}

Kisely S, Campbell LA, Skerritt P. Psychological interventions for symptomatic management of non-specific chest pain in 
patients with normal coronary anatomy. Cochrane Database of Systematic Reviews 2005, Issue 1. Art. No: CD004101. [DOI: 10.1002/14651858.CD004101.pub2]

\section{Kisely 2010}

Kisely S, Campbell LA, Skerritt P, Yelland MJ. Psychological interventions for symptomatic management of non-specific

\section{CHARACTERISTICS OF STUDIES}

Characteristics of included studies [ordered by study ID]

Asbury 2007

\section{Study characteristics}

\begin{tabular}{ll}
\hline Methods & RCT \\
\hline Participants & Fifty three female Syndrome X patients (mean \pm SD; $57.4 \pm 8.0$ yrs). \\
\hline Interventions & 2 groups. \\
& $\begin{array}{l}\text { Weekly group autogenic training (AT) sessions were supported by an individual home program and } \\
\text { symptom diary }\end{array}$ \\
\hline Symptom diary only control. \\
$\begin{array}{l}\text { The HADS Spielberger State-Trait Anxiety Inventory (STAI) Cardiac Anxiety Questionnaire (CAQ) and the } \\
\text { Ferrans \& Powers Quality of Life Index (QLI) were completed pre- and post-intervention and at 8-week } \\
\text { follow-up. }\end{array}$
\end{tabular}

\section{Risk of bias}

\begin{tabular}{|c|c|c|}
\hline Bias & Authors' judgement & Support for judgement \\
\hline $\begin{array}{l}\text { Random sequence genera- } \\
\text { tion (selection bias) }\end{array}$ & Unclear risk & Insufficient information to permit judgement \\
\hline $\begin{array}{l}\text { Allocation concealment } \\
\text { (selection bias) }\end{array}$ & Low risk & $\begin{array}{l}\text { Randomization was performed using identical opaque, sealed brown en- } \\
\text { velopes containing an equal number of paper strips marked 'autogenic train- } \\
\text { ing' or 'monitoring'. }\end{array}$ \\
\hline $\begin{array}{l}\text { Blinding of participants } \\
\text { and personnel (perfor- } \\
\text { mance bias) } \\
\text { All outcomes }\end{array}$ & High risk & $\begin{array}{l}\text { Due to the nature of the psychological intervention, it was impossible to blind } \\
\text { the people delivering the treatment to whether the participant was in the in- } \\
\text { tervention or control arm. In addition, the use of group blinding was express- } \\
\text { ly forbidden by the local ethics committee because of issues relating to obtain- } \\
\text { ing fully informed consent. }\end{array}$ \\
\hline
\end{tabular}

\begin{tabular}{lll}
$\begin{array}{l}\text { Blinding of outcome as- } \\
\text { sessment (detection bias) } \\
\text { All outcomes }\end{array}$ & High risk & Patients knew what group they were in, and assessment by self reports \\
\hline $\begin{array}{l}\text { Incomplete outcome data } \\
\text { (attrition bias) }\end{array}$ & Low risk & $\begin{array}{l}23 \text { out of } 27 \text { AT participants and } 25 \text { out of } 26 \text { symptom monitoring controls } \\
\text { successfully completed }\end{array}$ \\
All outcomes & the study with a full compliment of psychological and physiological measures.
\end{tabular}

Psychological interventions for symptomatic management of non-specific chest pain in patients with normal coronary anatomy (Review) 18 Copyright ( 2015 The Cochrane Collaboration. Published by John Wiley \& Sons, Ltd. 
Asbury 2007 (Continued)

Selective reporting (re- Low risk Appears that all outcomes were reported on. porting bias)

Asbury 2008

\section{Study characteristics}

\begin{tabular}{ll}
\hline Methods & RCT \\
\hline Participants & Sixty-four women aged $57.3 \pm 8.6$ years (mean \pm SD) with cardiac syndrome X. \\
\hline Interventions & 8-week phase III CR exercise program or symptom monitoring control. \\
\hline Outcomes & $\begin{array}{l}\text { HADS, Health Anxiety Questionnaire, and SF-36, energy, general health, Shuttle Walk Test, diastolic } \\
\text { blood pressure and body mass index. }\end{array}$ \\
\hline Notes &
\end{tabular}

\section{Risk of bias}

\begin{tabular}{lll}
\hline Bias & Authors' judgement & Support for judgement \\
\hline $\begin{array}{l}\text { Random sequence genera- } \\
\text { tion (selection bias) }\end{array}$ & Low risk & Randomly assigned using envelopes. Not described, but sounds plausible. \\
\hline $\begin{array}{l}\text { Allocation concealment } \\
\text { selection bias) }\end{array}$ & Low risk & $\begin{array}{l}\text { Patients given identical envelopes with either rehabilitation or monitoring } \\
\text { written on them. }\end{array}$ \\
\hline $\begin{array}{l}\text { Blinding of participants } \\
\text { and personnel (perfor- } \\
\text { mance bias) } \\
\text { All outcomes }\end{array}$ & High risk & $\begin{array}{l}\text { Due to the nature of the psychological intervention, it was impossible to blind } \\
\text { the people delivering the treatment to whether the participant was in the in- } \\
\text { tervention or control arm. In addition, the use of group blinding was express- } \\
\text { ly forbidden by the local ethics committee because of issues relating to obtain- } \\
\text { ing fully informed consent. }\end{array}$
\end{tabular}

Blinding of outcome as- High risk

Patients knew what group they were in, and assessment by self reports.

sessment (detection bias)

All outcomes

Incomplete outcome data $\quad$ Low risk $\quad$ Analysed as ITT. One additional patient dropped out of CR arm.
(attrition bias)

All outcomes

Selective reporting (re- Low risk $\quad$ All outcomes appear to have been reported.
porting bias)

\section{Asbury 2011}

\section{Study characteristics}

\begin{tabular}{ll}
\hline Methods & RCT \\
\hline Participants & Forty-nine women with cardiac syndrome X (mean + SD 61.8 + 8 years).
\end{tabular}

Psychological interventions for symptomatic management of non-specific chest pain in patients with normal coronary anatomy (Review) 
Asbury 2011 (Continued)

Interventions $\quad 12$ monthly support group meetings or usual care control.

Outcomes The Health Anxiety Questionnaire (HAQ), HADS, SF-36, York Angina Beliefs scale, ENRICHD Social Support Instrument (ESSI) and a demographic information scale, along with hospital admissions, GP or cardiologist appointments were measured at baseline, 6 months and 12 months.

Notes

\section{Risk of bias}

\begin{tabular}{lll}
\hline Bias & Authors' judgement & Support for judgement \\
\hline $\begin{array}{l}\text { Random sequence genera- } \\
\text { tion (selection bias) }\end{array}$ & Low risk & Randomly assigned using envelopes. Not described, but sounds plausible. \\
\hline $\begin{array}{l}\text { Allocation concealment } \\
\text { (selection bias) }\end{array}$ & Low risk & $\begin{array}{l}\text { Patients given identical envelopes with either support group or usual care } \\
\text { written on them. }\end{array}$ \\
\hline $\begin{array}{l}\text { Blinding of participants } \\
\text { and personnel (perfor- } \\
\text { mance bias) }\end{array}$ & High risk & $\begin{array}{l}\text { Due to the nature of the psychological intervention, it was impossible to blind } \\
\text { the people delivering the treatment to whether the participant was in the in- } \\
\text { tervention or control arm. In addition, the use of group blinding was expressly } \\
\text { forbidden by the local ethics committee due to issues relating to obtaining ful- } \\
\text { ly informed consent. }\end{array}$ \\
\hline
\end{tabular}

Blinding of outcome as- High risk

Patients knew what group they were in, and assessment by self reports. sessment (detection bias) All outcomes

\begin{tabular}{lll}
\hline $\begin{array}{l}\text { Incomplete outcome data } \\
\text { (attrition bias) }\end{array}$ & High risk & $\begin{array}{l}\text { Analysed as ITT. One patient from intervention group (4\%) and three (12\%) } \\
\text { from control group dropped out. }\end{array}$
\end{tabular}

All outcomes

Selective reporting (re- Low risk Appears that all outcomes reported on.

porting bias)

\section{DeGuire 1996}

\section{Study characteristics}

\begin{tabular}{ll}
\hline Methods & RCT \\
& Ratings of respiratory physiology and self-reports of cardiac symptoms. \\
& 66 subjects referred/responded of whom 41 (63\%) completed follow-up. \\
\hline Participants & $\begin{array}{l}\text { Referred from physicians or responded to newspaper advertisement } \\
\text { Inclusion criteria: } \\
\text { Seen by physician } \leq 1 \text { year before recruitment who had excluded organic causes for symptoms. } \\
\text { Symptoms occurred at least once/week and include chest pain, palpitations, tachycardia and arrhyth- } \\
\text { mias. }\end{array}$ \\
\hline Interventions & $\begin{array}{l}4 \text { groups: } \\
\text { - Guided breathing retraining and physiological monitoring of diaphragmatic breathing and end-tidal } \\
\text { CO }\end{array}$ \\
\hline & Guided breathing retraining and physiological monitoring of diaphragmatic breathing; \\
\hline
\end{tabular}

Psychological interventions for symptomatic management of non-specific chest pain in patients with normal coronary anatomy (Review) 
DeGuire 1996 (Continued)

- No treatment (controls).

Outcomes Chest pain: frequency \& severity over 2/52

Respiratory rate and mean end-tidal $\mathrm{CO} 2$ using an Ohmeda $5200 \mathrm{CO}_{2}$ monitor

Notes

High attrition rate leading to potential follow-up bias.

\section{Risk of bias}

\begin{tabular}{lll}
\hline Bias & Authors' judgement & Support for judgement \\
\hline $\begin{array}{l}\text { Random sequence genera- } \\
\text { tion (selection bias) }\end{array}$ & Unclear risk & Insufficient information to permit judgement \\
\hline $\begin{array}{l}\text { Allocation concealment } \\
\text { (selection bias) }\end{array}$ & Unclear risk & Insufficient information to permit judgement \\
\hline $\begin{array}{l}\text { Blinding of participants } \\
\text { and personnel (perfor- } \\
\text { mance bias) }\end{array}$ & High risk & $\begin{array}{l}\text { Due to the nature of the psychological intervention, it was impossible to blind } \\
\text { the people delivering the treatment to whether the participant was in the in- } \\
\text { tervention or control arm. }\end{array}$ \\
\hline
\end{tabular}

Blinding of outcome as- Unclear risk Insufficient information to permit judgement

sessment (detection bias)

All outcomes

Incomplete outcome data High risk $\quad 66$ subjects referred/responded of whom 41 (63\%) completed follow-up.
(attrition bias)

All outcomes

Selective reporting (re- Low risk All outcomes appear to be reported on.

porting bias)

\section{Esler 2003}

\section{Study characteristics}

\begin{tabular}{ll}
\hline Methods & RCT \\
& Self-report ratings of cardiac symptoms. \\
& 94 subjects referred of whom $59(63 \%)$ were randomised. 36 of the 59 subjects $(56 \%)$ completed all fol- \\
& low-up assessments.
\end{tabular}

Participants

Referred by Accident \& Emergency or observation ward physician.

Inclusion criteria:

- Chest pain as main presenting feature;

- Adequate medical work up and ready for discharge;

- Low suspicion of cardiac disease;

- Over 18 years old.

Exclusion criteria:

- Known/documented hx of MI, CABG, PTCA, prior angiography or stress testing indicating CAD;

- Other significant medical illness (e.g. CCF, PE, lung Discase) or cause of chest pain (e.g. pneumonia, bronchitis, trauma).

Psychological interventions for symptomatic management of non-specific chest pain in patients with normal coronary anatomy (Review) 
Esler 2003 (Continued)

Interventions
One brief CBT intervention lasting $1 \mathrm{hr}$ including psychoeducation, cognitive restructuring and breathing exercises.

Controls received treatment as usual including information, instructions and medications typically given by treating physicians to patients with negative cardiac findings.

Chest pain episodes over $1 / 12$. Severity of episodes over $1 / 52 \& 1 / 12$ (chest pain visual analogue scale)
QoL: SF-36
PM: Cardiac Anxiety Questionnaire, Anxiety Sensitivity Index, BSI
At $1 / 12$ and $3 / 12$ follow-up

Notes High attrition rate leading to potential follow-up bias.

\section{Risk of bias}

\begin{tabular}{|c|c|c|}
\hline Bias & Authors' judgement & Support for judgement \\
\hline $\begin{array}{l}\text { Random sequence genera- } \\
\text { tion (selection bias) }\end{array}$ & Unclear risk & Insufficient information to permit judgement \\
\hline $\begin{array}{l}\text { Allocation concealment } \\
\text { (selection bias) }\end{array}$ & Low risk & Participants were randomly assigned using sealed envelopes. \\
\hline $\begin{array}{l}\text { Blinding of participants } \\
\text { and personnel (perfor- } \\
\text { mance bias) } \\
\text { All outcomes }\end{array}$ & High risk & $\begin{array}{l}\text { Due to the nature of the psychological intervention, it was impossible to blind } \\
\text { the people delivering the treatment to whether the participant was in the in- } \\
\text { tervention or control arm. }\end{array}$ \\
\hline $\begin{array}{l}\text { Blinding of outcome as- } \\
\text { sessment (detection bias) } \\
\text { All outcomes }\end{array}$ & High risk & $\begin{array}{l}\text { Participants were contacted by mail } 1 \text { and } 3 \text { months after enrolment \& asked } \\
\text { to complete self-reported measures. However they would have been aware of } \\
\text { their allocation status }\end{array}$ \\
\hline $\begin{array}{l}\text { Incomplete outcome data } \\
\text { (attrition bias) } \\
\text { All outcomes }\end{array}$ & High risk & 36 of the 59 subjects ( $56 \%$ ) completed all follow-up. \\
\hline $\begin{array}{l}\text { Selective reporting (re- } \\
\text { porting bias) }\end{array}$ & Low risk & All outcomes appear to have been reported on. \\
\hline
\end{tabular}

Jones 2006

\section{Study characteristics}

\begin{tabular}{ll}
\hline Methods & RCT \\
\hline Participants & $\begin{array}{l}28 \text { patients with angina-like chest pain in whom coronary angiography was normal and oesophageal } \\
\text { reflux was not contributory. }\end{array}$ \\
\hline Interventions & $\begin{array}{l}12 \text { sessions of hypnotherapy or supportive therapy plus placebo medication over a } 17 \text { week period. A } \\
\text { further paper reported results of a } 2 \text { year follow-up. }\end{array}$ \\
\hline Outcomes & $\begin{array}{l}\text { The primary outcome measure was global assessment of chest pain improvement. Secondary variables } \\
\text { were a change in scores for quality of life, pain severity, pain frequency, anxiety, and depression, as well } \\
\text { as any alteration in the use of medication. }\end{array}$
\end{tabular}

Notes

Of 81 eligible patients, only 28 entered the RCT.

Psychological interventions for symptomatic management of non-specific chest pain in patients with normal coronary anatomy (Review) 
Jones 2006 (Continued)

Risk of bias

\begin{tabular}{|c|c|c|}
\hline Bias & Authors' judgement & Support for judgement \\
\hline $\begin{array}{l}\text { Random sequence genera- } \\
\text { tion (selection bias) }\end{array}$ & Low risk & Randomisation was by a computer generated randomisation list. \\
\hline $\begin{array}{l}\text { Allocation concealment } \\
\text { (selection bias) }\end{array}$ & Unclear risk & Insufficient information to permit judgement \\
\hline $\begin{array}{l}\text { Blinding of participants } \\
\text { and personnel (perfor- } \\
\text { mance bias) } \\
\text { All outcomes }\end{array}$ & High risk & $\begin{array}{l}\text { Due to the nature of the psychological intervention, it was impossible to blind } \\
\text { the people delivering the treatment to whether the participant was in the in- } \\
\text { tervention or control arm. Blinding of participants was not explicitly discussed } \\
\text { but the two treatments were designed to mimic each other except for the use } \\
\text { of hypnotherapy. }\end{array}$ \\
\hline $\begin{array}{l}\text { Blinding of outcome as- } \\
\text { sessment (detection bias) } \\
\text { All outcomes }\end{array}$ & Low risk & $\begin{array}{l}\text { All outcome data comparing status at baseline and the end of the treatment } \\
\text { period were collected and subsequently analysed by an independent re- } \\
\text { searcher who was not involved in any of the treatments and was kept com- } \\
\text { pletely blind to the treatment allocation of all patients throughout the course } \\
\text { of the study. }\end{array}$ \\
\hline $\begin{array}{l}\text { Incomplete outcome data } \\
\text { (attrition bias) } \\
\text { All outcomes }\end{array}$ & Low risk & All 28 randomised patients completed the study. \\
\hline $\begin{array}{l}\text { Selective reporting (re- } \\
\text { porting bias) }\end{array}$ & Low risk & $\begin{array}{l}\text { All outcomes appear to be reported on although study reported medians and } \\
\text { ranges for secondary outcomes rather than means and SDs. }\end{array}$ \\
\hline
\end{tabular}

Jonsbu 2011

\section{Study characteristics}

\begin{tabular}{ll}
\hline Methods & RCT \\
\hline Participants & $\begin{array}{l}\text { Patients with persistent complaints six months after a negative evaluation at a cardiological outpatient } \\
\text { clinic were invited to participate. Of the } 94 \text { eligible patients, } 40 \text { agreed to participate and were random- } \\
\text { ly assigned to either an intervention or control group. }\end{array}$
\end{tabular}

Interventions

Three manualised sessions with CBT, including one physical activity exposure session. The control group received

usual care from their general practitioner.

\begin{tabular}{ll}
\hline Outcomes & Health-related quality of life (HRQOL) - the Body Sensations Questionnaire (BSQ), SF-36, frequency of \\
symptoms of chest pain or palpitations, impact of cardiac symptoms on domains of family life, social \\
life and work, and avoidance of physical activity at up to 3-month follow-up. A subsequent paper evalu- \\
ated changes and impact of illness perceptions at up to 12-month follow-up.
\end{tabular}

Notes Only a half of the eligible subjects entered the study.

\section{Risk of bias}

Bias Authors' judgement Support for judgement


Jonsbu 2011 (Continued)

Random sequence genera- Low risk The participants were assigned to groups by a web module that offers block tion (selection bias) randomisation. This was performed by a clinical research unit that is separate from the intervention location.

Allocation concealment Low risk Allocation conducted at an institution unrelated to study.

(selection bias)

Blinding of participants High risk No blinding.

and personnel (perfor-

mance bias)

All outcomes

\begin{tabular}{lll}
\hline $\begin{array}{l}\text { Blinding of outcome as- } \\
\text { sessment (detection bias) } \\
\text { All outcomes }\end{array}$ & High risk & Assessment by self-reporting and patient not blinded to treatment. \\
\hline $\begin{array}{l}\text { Incomplete outcome data } \\
\begin{array}{l}\text { (attrition bias) } \\
\text { All outcomes }\end{array}\end{array}$ & Low risk & Same number of patients dropped out in both groups. \\
\hline $\begin{array}{l}\text { Selective reporting (re- } \\
\text { porting bias) }\end{array}$ & Low risk & All outcomes appear to be reported on. \\
\hline
\end{tabular}

Keefe 2011

\section{Study characteristics}

\begin{tabular}{|c|c|}
\hline Methods & $\begin{array}{l}\text { A randomised clinical trial of the separate and combined effects of coping skills training (CST) and anti- } \\
\text { depressant medication (sertraline) in participants with NCCP. }\end{array}$ \\
\hline \multirow[t]{6}{*}{ Participants } & Eligibility criteria for study entry were: \\
\hline & 1. Presented for medical care with complaints of chest pain in the previous six months; \\
\hline & $\begin{array}{l}\text { 2. Received a negative stress test within the past } 2 \text { years, normal coronary angiogram within the past } 2 \\
\text { years, or had a survival probability P } 98 \% \text { at } 2 \text { years (calculated from a prognostogram developed by } \\
\text { statistical modelling from the Duke Cardiovascular Database); }\end{array}$ \\
\hline & $\begin{array}{l}\text { 3. A low likelihood of significant coronary artery disease }(<25 \%) \text { on the National Cholesterol Education } \\
\text { Program's (NCEP) modification of the Framingham Risk Calculator (FRC); }\end{array}$ \\
\hline & 4. Able to swallow oral medication; \\
\hline & 5. Age 18 to 85 years.38 (33\%) men and $77(67 \%)$ women. \\
\hline
\end{tabular}

Interventions

Random assignment to one of four treatments:

1. CST plus sertraline(CST + sertraline);

2. CST plus placebo (CST + placebo);

3. Sertraline alone; or

4. Placebo alone.

\section{Outcomes}

Chest pain intensity and unpleasantness from pain diaries, State-Trait Anxiety Inventory (STAI), the 13item Pain Catastrophizing Scale (PCS), the BDI, the physical disability scale of the Sickness Impact Profile (SIP), two items from Stone and Neale's Daily Coping Inventory, two items from the Coping Strategies Questionnaire were used to assess daily perceived pain control over pain. 
Keefe 2011 (Continued)

Risk of bias

\begin{tabular}{|c|c|c|}
\hline Bias & Authors' judgement & Support for judgement \\
\hline $\begin{array}{l}\text { Random sequence genera- } \\
\text { tion (selection bias) }\end{array}$ & Low risk & $\begin{array}{l}\text { A statistician who was not involved with the rest of the study created a ran- } \\
\text { domisation table to randomly assign participants. }\end{array}$ \\
\hline $\begin{array}{l}\text { Allocation concealment } \\
\text { (selection bias) }\end{array}$ & Low risk & $\begin{array}{l}\text { Allocation concealment is described although treatment components were } \\
\text { blinded only for the medication and not for the CST component. }\end{array}$ \\
\hline $\begin{array}{l}\text { Blinding of participants } \\
\text { and personnel (perfor- } \\
\text { mance bias) } \\
\text { All outcomes }\end{array}$ & High risk & $\begin{array}{l}\text { Patients were blinded to the medication and not to the CST component (which } \\
\text { is training). Medication and placebo were given in identical capsules that both } \\
\text { investigators and participants were blind to. }\end{array}$ \\
\hline $\begin{array}{l}\text { Blinding of outcome as- } \\
\text { sessment (detection bias) } \\
\text { All outcomes }\end{array}$ & High risk & $\begin{array}{l}\text { Patient's outcomes were self assessed through pain scores, and pain diaries, } \\
\text { but internal consistency was high for all tests. }\end{array}$ \\
\hline $\begin{array}{l}\text { Incomplete outcome data } \\
\text { (attrition bias) } \\
\text { All outcomes }\end{array}$ & Low risk & $\begin{array}{l}\text { While there were many patients who did not complete therapy, there was no } \\
\text { difference in attrition among the four treatment groups. }\end{array}$ \\
\hline $\begin{array}{l}\text { Selective reporting (re- } \\
\text { porting bias) }\end{array}$ & Low risk & All stated outcomes reported on. \\
\hline
\end{tabular}

Klimes 1990

\section{Study characteristics}

\begin{tabular}{ll}
\hline Methods & RCCT \\
& Self-report and blind ratings. \\
& 35 out of 56 assessed were recruited (63\%) of whom $29(83 \%)$ completed follow-up. \\
& Undetermined if treatment manual was used.
\end{tabular}

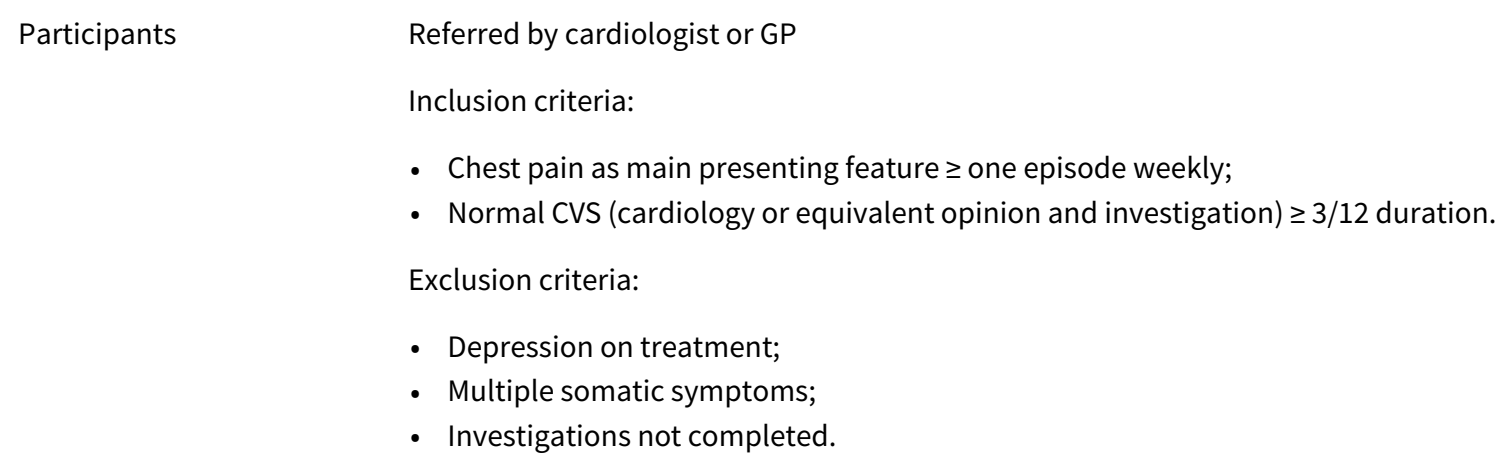

- Chest pain as main presenting feature $\geq$ one episode weekly;

- Normal CVS (cardiology or equivalent opinion and investigation) $\geq 3 / 12$ duration.

Exclusion criteria:

- Depression on treatment;

- Multiple somatic symptoms;

- Investigations not completed.

Interventions Individual CBT: Maximum 11 sessions over $3 / 12$ cognitive restructuring, problem solving, relaxation, breathing exercises.

Controls: Behavioural explanation of symptoms and offered CBT after 3/12 follow-up.

Chest pain free days and pain episodes over $1 / 52$
QoL: 5-point activity avoidance scale, 8-point distress scale
8-point disruption of everyday life scale
PM: PSE, STAI-T, BDI, SRT

Psychological interventions for symptomatic management of non-specific chest pain in patients with normal coronary anatomy (Review) 
Klimes 1990 (Continued)

Autonomic symptoms

Notes High drop-out rate at recruitment stage.

\section{Risk of bias}

\begin{tabular}{lll}
\hline Bias & Authors' judgement & Support for judgement \\
\hline $\begin{array}{l}\text { Random sequence genera- } \\
\text { tion (selection bias) }\end{array}$ & Unclear risk & Insufficient information to permit judgement \\
\hline $\begin{array}{l}\text { Allocation concealment } \\
\text { (selection bias) }\end{array}$ & Unclear risk & No description of randomisation. \\
\hline $\begin{array}{l}\text { Blinding of participants } \\
\text { and personnel (perfor- } \\
\text { mance bias) }\end{array}$ & High risk & $\begin{array}{l}\text { Due to the nature of the psychological intervention, it was impossible to blind } \\
\text { the people delivering the treatment to whether the participant was in the in- } \\
\text { tervention outcomes }\end{array}$
\end{tabular}

\begin{tabular}{|c|c|c|}
\hline $\begin{array}{l}\text { Blinding of outcome as- } \\
\text { sessment (detection bias) } \\
\text { All outcomes }\end{array}$ & Low risk & All subjects were independently assessed by a research assistant. \\
\hline $\begin{array}{l}\text { Incomplete outcome data } \\
\text { (attrition bias) } \\
\text { All outcomes }\end{array}$ & Low risk & $29(83 \%)$ completed follow-up \\
\hline $\begin{array}{l}\text { Selective reporting (re- } \\
\text { porting bias) }\end{array}$ & Low risk & All outcomes appear to be reported on. \\
\hline
\end{tabular}

Lahmann 2008

\section{Study characteristics}

\begin{tabular}{|c|c|}
\hline Methods & $\mathrm{RCT}$ \\
\hline Participants & $\begin{array}{l}\text { Patients included in the study were over the age of } 18 \text { years who presented with NSCP. } 22 \text { patients (10 } \\
\text { men, } 12 \text { women) were eligible to take part in the study. }\end{array}$ \\
\hline Interventions & $\begin{array}{l}\text { Functional Relaxation and Patient Education. The study period in the functional relaxation (FR) group } \\
\text { began with a } 60 \text {-minute psychosomatic-education session, in which the development of NSCP was pre- } \\
\text { sented, as well as basic information relating to structure and function of the cardiovascular and auto- } \\
\text { nomic nervous system. Throughout the course of the study, a total of } 10 \text { group-therapy sessions, } 90 \\
\text { minutes each, were held during the } 6 \text {-week treatment period. Controls assigned to "enhanced medical } \\
\text { care" were informed of their diagnosis and were encouraged to pass this information on without re- } \\
\text { strictions to their general-practitioner in order to initiate primary-care or specialty treatment. }\end{array}$ \\
\hline
\end{tabular}

Outcomes

The Symptom Checklist of Derogatis (SCL-90) and the Giessen Inventory of Complaints (GBB), which are both self-administered tests.

\section{Notes}

\section{Risk of bias}

Bias Authors' judgement Support for judgement

Psychological interventions for symptomatic management of non-specific chest pain in patients with normal coronary anatomy (Review) 
Lahmann 2008 (Continued)

Random sequence genera- Unclear risk "randomization was carried out confidentially". Likely ok, but not described. tion (selection bias)

\begin{tabular}{|c|c|c|}
\hline $\begin{array}{l}\text { Allocation concealment } \\
\text { (selection bias) }\end{array}$ & Unclear risk & $\begin{array}{l}\text { "allocation concealment implemented by the hospital's administration de- } \\
\text { partment". Likely ok, but not described. }\end{array}$ \\
\hline
\end{tabular}

\begin{tabular}{|c|c|c|}
\hline $\begin{array}{l}\text { Blinding of participants } \\
\text { and personnel (perfor- } \\
\text { mance bias) }\end{array}$ & High risk & $\begin{array}{l}\text { No discussion of blinding. However, due to the nature of the psychological in- } \\
\text { tervention, it was impossible to blind the people delivering the treatment to } \\
\text { whether the participant was in the intervention or control arm. }\end{array}$ \\
\hline
\end{tabular}

\begin{tabular}{lll}
\hline $\begin{array}{l}\text { Blinding of outcome as- } \\
\text { sessment (detection bias) } \\
\text { All outcomes }\end{array}$ & High risk & Patients not blinded, and outcome assessment by self reports. \\
\hline $\begin{array}{l}\text { Incomplete outcome data } \\
\begin{array}{l}\text { (attrition bias) } \\
\text { All outcomes }\end{array}\end{array}$ & Low risk & All patients (22) appear to have completed the trial. \\
\hline $\begin{array}{l}\text { Selective reporting (re- } \\
\text { porting bias) }\end{array}$ & Unclear risk & Study did not clearly outline outcomes of interest. \\
\hline
\end{tabular}

Mayou 1997

\section{Study characteristics}

\begin{tabular}{ll}
\hline Methods & RCT \\
Self-report measures and observer ratings (?blinded) \\
Of 133 referrals, $90(67 \%)$ reached baseline assessment, of whom 56 met inclusion criteria. \\
Of these, $37(66 \%)$ entered the study of whom $19(64 \%)$ completed follow-up. \\
Undetermined if treatment manual was used. \\
CBT group rated chest pain as more severe than control group.
\end{tabular}

\begin{tabular}{|c|c|}
\hline Participants & $\begin{array}{l}\text { Recruited from general hospital cardiology outpatient clinic } \\
\text { Inclusion criteria: } \\
\text { - Persisting NCCP } \geq \text { one episode weekly for } 1 / 12 \text {. } \\
\text { Exclusion criteria: } \\
\text { - Subsequent cardiac diagnosis; } \\
\text { - Current major depression; } \\
\text { - Living outside country; } \\
\text { - Unable to speak English. }\end{array}$ \\
\hline Interventions & $\begin{array}{l}\text { Individual CBT: Maximum } 12 \text { sessions including cognitive restructuring, problem solving, re } \\
\text { breathing exercises. } \\
\text { Controls: Assessment only. }\end{array}$ \\
\hline Outcomes & $\begin{array}{l}\text { Chest pain: frequency, severity, distress over } 1 / 12 \text {, and number of pain-free days over } 1 / 52 \text {. } \\
\text { QoL: } 4 \text {-point scales of avoidance, limitation and impairment (leisure, work, family, overall). } \\
\text { PM: BSI. } \\
\text { Health beliefs: Whitely score. }\end{array}$ \\
\hline
\end{tabular}

High attrition rate leading to potential follow-up bias. 
Mayou 1997 (Continued)

\section{Risk of bias}

\begin{tabular}{|c|c|c|}
\hline Bias & Authors' judgement & Support for judgement \\
\hline $\begin{array}{l}\text { Random sequence genera- } \\
\text { tion (selection bias) }\end{array}$ & Low risk & $\begin{array}{l}\text { Patients were randomly allocated to cognitive behavioural treatment (CBT) or } \\
\text { assessment only control }(A O C) \text { using a system of sealed envelopes prepared by } \\
\text { random number generation }\end{array}$ \\
\hline $\begin{array}{l}\text { Allocation concealment } \\
\text { (selection bias) }\end{array}$ & Low risk & $\begin{array}{l}\text { Patients were randomly allocated to cognitive behavioural treatment (CBT) or } \\
\text { assessment only control }(A O C) \text { using a system of sealed envelopes prepared by } \\
\text { random number generation }\end{array}$ \\
\hline $\begin{array}{l}\text { Blinding of participants } \\
\text { and personnel (perfor- } \\
\text { mance bias) } \\
\text { All outcomes }\end{array}$ & High risk & $\begin{array}{l}\text { Due to the nature of the psychological intervention, it was impossible to blind } \\
\text { the people delivering the treatment to whether the participant was in the in- } \\
\text { tervention or control arm. }\end{array}$ \\
\hline $\begin{array}{l}\text { Blinding of outcome as- } \\
\text { sessment (detection bias) } \\
\text { All outcomes }\end{array}$ & Unclear risk & Insufficient information to permit judgement \\
\hline $\begin{array}{l}\text { Incomplete outcome data } \\
\text { (attrition bias) } \\
\text { All outcomes }\end{array}$ & High risk & $\begin{array}{l}\text { Of } 56 \text { who met inclusion criteria, } 37(66 \%) \text { entered the study of whom } 19(64 \%) \\
\text { completed follow-up. }\end{array}$ \\
\hline $\begin{array}{l}\text { Selective reporting (re- } \\
\text { porting bias) }\end{array}$ & Low risk & All outcomes appear to be reported on. \\
\hline
\end{tabular}

Potts 1999

\section{Study characteristics}

\begin{tabular}{ll}
\hline Methods & RCCT \\
& No information on number of subjects asked to participate. \\
& 60 subjects randomised of whom $56(93 \%)$ completed follow-up. \\
\hline
\end{tabular}

\begin{tabular}{ll}
\hline Participants & Patients undergoing coronary angiography. \\
\hline Interventions & $\begin{array}{l}\text { Group CBT: } 6 \text { sessions including education, cognitive restructuring, relaxation, breathing exercises, } \\
\text { graded exposure and light physical exercise. } \\
\text { Waiting-list controls. }\end{array}$ \\
\hline
\end{tabular}

\begin{tabular}{ll}
\hline Outcomes & Chest pain free days and pain episodes over 1/52 \\
& HV score \\
& GTN dose/week \\
Exercise duration (minutes) & QoL: NHP, SIP \\
PM: HADS
\end{tabular}

Notes Impossible to assess attrition rate as no information on number of subjects asked to participate.

\section{Risk of bias}

Bias Authors' judgement Support for judgement

Psychological interventions for symptomatic management of non-specific chest pain in patients with normal coronary anatomy (Review) 
Potts 1999 (Continued)

\begin{tabular}{|c|c|c|}
\hline $\begin{array}{l}\text { Random sequence genera- } \\
\text { tion (selection bias) }\end{array}$ & Unclear risk & $\begin{array}{l}\text { Insufficient information about the sequence generation process to permit } \\
\text { judgement }\end{array}$ \\
\hline
\end{tabular}

Allocation concealment Unclear risk Insufficient information to permit judgement

(selection bias)

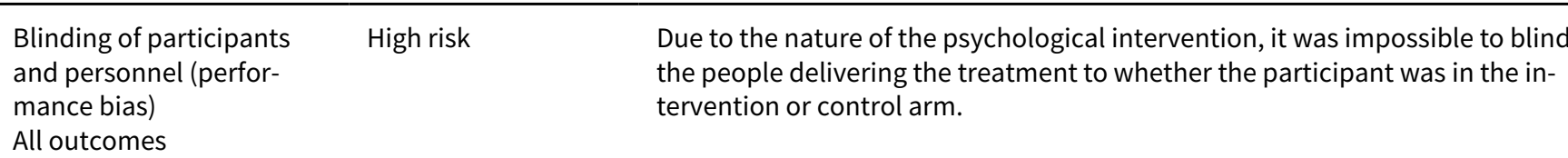

\begin{tabular}{|c|c|c|}
\hline $\begin{array}{l}\text { Blinding of outcome as- } \\
\text { sessment (detection bias) } \\
\text { All outcomes }\end{array}$ & Unclear risk & Insufficient information to permit judgement \\
\hline $\begin{array}{l}\text { Incomplete outcome data } \\
\text { (attrition bias) }\end{array}$ & Unclear risk & $\begin{array}{l}\text { Impossible to assess attrition rate as no information on number of subjects } \\
\text { asked to participate. }\end{array}$ \\
\hline
\end{tabular}

All outcomes

Selective reporting (re- Low risk $\quad$ All outcomes appear to be reported on.
porting bias)

porting bias)

Sanders 1997

\section{Study characteristics}

\begin{tabular}{ll}
\hline Methods & $\begin{array}{l}\text { RCT } \\
\text { Self-report measures \& observer ratings (blinded). } \\
\text { Of } 142 \text { referrals who met inclusion criteria, } 57 \text { ( } 40 \%) \text { entered the study of whom } 50 \text { ( } 88 \%) \text { completed } \\
\text { follow-up, although only } 41(72 \%) \text { completed psychological assessments. }\end{array}$ \\
\hline Participants & Patients undergoing coronary angiography. \\
\hline Interventions & $\begin{array}{l}\text { Brief CBT intervention by nurse consisting of a single hour-long session including education, relaxation, } \\
\text { breathing exercises, and graded exposure supplemented by a booklet and cassette tape of breathing } \\
\text { and relaxation exercises. }\end{array}$ \\
\hline
\end{tabular}

Chest pain: frequency, severity, distress, and number of pain-free days over $1 / 12$.
Associated sx i.e. palpitations and breathlessness.
QoL: SF-36.
PM: SCL, STAI-T, BDI.
Health beliefs: Whitely score.

Notes High attrition rate leading to potential follow-up bias.

\section{Risk of bias}

\begin{tabular}{lll}
\hline Bias & Authors' judgement & Support for judgement \\
\hline $\begin{array}{l}\text { Random sequence genera- } \\
\text { tion (selection bias) }\end{array}$ & Unclear risk & $\begin{array}{l}\text { Insufficient information about the sequence generation process to permit } \\
\text { judgement }\end{array}$ \\
\hline $\begin{array}{l}\text { Allocation concealment } \\
\text { (selection bias) }\end{array}$ & Unclear risk & Insufficient information to permit judgement \\
\hline
\end{tabular}

Psychological interventions for symptomatic management of non-specific chest pain in patients with normal coronary anatomy (Review) 
Sanders 1997 (Continued)

Blinding of participants High risk Due to the nature of the psychological intervention, it was impossible to blind and personnel (perforthe people delivering the treatment to whether the participant was in the inmance bias)

All outcomes tervention or control arm.

\begin{tabular}{lll}
$\begin{array}{l}\text { Blinding of outcome as- } \\
\text { sessment (detection bias) } \\
\text { All outcomes }\end{array}$ & Unclear risk & Outcomes were assessed blind to treatment allocation. \\
\hline $\begin{array}{l}\text { Incomplete outcome data } \\
\text { (attrition bias) }\end{array}$ & High risk & $\begin{array}{l}\text { Of } 142 \text { referrals who met inclusion criteria, } 57(40 \%) \text { entered the study of } \\
\text { whom } 50(88 \%) \text { completed follow-up, although only } 41(72 \%) \text { completed psy- } \\
\text { choll outcomes }\end{array}$
\end{tabular}

Selective reporting (re- Low risk All outcomes appear to be reported on.
porting bias)

Spinhoven 2010

\section{Study characteristics}

\begin{tabular}{ll}
\hline Methods & RCT of CBT, paroxetine and placebo in the treatment of NCCP. \\
\hline Participants & Eligible participants were cardiology outpatients of two academic and two nonacademic hospitals who \\
had been discharged with a diagnosis of NCCP. Inclusion criteria were NCCP as main presenting com- \\
plaint; NCCP occurring at least once a week, or at least once per month if accompanied by severe psy- \\
chological distress; age between 18 and 75 years. An initial charts review identified 3270 patients diag- \\
nosed with NCCP. Between January 1997 and January 2002. Of these, 2367 patients ( $72.4 \%)$ returned \\
a questionnaire about current symptoms, of whom 583 (24.6\%) had no interest in the study, and 1310 \\
(55.3\%) did not fulfil the inclusion criteria regarding chest pain frequency. The remaining 474 potential \\
participants received detailed information about the study and were invited for a screening and infor- \\
mation session. After the screening session, 95 patients ( $20.0 \%)$ agreed to be randomised. After the in- \\
take, 26 patients had to be excluded, leaving 69 patients (37 males) who started the trial.
\end{tabular}

Interventions $\quad$ CBT, paroxetine and placebo.

Outcomes Frequency, duration, and intensity of chest pain, The HADS, heart-focused anxiety by the Cardiac Anxiety Questionnaire (CAQ), the M.I.N.I.-Plus.

Notes High attrition rate.

\section{Risk of bias}

\begin{tabular}{lll}
\hline Bias & Authors' judgement & Support for judgement \\
\hline $\begin{array}{l}\text { Random sequence genera- } \\
\text { tion (selection bias) }\end{array}$ & Low risk & Patients were randomised using random permuted blocks with a length of six. \\
\hline $\begin{array}{l}\text { Allocation concealment } \\
\text { (selection bias) }\end{array}$ & Low risk & $\begin{array}{l}\text { Randomisation carried out by the hospital pharmacist and the details were un- } \\
\text { known to any of the researchers. }\end{array}$ \\
$\begin{array}{l}\text { Blinding of participants } \\
\begin{array}{l}\text { and personnel (perfor- } \\
\text { mance bias) }\end{array}\end{array}$ & High risk & Medical treatment blinded, but CBT not. \\
$\begin{array}{l}\text { All outcomes } \\
\end{array}$
\end{tabular}


Spinhoven 2010 (Continued)
Blinding of outcome as-
High risk
Outcome assessment by self report. sessment (detection bias) All outcomes

\begin{tabular}{lll}
\hline Incomplete outcome data & High risk & Analyses conducted on ITT, but differences in drop outs between arms. No pa- \\
(attrition bias) & & tients dropped out of CBT, but four (17\%) dropped out of placebo group and \\
All outcomes & seven (30\%) dropped out of paroxetine group, mostly because of adverse ef- \\
& fects.
\end{tabular}

Selective reporting (re- Unclear risk $\quad$ Did not clearly state outcomes of interest.
porting bias)
porting bias)

Tyni-Lenne 2002

\section{Study characteristics}

\begin{tabular}{|c|c|c|}
\hline Methods & \multicolumn{2}{|c|}{$\begin{array}{l}\text { Single-blind RCT with three groups: physical training, relaxation and control groups. } \\
\text { No information on number of subjects asked to participate. } 24 \text { subjects entered study of whom } 21 \\
(88 \%) \text { were followed-up. } \\
\text { Measurement of exercise capacity, peak heart rate \& distance walked during } 6 \text { minutes. } \\
\text { Self-report measures of exertion \& Quality of Life. }\end{array}$} \\
\hline Participants & \multicolumn{2}{|c|}{$\begin{array}{l}\text { Inclusion criteria: females only, limited by chest pain (Canadian Cardiovascular Society functional class } \\
\text { II). } \\
\text { Exclusion criteria: History of musculoskeletal impairment, hypertension, DM or other systemic illness. }\end{array}$} \\
\hline Interventions & \multicolumn{2}{|c|}{$\begin{array}{l}\text { Physical training: endurance training on a cycle ergometer three times/week for } 8 / 52 \text {. } \\
\text { Relaxation training twice/week for } 8 / 52 \text {. } \\
\text { Controls: normal daily activities. }\end{array}$} \\
\hline Outcomes & \multicolumn{2}{|c|}{$\begin{array}{l}\text { Peak oxygen uptake, peak work rate and distance walked during } 6 \text { minutes. } \\
\text { Rating of perceived exertion. } \\
\text { QoL: SOC, SCI-93, SIP. }\end{array}$} \\
\hline \multicolumn{3}{|l|}{ Notes } \\
\hline \multicolumn{3}{|l|}{ Risk of bias } \\
\hline Bias & Authors' judgement & Support for judgement \\
\hline $\begin{array}{l}\text { Random sequence genera- } \\
\text { tion (selection bias) }\end{array}$ & Unclear risk & $\begin{array}{l}\text { Insufficient information about the sequence generation process to permit } \\
\text { judgement }\end{array}$ \\
\hline $\begin{array}{l}\text { Allocation concealment } \\
\text { (selection bias) }\end{array}$ & Unclear risk & Insufficient information to permit judgement \\
\hline $\begin{array}{l}\text { Blinding of participants } \\
\text { and personnel (perfor- } \\
\text { mance bias) } \\
\text { All outcomes }\end{array}$ & High risk & Single-blinded only. \\
\hline
\end{tabular}

\begin{tabular}{|c|c|c|}
\hline $\begin{array}{l}\text { Blinding of outcome as- } \\
\text { sessment (detection bias) } \\
\text { All outcomes }\end{array}$ & Unclear risk & Insufficient information to permit judgement \\
\hline
\end{tabular}


Tyni-Lenne 2002 (Continued)

Incomplete outcome data Unclear risk No information on number of subjects asked to participate. 24 subjects en(attrition bias) tered study of whom 21 (88\%) were followed-up.

All outcomes

Selective reporting (re- Low risk All outcomes appear to be reported on. porting bias)

van Beek 2013

\section{Study characteristics}

$\begin{array}{ll}\text { Methods } & \text { RCT } \\ & \begin{array}{l}\text { Of } 137 \text { referrals who met inclusion criteria, } 113 \text { (82\%) subjects entered study of whom } 75 \text { (54\%) were } \\ \text { followed-up up to six months. }\end{array}\end{array}$

Participants
encing a heart attack. Eligible patients were subjects in whom full medical examination revealed no
cardiopulmonary, gastrointestinal or endocrinal explanation for their complaints (and thus were diag-
nosed with "noncardiac chest pain") and who scored eight or higher on either or both subscales of the
HADS.

Interventions $\quad$ CBT consisted of six individual sessions with a duration of $45 \mathrm{~min}$.

TAU consisted of reassurance by a cardiologist that patients' complaints were not caused by cardiac disease. TAU was tailored to the individual needs of the patients but did not include psychotherapy, including CBT, or antidepressants.

The main outcome was disease severity assessed with the CGI by a blinded independent rater.
Secondary outcomes were anxiety as measured by the HADS-anxiety and state trait anxiety inventory
(STAI)-trait), as well as depressive symptoms on the Hamilton depression rating scale.

Notes

\section{Risk of bias}

\begin{tabular}{lll}
\hline Bias & Authors' judgement & Support for judgement \\
\hline $\begin{array}{l}\text { Random sequence genera- } \\
\text { tion (selection bias) }\end{array}$ & Low risk & $\begin{array}{l}\text { Simple randomization, with an equal allocation ratio, with reference to a table } \\
\text { of random numbers (to which all researchers and physicians were blinded). }\end{array}$ \\
\hline $\begin{array}{l}\text { Allocation concealment } \\
\text { (selection bias) }\end{array}$ & Low risk & See above. \\
\hline $\begin{array}{l}\text { Blinding of participants } \\
\begin{array}{l}\text { and personnel (perfor- } \\
\text { mance bias) } \\
\text { All outcomes }\end{array}\end{array}$ & High risk & $\begin{array}{l}\text { Due to the nature of the psychological intervention, it was impossible to blind } \\
\text { the people delivering the treatment to whether the participant was in the in- } \\
\text { tervention or control arm. }\end{array}$ \\
\hline
\end{tabular}

\begin{tabular}{lll}
\hline $\begin{array}{l}\text { Blinding of outcome as- } \\
\text { sessment (detection bias) } \\
\text { All outcomes }\end{array}$ & Low risk & $\begin{array}{l}\text { Patients were assessed by an independent rater, who was blinded to the con- } \\
\text { dition to which they were allocated. }\end{array}$ \\
\hline $\begin{array}{l}\text { Incomplete outcome data } \\
\text { (attrition bias) }\end{array}$ & High risk & $\begin{array}{l}\text { Only } 75 \text { (54\%) were followed-up at six months but bias was reduced through } \\
\text { the use of ITT analyses. }\end{array}$
\end{tabular}

Psychological interventions for symptomatic management of non-specific chest pain in patients with normal coronary anatomy (Review) 
van Beek 2013 (Continued)

All outcomes

Selective reporting (re- Low risk $\quad$ All outcomes appear to be reported on.

porting bias)

\section{Van Peski-Oosterbaan 1999}

\section{Study characteristics}

\begin{tabular}{ll}
\hline Methods & RCT \\
& Self-report measures some confirmed with treating doctor. \\
& Of 143 referrals who met inclusion criteria, 65 (44\%) subjects entered study of whom 63 (43\%) were fol- \\
& lowed-up at $12 / 12$. \\
\hline Participants & Inclusion criteria: 18 to 75 yrs old. \\
& Normal CVS according to a cardiologist. \\
& Exclusion criteria: Proven CAD of MI on coronary angiography, exercise test, laboratory results, ECG of \\
& CXR, a history of typical angina, insufficient fluency in Dutch, current psychiatric treatment for NCCP, \\
current diagnosis of major depression, bipolar disorder, psychoactive substance use (except nicotine) \\
in previous 3/12.
\end{tabular}

$\begin{array}{ll}\text { Interventions } & \text { Individual CBT: maximum } 12 \text { sessions including cognitive restructuring, problem solving, relaxation, } \\ \text { breathing exercises. }\end{array}$
Controls: assessment only and usual care.

\begin{tabular}{ll}
\hline Outcomes & Chest pain free days and pain episodes including severity over 1/52 \\
& PM: HADS \\
QoL: SF-36 & Health service use \\
\hline Notes & High attrition rate leading to potential follow-up bias.
\end{tabular}

\section{Risk of bias}

\begin{tabular}{|c|c|c|}
\hline Bias & Authors' judgement & Support for judgement \\
\hline $\begin{array}{l}\text { Random sequence genera- } \\
\text { tion (selection bias) }\end{array}$ & Unclear risk & $\begin{array}{l}\text { Insufficient information about the sequence generation process to permit } \\
\text { judgement }\end{array}$ \\
\hline $\begin{array}{l}\text { Allocation concealment } \\
\text { (selection bias) }\end{array}$ & Unclear risk & Insufficient information to permit judgement \\
\hline $\begin{array}{l}\text { Blinding of participants } \\
\text { and personnel (perfor- } \\
\text { mance bias) } \\
\text { All outcomes }\end{array}$ & High risk & $\begin{array}{l}\text { Due to the nature of the psychological intervention, it was impossible to blind } \\
\text { the people delivering the treatment to whether the participant was in the in- } \\
\text { tervention or control arm. }\end{array}$ \\
\hline $\begin{array}{l}\text { Blinding of outcome as- } \\
\text { sessment (detection bias) } \\
\text { All outcomes }\end{array}$ & Unclear risk & Insufficient information to permit judgement \\
\hline $\begin{array}{l}\text { Incomplete outcome data } \\
\text { (attrition bias) } \\
\text { All outcomes }\end{array}$ & High risk & $\begin{array}{l}\text { Of } 143 \text { referrals who met inclusion criteria, } 65(44 \%) \text { subjects entered study of } \\
\text { whom } 63(43 \%) \text { were followed-up at } 12 / 12 \text {. }\end{array}$ \\
\hline
\end{tabular}


Van Peski-Oosterbaan 1999 (Continued)
Selective reporting (re-
Low risk
All outcomes appear to be reported on. porting bias)

Abbreviations: $\mathrm{RCCT}$ = randomised controlled cross-over trial; RCT = randomised controlled trial; $\mathrm{QoL}=$ quality of life; $\mathrm{PM}=\mathrm{psychological}$ morbidity; PSE = Present State Examination; STAI-T = State-trait Anxiety Inventory; BDI = Beck Depression Inventory; SRT = symptom rating test; $\mathrm{AS}=$ autonomic symptoms; $\mathrm{BSI}$ = brief symptom inventory; CGI = Clinical Global Inventory.

Characteristics of excluded studies [ordered by study ID]

\begin{tabular}{|c|c|}
\hline Study & Reason for exclusion \\
\hline Achem 2008 & Review article - no primary data. \\
\hline Adler 2001 & Review article - no primary data. Psychological interventions not covered. \\
\hline Asbury 2005a & Review article - no primary data. \\
\hline Asbury $2005 b$ & Review article - no primary data. \\
\hline Barker 2013 & Review article on hyperventillation in children - no primary data. \\
\hline Carter 1992a & Not an intervention study. \\
\hline Carter 1992b & Not an intervention study. \\
\hline Chambers 1998 & $\begin{array}{l}\text { Review article - no primary data. Suggests that cognitive-behavioural therapy is effective for non- } \\
\text { cardiac chest pain. }\end{array}$ \\
\hline Chen 2010 & An RCT of treatments for gastroesophageal reflux disease (GERD). \\
\hline Coss-Adame 2014 & $\begin{array}{l}\text { Review article - no primary data. Systematic review of treatments for esophageal (noncardiac) } \\
\text { chest pain. }\end{array}$ \\
\hline Cott 1992 & $\begin{array}{l}\text { An RCT that pooled data from } 90 \text { patients with mitral valve prolapse with only } 14 \text { subjects with } \\
\text { NSCP. }\end{array}$ \\
\hline Cox 1998 & RCT of antidepressant medication. \\
\hline Elkins 2012 & Review article on cognitive hypnotherapy for pain management - no primary data. \\
\hline Esler 2004 & $\begin{array}{l}\text { Review article - no primary data. Suggests that biopsychosocial rather than attribution models may } \\
\text { be more effective for noncardiac chest pain. }\end{array}$ \\
\hline Eslick 2004 & Not an intervention study. \\
\hline Eslick 2005 & Review article - no primary data. \\
\hline Faybush 2004 & Not an intervention study. \\
\hline Fleet 1998 & Not an intervention study. \\
\hline Goodacre 2001 & Not an intervention study of a psychological treatment. \\
\hline Goodacre 2004 & Not an intervention study of a psychological treatment. \\
\hline
\end{tabular}




\begin{tabular}{|c|c|}
\hline Study & Reason for exclusion \\
\hline Handa 1999 & Non-RCT of antidepressant medication. \\
\hline Hegel 1989 & Uncontrolled trial of behavioural therapy. \\
\hline Hershcovici 2012 & $\begin{array}{l}\text { Review article - no primary data. Suggests that patients with GERD-related noncardiac chest pain } \\
\text { should be treated with at least double dose PPI. }\end{array}$ \\
\hline Jackson 2006 & $\begin{array}{l}\text { Review article - no primary data. Suggests that cognitive-behavioural therapy is effective for non- } \\
\text { cardiac chest pain. }\end{array}$ \\
\hline Jeejeebhoy 2000 & $\begin{array}{l}\text { Review article - no primary data. Suggests that cognitive-behavioural therapy is effective for non- } \\
\text { cardiac chest pain. }\end{array}$ \\
\hline Kaski 2001 & $\begin{array}{l}\text { Review article - no primary data. Suggests that cognitive-behavioural therapy is effective for non- } \\
\text { cardiac chest pain. }\end{array}$ \\
\hline Katz 2000 & $\begin{array}{l}\text { Review article - no primary data. Suggests that cognitive-behavioural therapy is effective for non- } \\
\text { cardiac chest pain. }\end{array}$ \\
\hline Kroenke 2000 & Review article - no primary data. \\
\hline Lahmann 2010 & No primary data. \\
\hline Lessard 2012 & Quasi-experimental study. \\
\hline Looper 2002 & $\begin{array}{l}\text { Review article - no primary data. Suggests that cognitive-behavioural therapy is effective for non- } \\
\text { cardiac chest pain. }\end{array}$ \\
\hline Masanga 2011 & A study of a pulmonary rehabilitation programme. \\
\hline Mayou 1989 & Conference abstract - insufficient information on intervention and control groups. \\
\hline Mayou 1994 & Not an intervention study. \\
\hline Mayou 1999 & A consecutive sample of 133 outpatients referred to cardiac outpatient clinics, not an RCT \\
\hline Nanke 2004 & $\begin{array}{l}\text { Review article - no primary data. Suggests that biofeedback, relaxation and cognitive-behavioural } \\
\text { therapy are effective for somatoform symptoms including noncardiac chest pain. }\end{array}$ \\
\hline Nezu 2001 & $\begin{array}{l}\text { Review article - no primary data. Suggests that cognitive-behavioural therapy is effective for non- } \\
\text { cardiac chest pain. }\end{array}$ \\
\hline Olden 2004 & Not an intervention study. \\
\hline Olden 2006 & Review article - no primary data. \\
\hline Otte 2011 & $\begin{array}{l}\text { Review article - no primary data. Suggests that CBT is both efficacious and effective in the treat- } \\
\text { ment of anxiety disorders. }\end{array}$ \\
\hline Palsson 2006 & Commentary - no primary data. \\
\hline Petrie 2007 & Not a study of non-specific chest pain. \\
\hline Ringel 1999 & $\begin{array}{l}\text { Review article - no primary data. Suggests that cognitive-behavioural therapy is effective for non- } \\
\text { cardiac chest pain. }\end{array}$ \\
\hline
\end{tabular}




\begin{tabular}{|c|c|}
\hline Study & Reason for exclusion \\
\hline Romeo 1993 & Not an intervention study. \\
\hline Ryan 2004 & $\begin{array}{l}\text { Of the } 70 \text { subjects, only } 11 \text { had functional cardiac pain and data for these were not presented sepa- } \\
\text { rately. }\end{array}$ \\
\hline Schey 2007 & Review article - no primary data. Suggests that hypnotherapy is effective for noncardiac chest pain. \\
\hline Schmulson 2004 & $\begin{array}{l}\text { Review article - no primary data. Suggests that cognitive-behavioural therapy is effective for non- } \\
\text { cardiac chest pain. }\end{array}$ \\
\hline Serlie 1995 & $\begin{array}{l}\text { Review article - no primary data. Suggests that cognitive-behavioural therapy is effective for non- } \\
\text { cardiac chest pain. }\end{array}$ \\
\hline Sert 2013 & $\begin{array}{l}\text { Not an RCT but a descriptive study of the clinical characteristics and causes of chest pain in chil- } \\
\text { dren referred to a paediatric cardiology unit. }\end{array}$ \\
\hline Van Peski-Oosterbaan 1997 & Uncontrolled trial of cognitive-behavioural therapy. \\
\hline Wang 2012 & $\begin{array}{l}\text { Review article - no primary data. Suggests that antidepressant medications are associated with im- } \\
\text { provements in pain and psychological symptoms in non-cardiac chest pain. }\end{array}$ \\
\hline Wertli 2013 & A systematic review and meta-analysis of diagnostic indicators of non-cardiovascular chest pain. \\
\hline Wu 2002 & $\begin{array}{l}\text { Review article - no primary data. Suggests that cognitive-behavioural therapy is effective for non- } \\
\text { cardiac chest pain. }\end{array}$ \\
\hline Wulsin 2002 & Pharmacotherapy only. \\
\hline Zachariae 2001 & Not an intervention study. \\
\hline Zaubler 1998 & $\begin{array}{l}\text { Review article - no primary data. Suggests that cognitive-behavioural therapy is effective for non- } \\
\text { cardiac chest pain. }\end{array}$ \\
\hline
\end{tabular}

\section{DATA AND ANALYSES}

\section{Comparison 1. Psychological intervention versus no such therapy}

\begin{tabular}{|c|c|c|c|c|}
\hline Outcome or subgroup title & No. of studies & $\begin{array}{l}\text { No. of partici- } \\
\text { pants }\end{array}$ & Statistical method & Effect size \\
\hline $\begin{array}{l}1.1 \text { Any chest pain up to } 3 \text { months after in- } \\
\text { tervention }\end{array}$ & 3 & 172 & $\begin{array}{l}\text { Risk Ratio (M-H, Random, } \\
95 \% \mathrm{Cl} \text { ) }\end{array}$ & $0.70[0.53,0.92]$ \\
\hline $\begin{array}{l}1.2 \text { Any chest pain from } 3 \text { to } 12 \text { months af- } \\
\text { ter intervention }\end{array}$ & 2 & 111 & $\begin{array}{l}\text { Risk Ratio (M-H, Random, } \\
95 \% \mathrm{Cl} \text { ) }\end{array}$ & $0.59[0.45,0.76]$ \\
\hline $\begin{array}{l}1.3 \text { Chest pain free days up to } 3 \text { months } \\
\text { after intervention }\end{array}$ & 2 & 81 & $\begin{array}{l}\text { Mean Difference (IV, Ran- } \\
\text { dom, } 95 \% \mathrm{CI} \text { ) }\end{array}$ & $3.00[0.23,5.77]$ \\
\hline $\begin{array}{l}\text { 1.4 Chest pain frequency up to } 3 \text { months } \\
\text { after intervention }\end{array}$ & 7 & 294 & $\begin{array}{l}\text { Mean Difference (IV, Ran- } \\
\text { dom, } 95 \% \mathrm{CI} \text { ) }\end{array}$ & $\begin{array}{l}-2.26[-4.41 \\
-0.12]\end{array}$ \\
\hline
\end{tabular}

Psychological interventions for symptomatic management of non-specific chest pain in patients with normal coronary anatomy (Review) 36 Copyright $\odot 2015$ The Cochrane Collaboration. Published by John Wiley \& Sons, Ltd. 


\begin{tabular}{|c|c|c|c|c|}
\hline Outcome or subgroup title & No. of studies & $\begin{array}{l}\text { No. of partici- } \\
\text { pants }\end{array}$ & Statistical method & Effect size \\
\hline $\begin{array}{l}1.5 \text { Chest pain frequency } 3 \text { to } 12 \text { months } \\
\text { after intervention }\end{array}$ & 4 & 164 & $\begin{array}{l}\text { Mean Difference (IV, Ran- } \\
\text { dom, } 95 \% \mathrm{CI} \text { ) }\end{array}$ & $-0.81[-2.35,0.74]$ \\
\hline 1.6 Chest pain severity up to 3 months & 4 & 180 & $\begin{array}{l}\text { Mean Difference (IV, Ran- } \\
\text { dom, } 95 \% \mathrm{CI} \text { ) }\end{array}$ & $\begin{array}{l}-4.64[-12.18 \\
2.89]\end{array}$ \\
\hline $\begin{array}{l}1.7 \text { Quality of life - physical functioning up } \\
\text { to } 3 \text { months after intervention }\end{array}$ & 5 & 221 & $\begin{array}{l}\text { Std. Mean Difference (IV, } \\
\text { Random, } 95 \% \mathrm{CI} \text { ) }\end{array}$ & $0.24[-0.03,0.50]$ \\
\hline $\begin{array}{l}\text { 1.8 Quality of life - physical functioning } 3 \\
\text { to } 12 \text { months after intervention }\end{array}$ & 4 & 192 & $\begin{array}{l}\text { Std. Mean Difference (IV, } \\
\text { Random, } 95 \% \mathrm{CI} \text { ) }\end{array}$ & $0.29[0.01,0.58]$ \\
\hline $\begin{array}{l}\text { 1.9 Quality of life - role problems due to } \\
\text { emotional limitations up to } 3 \text { months af- } \\
\text { ter intervention }\end{array}$ & 6 & 284 & $\begin{array}{l}\text { Std. Mean Difference (IV, } \\
\text { Random, } 95 \% \mathrm{Cl} \text { ) }\end{array}$ & $0.35[0.11,0.58]$ \\
\hline $\begin{array}{l}\text { 1.10 Quality of life - role problems due to } \\
\text { emotional limitations } 3 \text { to } 12 \text { months af- } \\
\text { ter intervention }\end{array}$ & 4 & 192 & $\begin{array}{l}\text { Std. Mean Difference (IV, } \\
\text { Random, } 95 \% \mathrm{CI} \text { ) }\end{array}$ & $0.18[-0.22,0.57]$ \\
\hline $\begin{array}{l}1.11 \text { Quality of life - social functioning up } \\
\text { to } 3 \text { months after intervention }\end{array}$ & 7 & 310 & $\begin{array}{l}\text { Std. Mean Difference (IV, } \\
\text { Random, } 95 \% \mathrm{CI} \text { ) }\end{array}$ & $0.19[-0.04,0.41]$ \\
\hline $\begin{array}{l}1.12 \text { Quality of life - social functioning } 3 \text { to } \\
12 \text { months after intervention }\end{array}$ & 4 & 173 & $\begin{array}{l}\text { Std. Mean Difference (IV, } \\
\text { Random, } 95 \% \mathrm{Cl} \text { ) }\end{array}$ & $0.43[0.12,0.73]$ \\
\hline $\begin{array}{l}1.13 \text { Psychological symptoms up to } 3 \\
\text { months after the intervention (depres- } \\
\text { sion \& overall) }\end{array}$ & 8 & 377 & $\begin{array}{l}\text { Std. Mean Difference (IV, } \\
\text { Random, } 95 \% \mathrm{CI} \text { ) }\end{array}$ & $-0.18[-0.46,0.10]$ \\
\hline $\begin{array}{l}1.14 \text { Psychological symptoms up to } 3 \\
\text { months after the intervention (anxiety } \\
\text { and overall) }\end{array}$ & 8 & 383 & $\begin{array}{l}\text { Std. Mean Difference (IV, } \\
\text { Random, } 95 \% \mathrm{CI} \text { ) }\end{array}$ & $\begin{array}{l}-0.24[-0.47 \\
-0.01]\end{array}$ \\
\hline $\begin{array}{l}1.15 \text { Psychological symptoms } 3 \text { to } 12 \\
\text { months after the intervention }\end{array}$ & 4 & 246 & $\begin{array}{l}\text { Std. Mean Difference (IV, } \\
\text { Random, } 95 \% \mathrm{CI} \text { ) }\end{array}$ & $-0.14[-0.39,0.11]$ \\
\hline 1.16 Cardiac anxiety fear up to 3 months & 4 & 199 & $\begin{array}{l}\text { Std. Mean Difference (IV, } \\
\text { Random, } 95 \% \mathrm{CI} \text { ) }\end{array}$ & $-0.08[-0.36,0.20]$ \\
\hline 1.17 Cardiac anxiety fear 3 to 12 months & 2 & 89 & $\begin{array}{l}\text { Mean Difference (IV, Ran- } \\
\text { dom, } 95 \% \mathrm{CI} \text { ) }\end{array}$ & $0.05[-0.24,0.33]$ \\
\hline $\begin{array}{l}1.18 \text { Cardiac anxiety avoidance up to } 3 \\
\text { months }\end{array}$ & 3 & 153 & $\begin{array}{l}\text { Mean Difference (IV, Ran- } \\
\text { dom, } 95 \% \mathrm{CI} \text { ) }\end{array}$ & $-0.04[-0.32,0.25]$ \\
\hline $\begin{array}{l}1.19 \text { Cardiac anxiety avoidance } 3 \text { to } 12 \\
\text { months }\end{array}$ & 2 & 89 & $\begin{array}{l}\text { Mean Difference (IV, Ran- } \\
\text { dom, } 95 \% \mathrm{CI} \text { ) }\end{array}$ & $0.08[-0.47,0.64]$ \\
\hline $\begin{array}{l}1.20 \text { Cardiac anxiety attention up to } 3 \\
\text { months }\end{array}$ & 3 & 153 & $\begin{array}{l}\text { Mean Difference (IV, Ran- } \\
\text { dom, } 95 \% \mathrm{CI} \text { ) }\end{array}$ & $0.17[-0.04,0.37]$ \\
\hline $\begin{array}{l}1.21 \text { Cardiac anxiety attention } 3 \text { to } 12 \\
\text { months }\end{array}$ & 2 & 89 & $\begin{array}{l}\text { Mean Difference (IV, Ran- } \\
\text { dom, } 95 \% \mathrm{CI} \text { ) }\end{array}$ & $0.03[-0.21,0.27]$ \\
\hline
\end{tabular}


Analysis 1.1. Comparison 1: Psychological intervention versus no such therapy, Outcome 1: Any chest pain up to 3 months after intervention

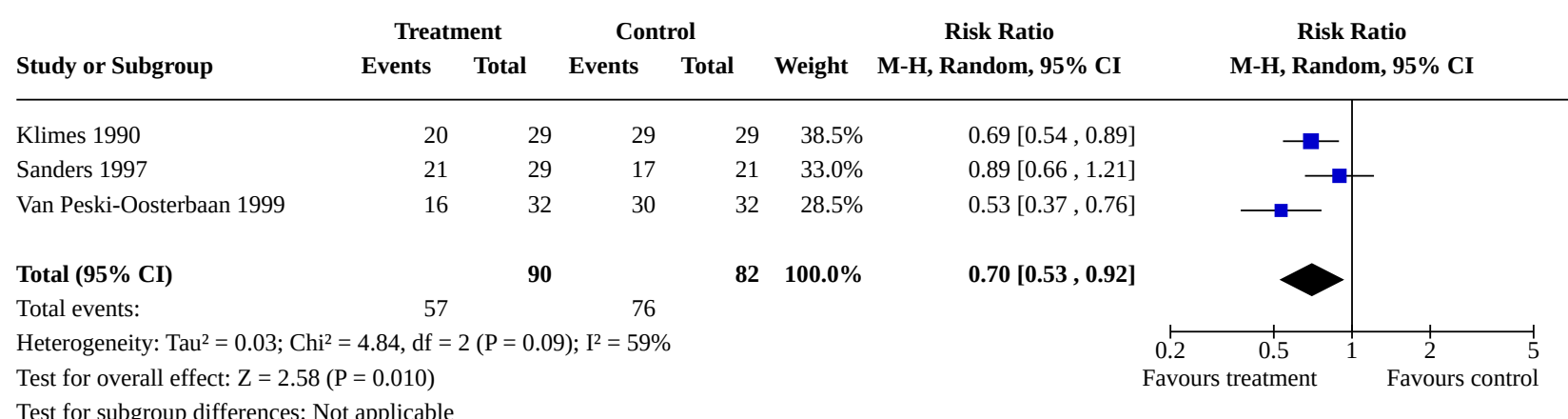

Analysis 1.2. Comparison 1: Psychological intervention versus no such therapy, Outcome 2: Any chest pain from 3 to 12 months after intervention

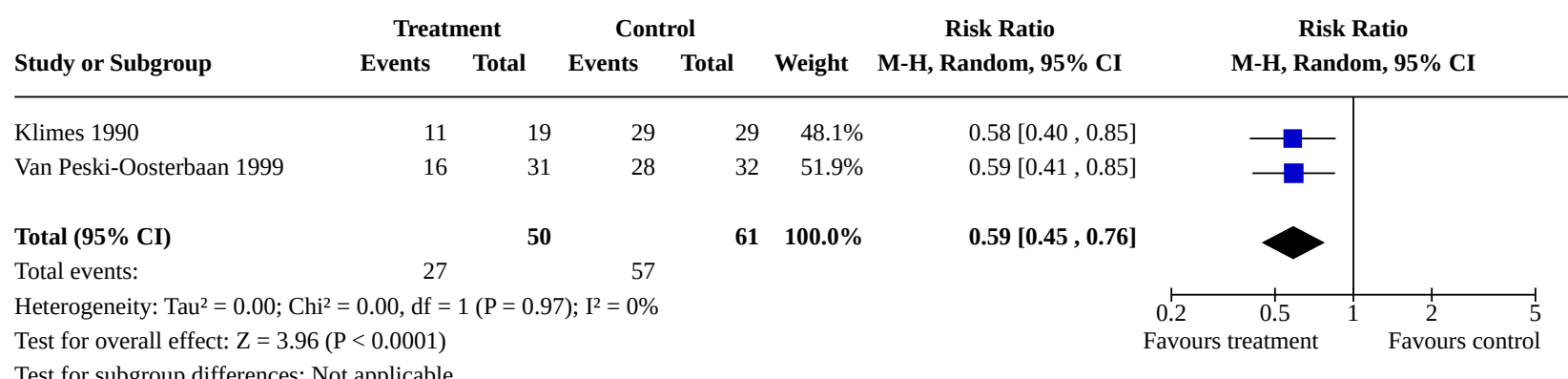

Test for subgroup differences: Not applicable

Analysis 1.3. Comparison 1: Psychological intervention versus no such therapy, Outcome 3: Chest pain free days up to 3 months after intervention

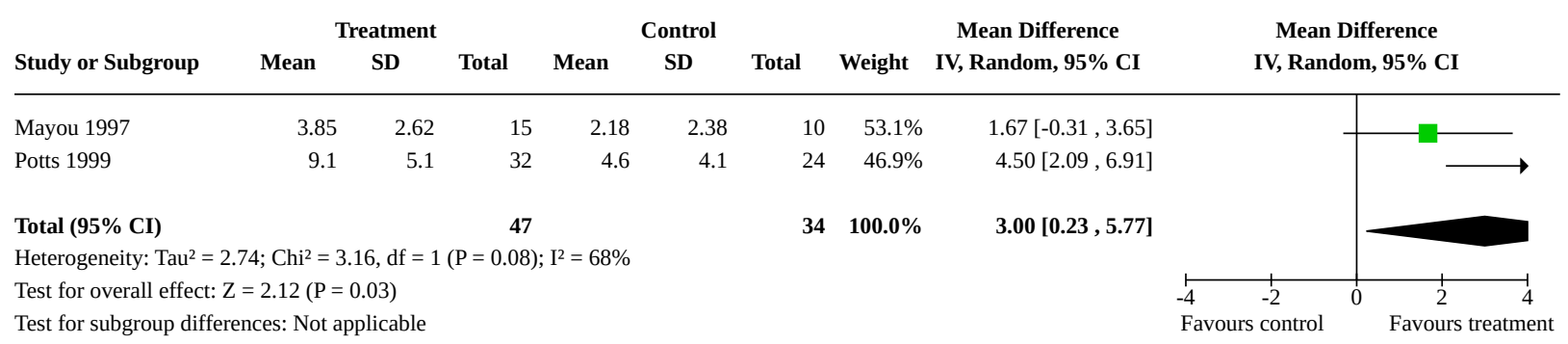


Analysis 1.4. Comparison 1: Psychological intervention versus no such therapy, Outcome 4: Chest pain frequency up to 3 months after intervention

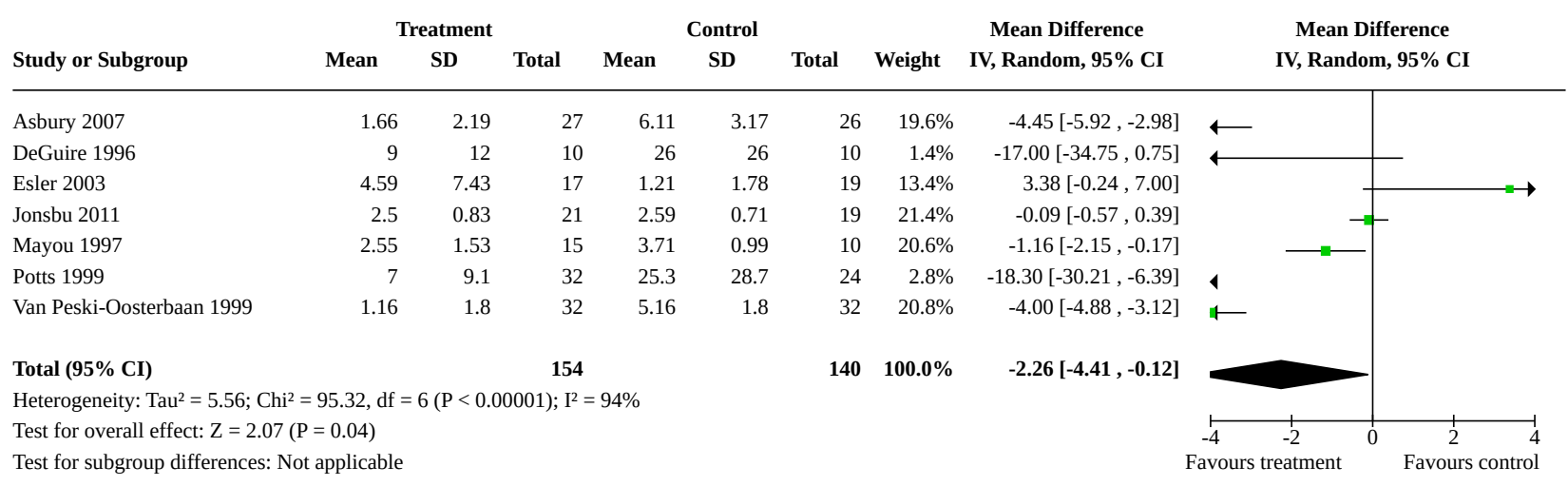

Analysis 1.5. Comparison 1: Psychological intervention versus no such therapy, Outcome 5: Chest pain frequency 3 to 12 months after intervention

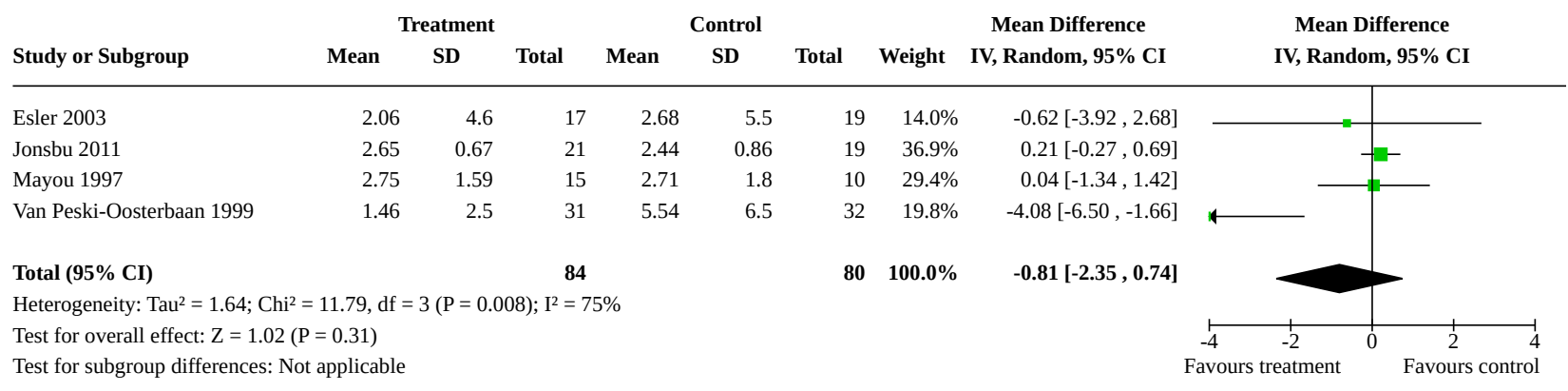

Analysis 1.6. Comparison 1: Psychological intervention versus no such therapy, Outcome 6: Chest pain severity up to 3 months

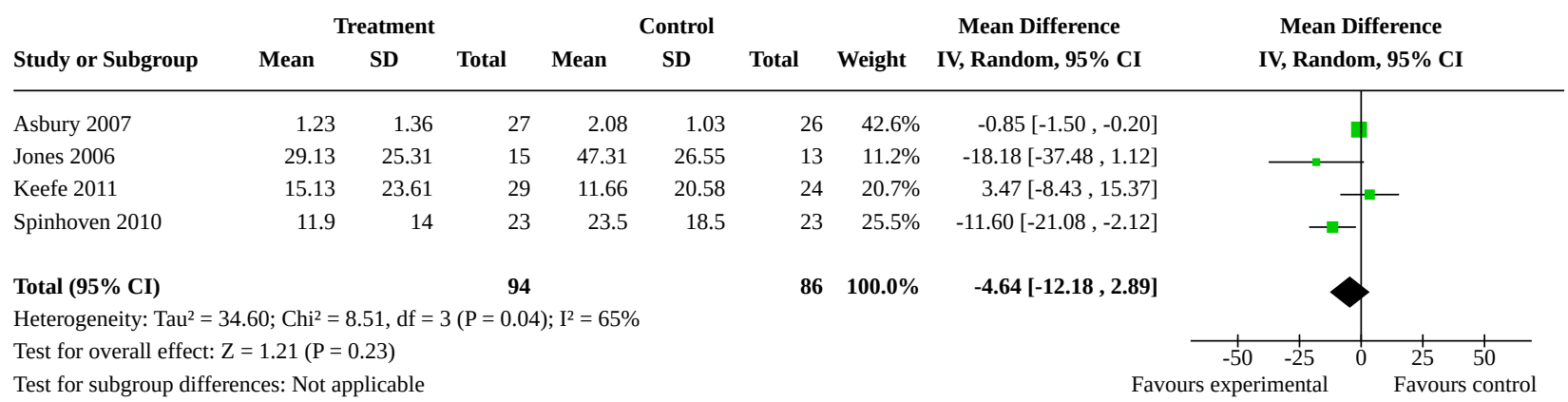


Analysis 1.7. Comparison 1: Psychological intervention versus no such therapy, Outcome 7: Quality of life - physical functioning up to 3 months after intervention

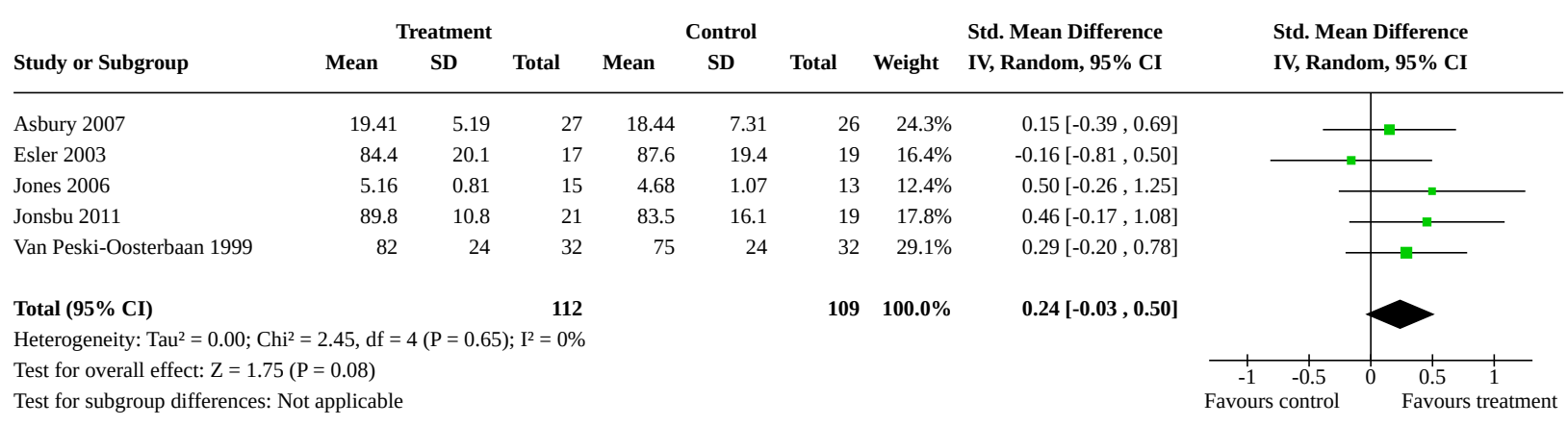

Analysis 1.8. Comparison 1: Psychological intervention versus no such therapy, Outcome 8: Quality of life - physical functioning 3 to 12 months after intervention

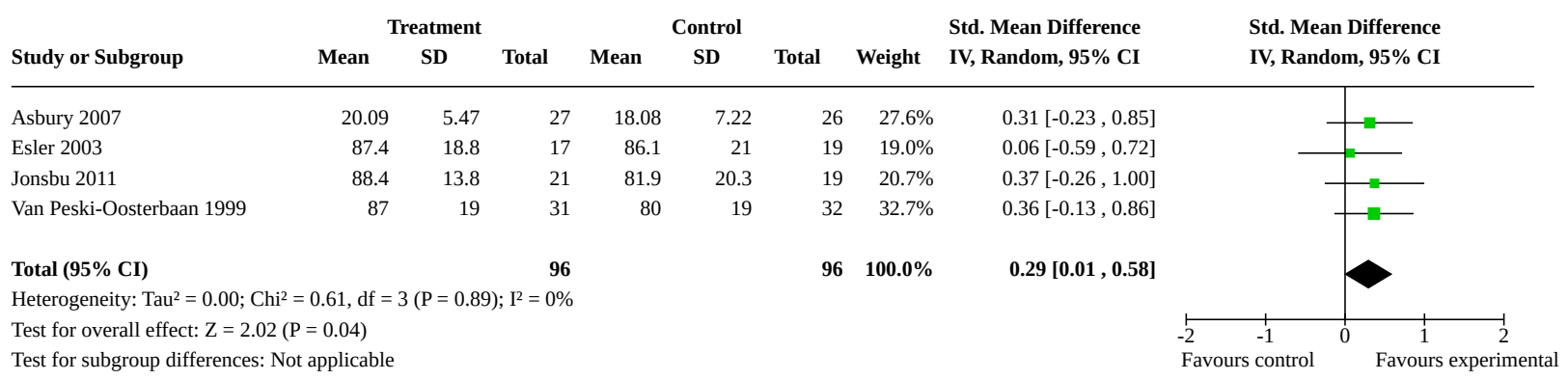

Analysis 1.9. Comparison 1: Psychological intervention versus no such therapy, Outcome 9: Quality of life - role problems due to emotional limitations up to 3 months after intervention

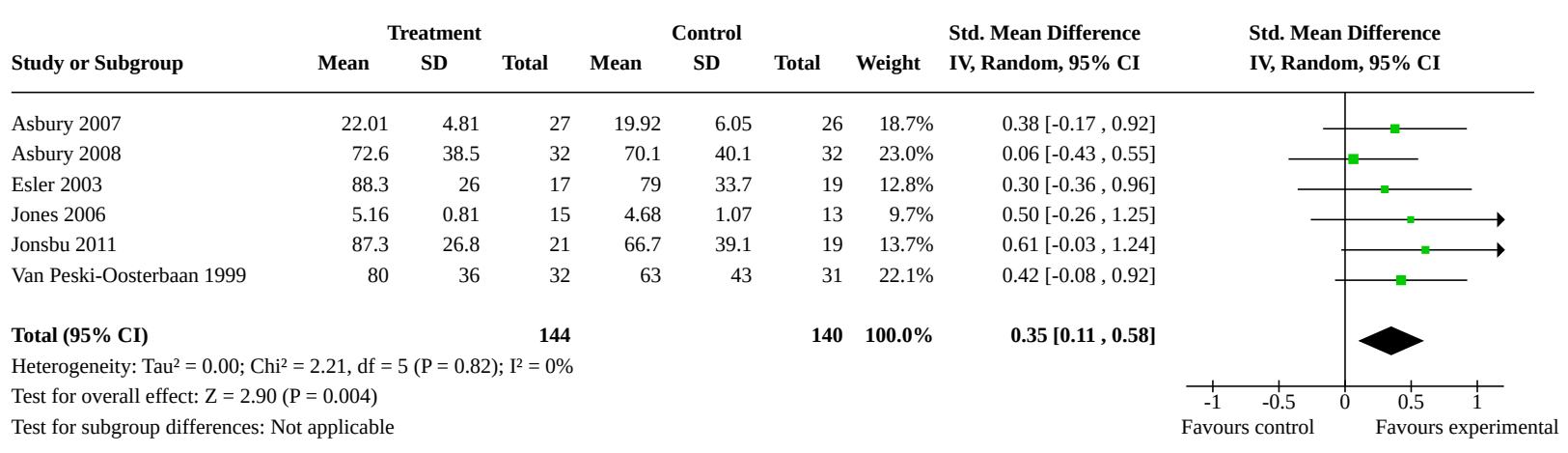


Analysis 1.10. Comparison 1: Psychological intervention versus no such therapy, Outcome 10: Quality of life - role problems due to emotional limitations 3 to 12 months after intervention

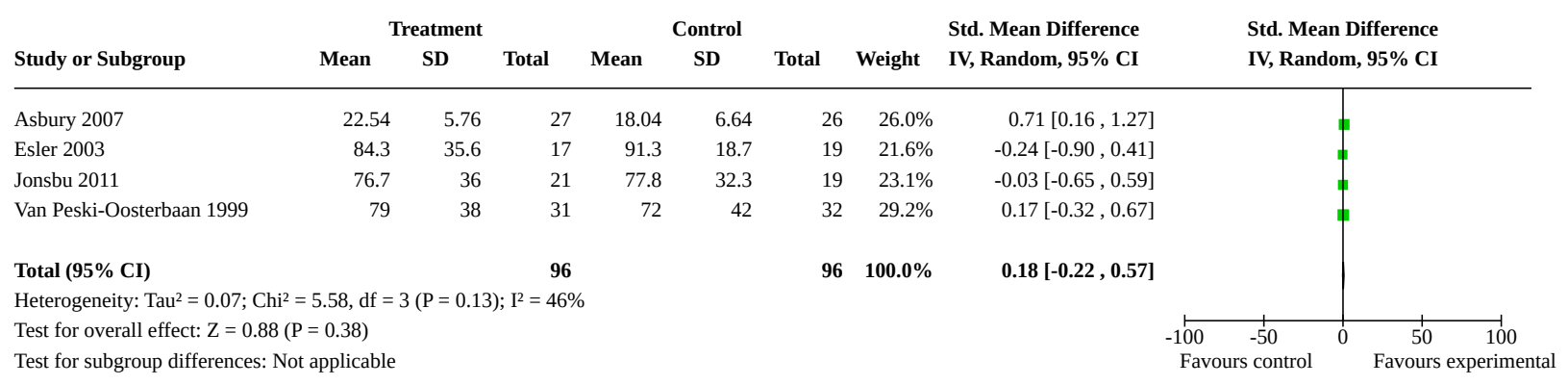

\section{Analysis 1.11. Comparison 1: Psychological intervention versus no such therapy, Outcome 11: Quality of life - social functioning up to 3 months after intervention}

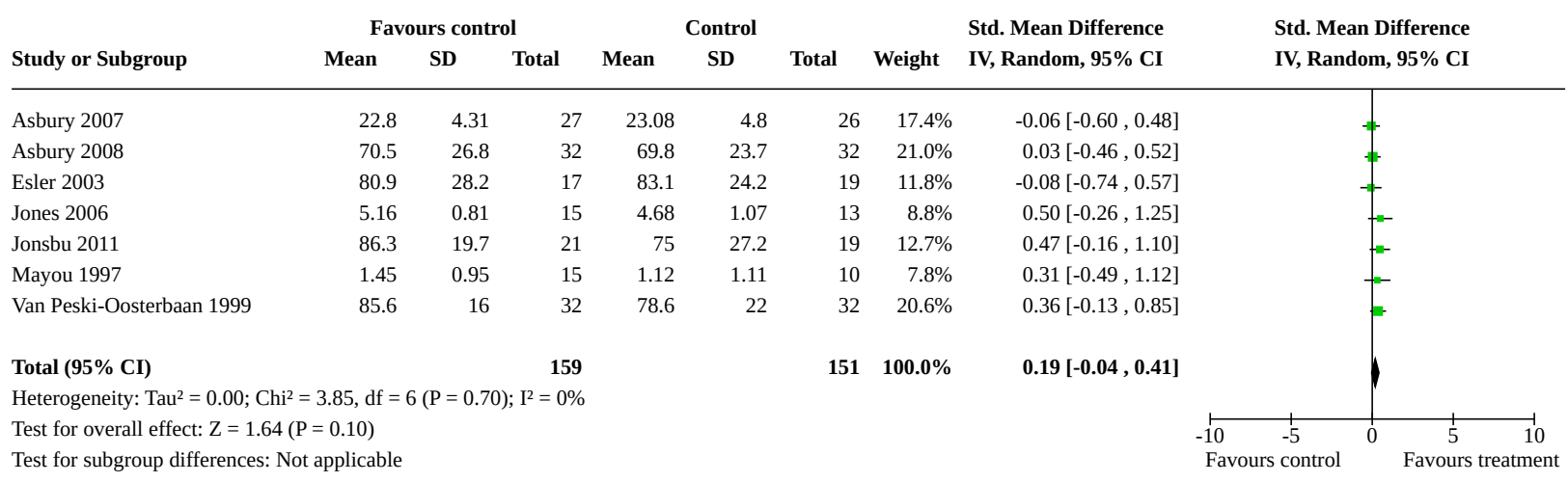

Analysis 1.12. Comparison 1: Psychological intervention versus no such therapy, Outcome 12: Quality of life - social functioning 3 to 12 months after intervention

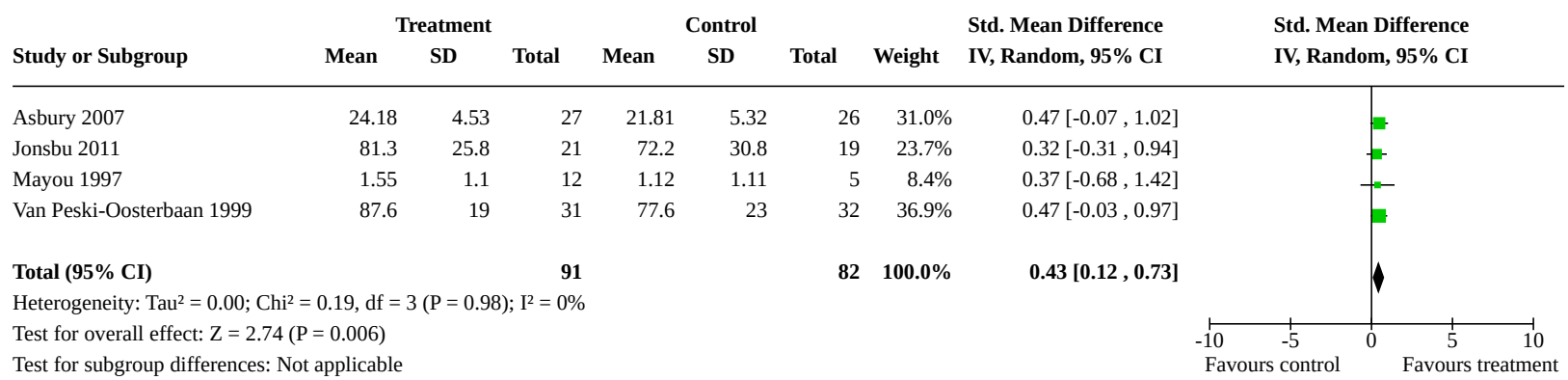


Analysis 1.13. Comparison 1: Psychological intervention versus no such therapy, Outcome 13: Psychological symptoms up to 3 months after the intervention (depression \& overall)

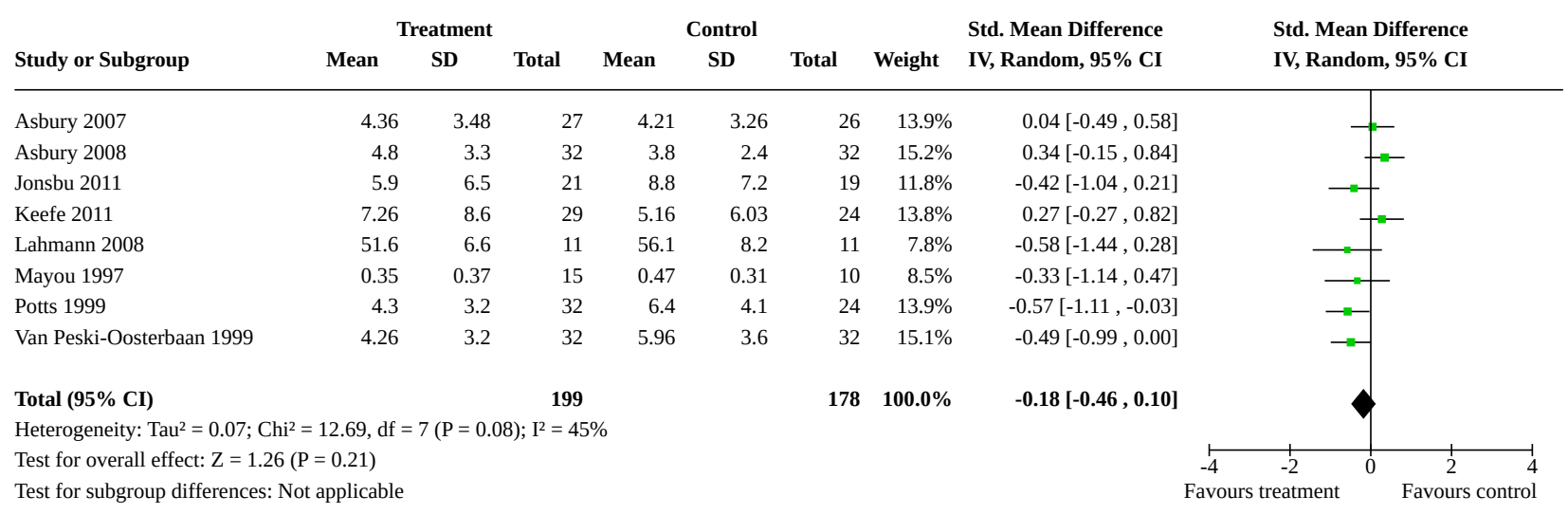

Analysis 1.14. Comparison 1: Psychological intervention versus no such therapy, Outcome 14: Psychological symptoms up to 3 months after the intervention (anxiety and overall)

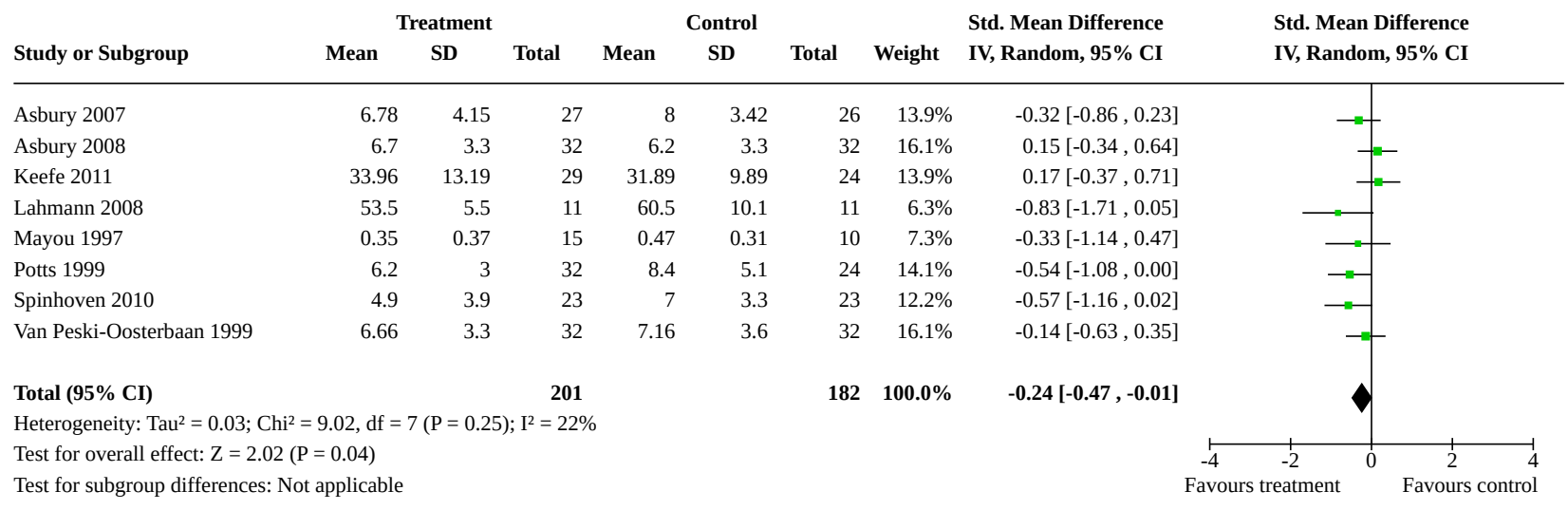

\section{Analysis 1.15. Comparison 1: Psychological intervention versus no such therapy, Outcome 15: Psychological symptoms 3 to 12 months after the intervention}

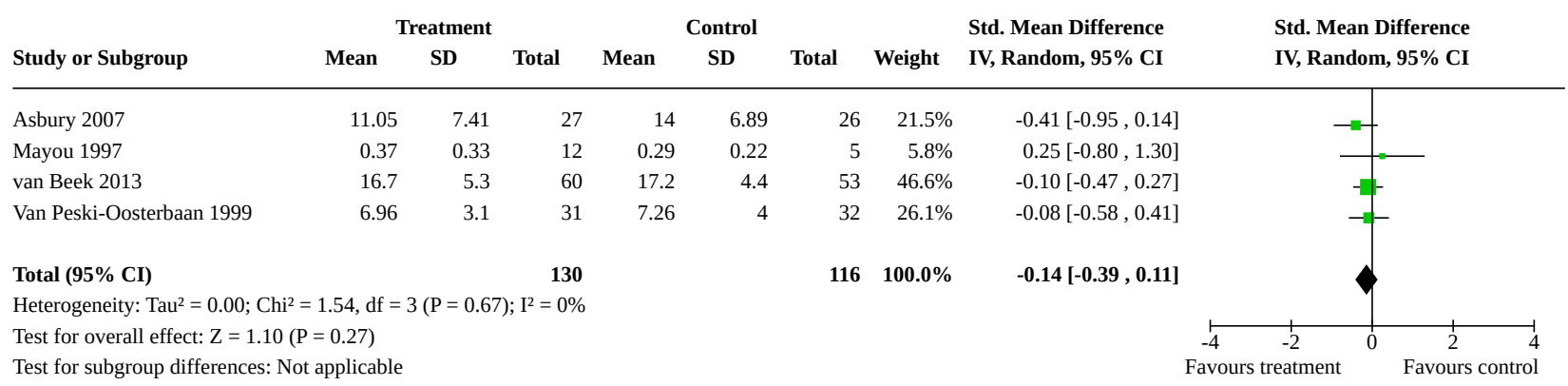


Analysis 1.16. Comparison 1: Psychological intervention versus no such therapy, Outcome 16: Cardiac anxiety fear up to 3 months

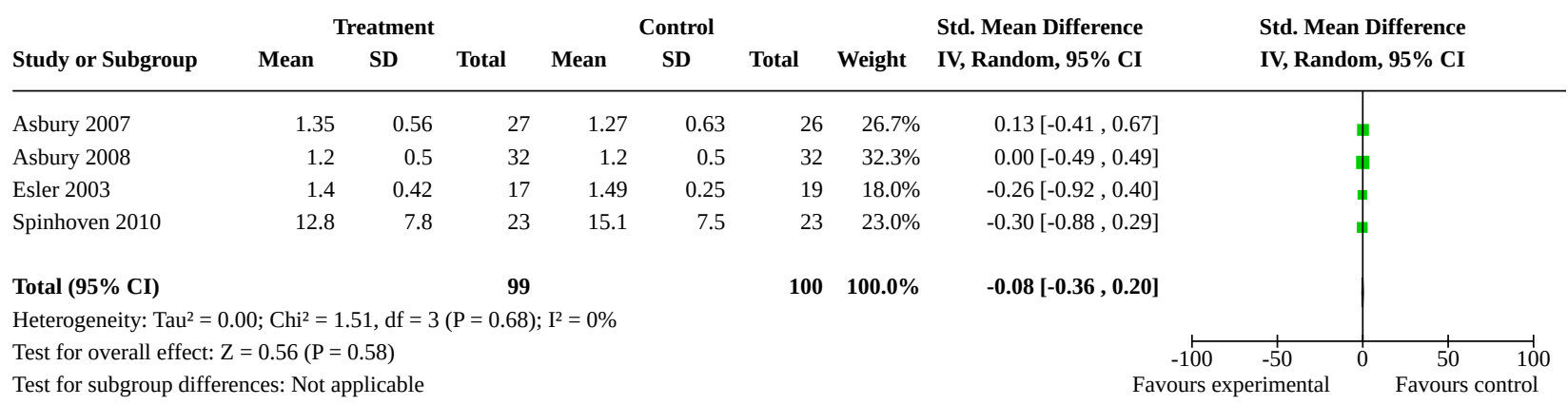

Analysis 1.17. Comparison 1: Psychological intervention versus no such therapy, Outcome 17: Cardiac anxiety fear 3 to 12 months

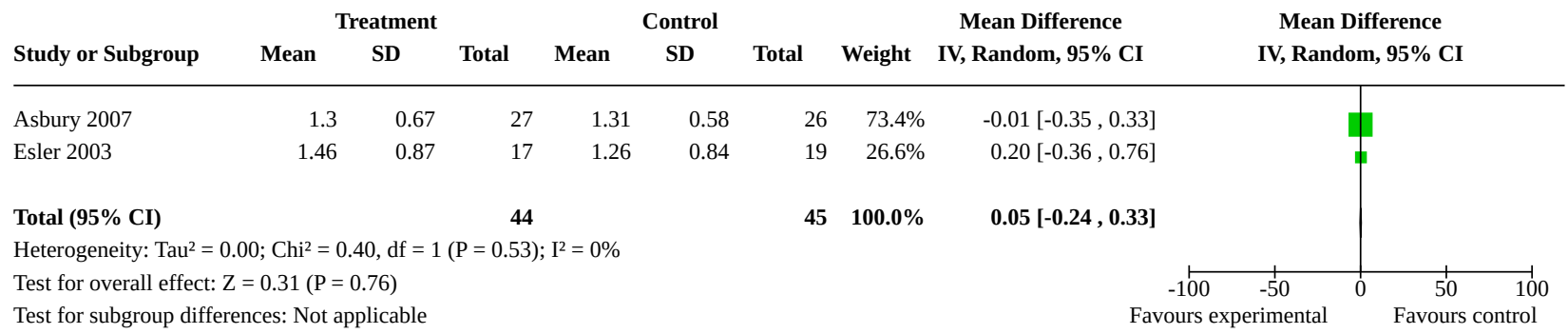

Analysis 1.18. Comparison 1: Psychological intervention versus no such therapy, Outcome 18: Cardiac anxiety avoidance up to 3 months

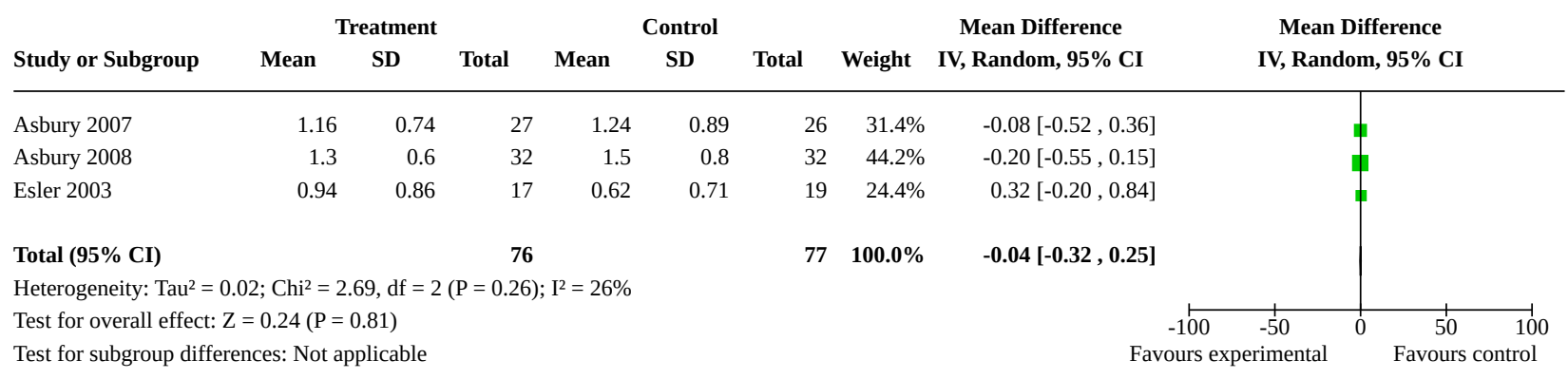

Analysis 1.19. Comparison 1: Psychological intervention versus no such therapy, Outcome 19: Cardiac anxiety avoidance 3 to 12 months

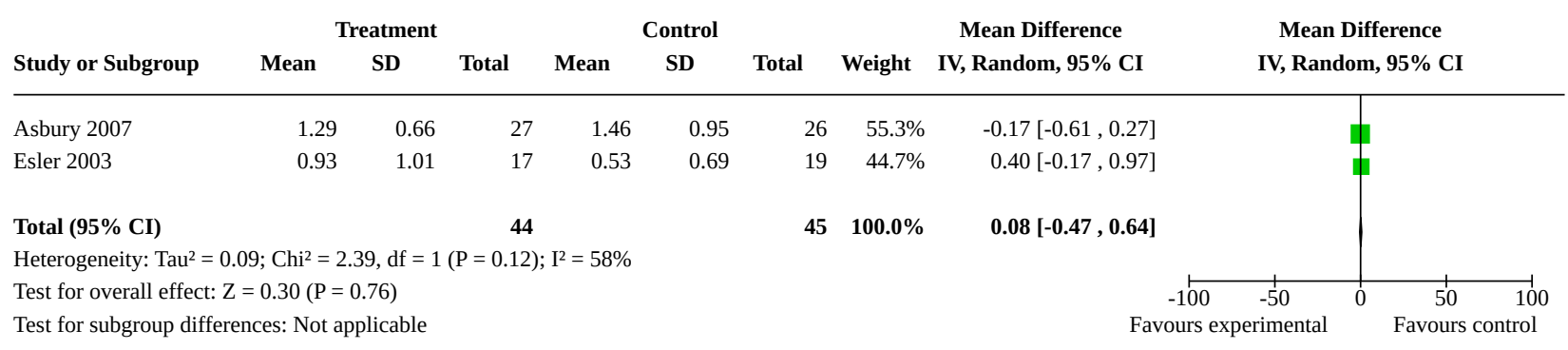


Analysis 1.20. Comparison 1: Psychological intervention versus no such therapy, Outcome 20: Cardiac anxiety attention up to 3 months

\begin{tabular}{|c|c|c|c|c|c|c|c|c|c|c|}
\hline Study or Subgroup & Mean & \multicolumn{2}{|c|}{ Treatment } & Mean & $\begin{array}{l}\text { ontrol } \\
\text { SD }\end{array}$ & Total & Weight & $\begin{array}{c}\text { Mean Difference } \\
\text { IV, Random, 95\% CI }\end{array}$ & $\begin{array}{c}\text { Mean Difference } \\
\text { IV, Random, 95\% CI }\end{array}$ & \\
\hline Asbury 2007 & 1.37 & 0.66 & 27 & 1.16 & 0.57 & 26 & $39.3 \%$ & $0.21[-0.12,0.54]$ & 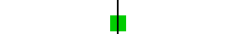 & \\
\hline Asbury 2008 & 1.4 & 0.6 & 32 & 1.2 & 0.7 & 32 & $42.3 \%$ & $0.20[-0.12,0.52]$ & 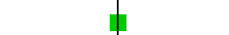 & \\
\hline Esler 2003 & 1.06 & 0.74 & 17 & 1.07 & 0.74 & 19 & $18.4 \%$ & $-0.01[-0.49,0.47]$ & I & \\
\hline Total (95\% CI) & & & 76 & & & 77 & $100.0 \%$ & $0.17[-0.04,0.37]$ & & \\
\hline \multicolumn{11}{|c|}{ Heterogeneity: Tau $^{2}=0.00 ; \mathrm{Chi}^{2}=0.62, \mathrm{df}=2(\mathrm{P}=0.73) ; \mathrm{I}^{2}=0 \%$} \\
\hline \multirow{2}{*}{\multicolumn{5}{|c|}{$\begin{array}{l}\text { Test for overall effect: } \mathrm{Z}=1.56(\mathrm{P}=0.12) \\
\text { Test for subgroup differences: Not applicable }\end{array}$}} & & & & -100 & -50 & 100 \\
\hline & & & & & & & & Favours e & rimental & trol \\
\hline
\end{tabular}

Analysis 1.21. Comparison 1: Psychological intervention versus no such therapy, Outcome 21: Cardiac anxiety attention 3 to 12 months

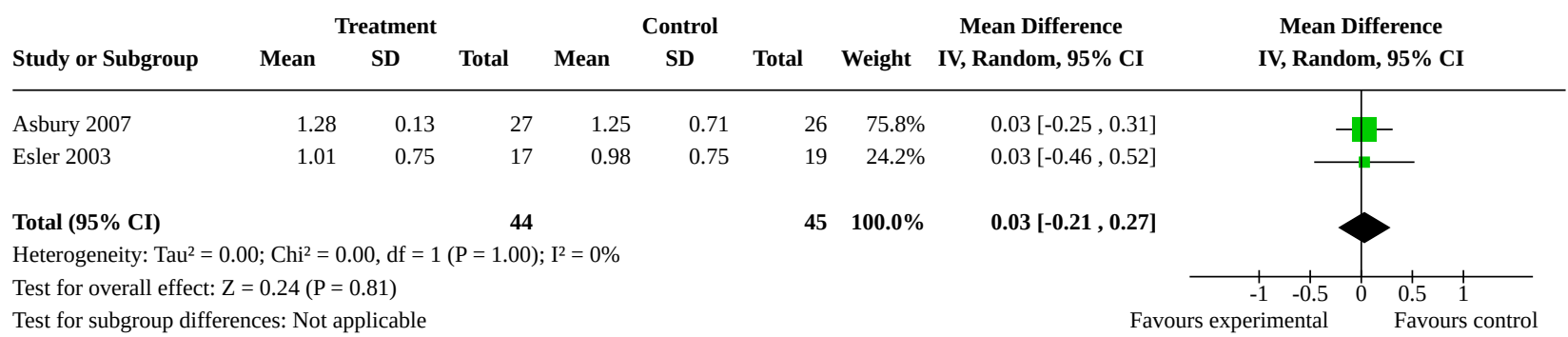

\section{APPENDICES}

\section{Appendix 1.2002 search strategies}

\section{MEDLINE}

1 Chest Pain/

2 Syndrome X/

3 "syndrome x".tw.

4 microvascular angina.tw.

5 cardiac syndrome\$.tw.

6 chest pain\$.tw.

7 ((thorax or thoracic) adj1 pain\$).tw.

8 or/1-7

9 Angina Pectoris/

10 angina.tw.

11 (normal adj5 coronary).tw.

12 (normal adj5 angiogram\$).tw.

13 (normal adj5 anatomy).tw.

14 or/11-13

159 or 10

1614 and 15

178 or 16

18 exp Psychotherapy/

19 exp Counseling/

20 psychotherap\$.tw.

21 counsel\$.tw.

22 psychodynamic $\$ . t w$.

23 (behavio $\$$ adj3 therap\$).tw.

Psychological interventions for symptomatic management of non-specific chest pain in patients with normal coronary anatomy (Review) Copyright $\odot 2015$ The Cochrane Collaboration. Published by John Wiley \& Sons, Ltd. 
24 (cognitiv\$ adj3 therap\$).tw.

25 psychologic $\$ . t w$.

26 exp "Mind-Body and Relaxation Techniques"/

27 (relaxation adj5 (treat\$ or therap\$ or technique\$)).tw.

28 or/18-27

2917 and 28

\section{EMBASE}

1 Thorax Pain/

2 Syndrome X/

3 "syndrome $x$ ".tw.

4 microvascular angina.tw.

5 cardiac syndrome $\$$.tw.

6 chest pain $\$$.tw.

7 ((thorax or thoracic) adj1 pain\$).tw.

8 or/1-7

9 Angina Pectoris/

10 angina.tw.

11 (normal adj5 coronary).tw.

12 (normal adj5 angiogram\$).tw.

13 (normal adj5 anatomy).tw.

14 or/11-13

159 or 10

1614 and 15

178 or 16

18 exp Psychiatric treatment/

19 exp Counseling/

20 psychotherap\$.tw.

21 counsel\$.tw.

22 psychodynamic $\$ . t w$.

23 (behavio $\$$ adj3 therap\$).tw.

24 (cognitiv\$ adj3 therap\$).tw.

25 psychologic $\$ . t w$.

26 (relaxation adj5 (treat\$ or therap\$ or technique\$)).tw.

27 or/18-26

2817 and 27

\section{CINAHL on Ovid}

1 Chest Pain/

2 "syndrome $x$ ".tw.

3 microvascular angina.tw.

4 cardiac syndrome $\$$.tw.

5 chest pain\$.tw.

6 ((thorax or thoracic) adj1 pain\$).tw.

7 Angina Pectoris/

8 angina.tw.

9 (normal adj5 coronary).tw.

10 (normal adj5 angiogram\$).tw.

11 (normal adj5 anatomy).tw.

12 or/9-11

137 or 8

1412 and 13

15 exp Psychotherapy/

16 exp Counseling/

17 psychotherap $\$ . t w$.

18 counsel\$.tw.

19 psychodynamic $\$ . t w$.

20 (behavio $\$$ adj3 therap\$).tw.

21 (cognitiv\$ adj3 therap\$).tw.

22 psychologic\$.tw.

23 (relaxation adj5 (treat\$ or therap\$ or technique\$)).tw.

Psychological interventions for symptomatic management of non-specific chest pain in patients with normal coronary anatomy (Review) 
24 or/ $1-6,14$

25 or/ $15-23$

2624 and 25

\section{PsycLIT}

\#23 ((((thorax or thoracic) next pain) or (cardiac syndrome*) or (microvascular angina) or (chest pain)) or (((angina) or (explode "Angina-Pectoris" in DE)) and ((normal near anatomy) or (normal near angiogram*) or (normal near coronary)))) and ((relaxation) or (psychodynamic $^{\star}$ ) or (behavio? $r^{\star}$ therap* ${ }^{\star}$ or (counsel $\left.{ }^{\star}\right)$ or (psychotherap*) or (explode "Counseling-" in DE) or (explode "Psychotherapy-" in DE))

\#22 (relaxation) or (psychodynamic ${ }^{\star}$ ) or (behavio?r* therap*) or (counsel*) or (psychotherap*) or (explode "Counseling-" in DE) or (explode "Psychotherapy-" in DE)

\#21 behavio? ${ }^{\star}$ therap*

\#20 relaxation

\#19 psychodynamic*

\#18 counsel* $^{*}$

\#17 psychotherap*

\#16 explode "Counseling-" in DE

\#15 explode "Psychotherapy-" in DE

\#14 (((thorax or thoracic) next pain) or (cardiac syndrome*) or (microvascular angina) or (chest pain)) or (((angina) or (explode "AnginaPectoris" in DE)) and ((normal near anatomy) or (normal near angiogram*) or (normal near coronary)))

\#13 ((angina) or (explode "Angina-Pectoris" in DE)) and ((normal near anatomy) or (normal near angiogram) or (normal near coronary)) \#12 (normal near anatomy) or (normal near angiogram) or (normal near coronary)

\#11 normal near anatomy

\#10 normal near angiogram*

\#9 normal near coronary

\#8 (angina) or (explode "Angina-Pectoris" in DE)

\#7 angina

\#6 explode "Angina-Pectoris" in DE

\#5 ((thorax or thoracic) next pain) or (cardiac syndrome*) or (microvascular angina) or (chest pain)

\#4 (thorax or thoracic) next pain

\#3 cardiac syndrome*

\#2 microvascular angina

\#1 chest pain

\section{BIOSIS (EDINA)}

((al: (relaxation)) or (al: ((behavio* $w$ therap $\left.{ }^{\star}\right)$ or $\left(\operatorname{cognitiv}^{\star} w\right.$ therap $\left.{ }^{\star}\right)$ or psychotherap ${ }^{\star}$ or counsel ${ }^{\star}$ or psychologic or psychodynamic $\left.\left.\left.^{\star}\right)\right)\right)$ and ((((al: ((normal w angiogram* $)$ or (normal with coronary) or (normal w anatomy))) and al: (angina)) or (al: ((chest w pain) or (microvascula* w angina) or (cardiac w syndrome)))) and (al: ((clin* $n 3$ trial $\left.{ }^{\star}\right)$ or random ${ }^{\star}$ or singl ${ }^{\star}$ or doubl* or blind ${ }^{\star}$ or mask $^{\star}$ or placebo* or (clin* n3 study) or controlled)))

\section{Appendix 2. 2008 search strategies}

\section{CENTRAL on the Cochrane LIbrary}

\#1 MeSH descriptor chest pain this term only \#2 chest next pain in All Text \#3 thorax next pain in All Text \#4 thoracic next pain in All Text \#5 MeSH descriptor Microvascular Angina explode all trees \#6 cardiac next syndrome* in All Text \#7 microvascular next angina in All Text \#8 ( ( ( ( ( (\#1 or \#2) or \#3) or \#4) or \#5) or \#6) or \#7)

$\# 9$ angina in All Text

\#10 (normal in All Text near/6 coronary in All Text)

\#11 (normal in All Text near/6 angiogram* in All Text)

\#12 (normal in All Text near/6 anatomy in All Text)

$\# 13$ ( (\#10 or \#11) or \#12)

$\# 14$ (\#13 and \#9)

\#15 (\#14 or \#8)

\#16 MeSH descriptor PSYCHOTHERAPY explode all trees

\#17 psychotherap* in All Text

\#18 (cognitive in All Text near/6 therap* in All Text)

Psychological interventions for symptomatic management of non-specific chest pain in patients with normal coronary anatomy (Review) 
\#19 (behaviour* in All Text near/6 therap* in All Text)

\#20 (behavior* in All Text near/6 therap* in All Text) 7551

\#21 MeSH descriptor COUNSELING explode all trees

\#22 counsel* in All Text

\#23 psychodynamic* in All Text

\#24 (relax* in All Text near/6 therap* in All Text)

\#25 psychologic ${ }^{*}$ in All Text

\#26 hyperventilation in All Text

\#27 (breath* in All Text near/6 control* in All Text)

$\# 28$ (\#16 or \#17 or \#18 or \#19 or \#20 or \#21 or \#22 or \#23 or \#24 or \#25 or \#26 or \#27)

\#29 (\#15 and \#28) 148

\section{MEDLINE on Ovid}

1 Chest Pain/ (6468)

2 exp Microvascular Angina/ (727)

3 "syndrome x".tw. (1275)

4 microvascular angina.tw. (150)

5 cardiac syndrome\$.tw. (339)

6 chest pain\$.tw. (16817)

7 ((thorax or thoracic) adj1 pain\$).tw. (731)

8 cardiac syndrome\$.tw. (339)

9 or/1-8 (21108)

10 Angina Pectoris/ (28905)

11 angina.tw. (37131)

12 (normal adj5 coronary).tw. (6979)

13 (normal adj5 angiogram\$).tw. (1260)

14 (normal adj5 anatomy).tw. (4111)

15 or/12-14 (11535)

1610 or $11(49340)$

1715 and 16 (1725)

189 or 17 (22123)

19 exp Psychotherapy/ (122234)

20 exp Counseling/ (26136)

21 psychotherap\$.tw. (24990)

22 counsel\$.tw. (44851)

23 psychodynamic\$.tw. (4079)

24 (behavio\$ adj3 therap\$).tw. (9026)

25 (cognitiv\$ adj3 therap\$).tw. (5666)

26 psychologic $\$ . t w .(93626)$

27 exp "Mind-Body and Relaxation Techniques"/ (33980)

28 (relaxation adj5 (treat\$ or therap\$ or technique\$)).tw. (3240)

29 cbt.tw. (2105)

30 guided imagery.tw. (330)

31 (hyperventilat\$ adj3 control\$).tw. (235)

32 (hyperventilat $\$$ adj5 (treat $\$$ or therap\$ or technique\$)).tw. (404)

33 (talk\$ adj3 (therap\$ or treat\$)).tw. (180)

34 or/19-33 (282622)

3534 and 18 (414)

36 randomized controlled trial.pt. (269477)

37 controlled clinical trial.pt. (80776)

38 Randomized controlled trials/ (58509)

39 random allocation/ (63710)

40 double blind method/ (101566)

41 single-blind method/ (12762)

42 or/36-41 (454816)

43 exp animal/ not humans/ (3412892)

4442 not 43 (425364)

45 clinical trial.pt. (460981)

46 exp Clinical Trials as Topic/ (215116)

47 (clin\$ adj25 trial\$).ti,ab. (155757)

48 ((singl\$ or doubl\$ or trebl\$ or tripl\$) adj (blind\$ or mask\$)).ti,ab. (98377) 
49 placebos/ (28390)

50 placebo\$.ti,ab. (115404)

51 random $\$ . t i, a b$. (435396)

52 research design/ (55352)

53 or/45-52 (961765)

5453 not 43 (892832)

5544 or 54 (919159)

5635 and 55 (70)

57 limit 56 to yr="2002 - 2008" (30)

\section{EMBASE on Ovid <to 2008 Week 49>}

1 Thorax Pain/ (19589)

2 Syndrome X/ (1145)

3 "syndrome x".tw. (1187)

4 microvascular angina.tw. (151)

5 cardiac syndrome\$.tw. (245)

6 chest pain\$.tw. (14796)

7 ((thorax or thoracic) adj1 pain\$).tw. (611)

8 cardiac syndrome\$.tw. (245)

9 or/1-8 (27777)

10 Angina Pectoris/ (25627)

11 angina.tw. (29619)

12 (normal adj5 coronary).tw. (6060)

13 (normal adj5 angiogram\$).tw. (1075)

14 (normal adj5 anatomy).tw. (3182)

15 or/12-14 (9561)

1610 or 11 (40997)

1715 and 16 (1485)

189 or 17 (28598)

19 exp Psychiatric treatment/ (115676)

20 exp Counseling/ (46367)

21 psychotherap\$.tw. (22346)

22 counsel\$.tw. (36138)

23 psychodynamic\$.tw. (4102)

24 (behavio $\$$ adj3 therap\$).tw. (9850)

25 (cognitiv\$ adj3 therap\$).tw. (7174)

26 psychologic $\$ . t w . ~(79410)$

27 (relaxation adj5 (treat\$ or therap\$ or technique\$)).tw. (2922)

28 cbt.tw. (2504)

29 guided imagery.tw. (233)

30 (hyperventilat\$ adj3 control\$).tw. (175)

31 (hyperventilat\$ adj5 (treat\$ or therap\$ or technique\$)).tw. (317)

32 (talk\$ adj3 (therap\$ or treat\$)).tw. (143)

33 or/19-32 (242638)

3433 and 18 (717)

35 controlled clinical trial/ (54279)

36 random $\$ . t w$. (384980)

37 randomized controlled trial/ (163469)

38 follow-up.tw. (346476)

39 double blind procedure/ (70681)

40 placebo\$.tw. (108133)

41 placebo/ (120719)

42 factorial\$.ti,ab. (8024)

43 (crossover\$ or cross-over\$).ti,ab. (38882)

44 (double\$ adj blind\$).ti,ab. (83559)

45 (singl\$ adj blind\$).ti,ab. (7337)

46 assign\$.ti,ab. (106482)

47 allocat\$.ti,ab. (33672)

48 volunteer\$.ti,ab. (97667)

49 Crossover Procedure/ (20766)

50 Single Blind Procedure/ (7842) 
51 or/35-50 (1002039)

5234 and 51 (218)

\section{PsycINFO on Ovid < to December Week 12008}

1 Thorax/ (220)

2 Pain/ (10982)

31 and 2 (124)

4 "syndrome $x " . t w . ~(34)$

5 microvascular angina.tw. (1)

6 cardiac syndrome $\$ . t w . ~(7)$

7 chest pain\$.tw. (588)

8 ((thorax or thoracic) adj1 pain\$).tw. (18)

9 or/3-8 (644)

10 Angina Pectoris/ (228)

11 angina.tw. (614)

12 (normal adj5 coronary).tw. (58)

13 (normal adj5 angiogram\$).tw. (9)

14 (normal adj5 anatomy).tw. (58)

15 or/12-14 (121)

1610 or $11(632)$

1715 and $16(8)$

189 or $17(644)$

19 exp Psychotherapy/ (134584)

20 exp Counseling/ (54251)

21 psychotherap\$.tw. (79096)

22 counsel\$.tw. (69295)

23 psychodynamic $\$ . t w .(15557)$

24 (behavio $\$$ adj3 therap\$).tw. (20467)

25 (cognitiv\$ adj3 therap\$).tw. (13689)

26 psychologic\$.tw. (208058)

27 (relaxation adj5 (treat\$ or therap\$ or technique\$)).tw. (3337)

28 cbt.tw. (3295)

29 guided imagery.tw. (795)

30 (hyperventilat\$ adj3 control\$).tw. (29)

31 (hyperventilat\$ adj5 (treat\$ or therap\$ or technique\$)).tw. (91)

32 (talk\$ adj3 (therap\$ or treat\$)).tw. (562)

33 or/19-32 (428634)

3433 and 18 (171)

35 clinical trials/ (2481)

36 "Empirical Study".md. (1109008)

37 random\$.tw. (77684)

38 groups.tw. (261176)

39 (double adj3 blind).tw. (12272)

40 (single adj3 blind).tw. (818)

41 experimental design/ (7154)

42 controlled.tw. (49420)

43 (clinical adj3 study).tw. (5165)

44 trial.tw. (41661)

45 or/35-44 (1267552)

4634 and 45 (109)

47 limit 46 to yr="2002 - 2008" (40)

\section{CINAHL ON EBSCO}

( (MH "Clinical Trials+") or ( random* or rct or groups or trial or "clinical study" ) ) and ( (MH "Syndrome X") or (MH "Chest Pain") or ( "chest pain" or "microvascular angina" ) ) and ( (MH "Psychology, Applied+") or (MH "Psychotherapy+") or ( psychol* or counsel* or talk* or relaxation or hyperventilat* or CBT or cognitive or behavio*))

\section{BIOSIS on ISI Web of Knowledge}

\# 352 \#1 and \#2 AND Taxa Notes=(Humans)

Databases=PREVIEWS Timespan=2002-2008

Psychological interventions for symptomatic management of non-specific chest pain in patients with normal coronary anatomy (Review) 
\# 2715 (ts=(angina and ((normal same angiogram *) or (normal same coronary) or (normal same anatomy))) or ts= ("microvascular angina" or "chest pain") ) and TS=(random* or trial or RCT or groups or controlled or (double same blind) or (single same blind)) AND Taxa Notes $=$ (Humans)

Databases=PREVIEWS Timespan=2002-2008

\# 1989 ts=(psychotherap* or counsel* or psychologic* or psychodynamic* or talk or talking or (behavio* same therap*) or (cognitive same therap $\left.^{\star}\right)$ or CBT or hyperventilat $\left.{ }^{\star}\right)$ and $\mathrm{ts}=($ chest or angina or thora*)

Databases=PREVIEWS Timespan $=2002-2008$

\section{Appendix 3. 2011 search strategies}

\section{CENTRAL AND DARE (the Cochrane Library)}

\#1 MeSH descriptor Chest Pain, this term only

\#2 chest next pain

\#3 thorax next pain

\#4 thoracic next pain

\#5 MeSH descriptor Microvascular Angina, this term only

\#6 cardiac next syndrome*

$\# 7$ microvascular next angina

\#8 (\#1 OR \#2 OR \#3 OR \#4 OR \#5 OR \#6 OR \#7)

\#9 angina

\#10 normal near/6 coronary

\#11 normal near/6 coronary

\#12 normal near/6 anatomy

\#13 (\#10 OR \#11 OR \#12)

\#14 (\#9 AND \#13)

\#15 (\#8 OR \#14)

\#16 MeSH descriptor Psychotherapy explode all trees

\#17 psychotherap*

\#18 cognitive near/6 therap*

\#19 behaviour* near/6 therap*

\#20 behavior ${ }^{\star}$ near/6 therap*

\#21 MeSH descriptor Counseling explode all trees

\#22 counsel $^{*}$

\#23 psychodynamic*

\#24 relax* near/6 therap*

\#25 psychologic*

\#26 hyperventilation

\#27 breath* near 6 control $^{*}$

\#28 (\#16 OR \#17 OR \#18 OR \#19 OR \#20 OR \#21 OR \#22 OR \#23 OR \#24 OR \#25 OR \#26 OR \#27)

\#29 (\#15 AND \#28)

\section{MEDLINE (OVID)}

1. Chest Pain/

2. exp Microvascular Angina/

3. "syndrome x".tw.

4. microvascular angina.tw.

5. cardiac syndrome ${ }^{\star}$.tw.

6. chest pain ${ }^{\star}$. tw.

7. ((thorax or thoracic) adj1 pain*).tw.

8. cardiac syndrome*.tw.

9. or/1-8

10. Angina Pectoris/

11. angina.tw.

12. (normal adj5 coronary).tw.

13. (normal adj5 angiogram ${ }^{\star}$ ).tw.

14. (normal adj5 anatomy).tw.

15. or/12-14

16. 10 or 11

17. 15 and 16

18. 9 or 17

19. exp Psychotherapy/

Psychological interventions for symptomatic management of non-specific chest pain in patients with normal coronary anatomy (Review) 
20. exp Counseling/

21. psychotherap*.tw.

22. counsel ${ }^{\star}$.tw.

23. psychodynamic ${ }^{\star}$. tw.

24. (behavio* adj3 therap*).tw.

25. (cognitiv ${ }^{\star}$ adj3 therap $\left.{ }^{\star}\right)$.tw.

26. psychologic ${ }^{\star}$.tw.

27. exp Mind-Body Therapies/

28. (relaxation adj5 (treat ${ }^{\star}$ or therap* ${ }^{\star}$ or technique $\left.{ }^{\star}\right)$ ).tw.

29. cbt.tw.

30. guided imagery.tw.

31. (hyperventilate* adj3 control*).tw.

32. (hyperventilate ${ }^{\star}$ adj5 (treat ${ }^{\star}$ or therap $^{\star}$ or technique $\left.{ }^{\star}\right)$ ).tw.

33. (talk* adj3 (therap* ${ }^{\star}$ or treat $\left.\left.{ }^{\star}\right)\right)$. tw.

34. or/19-33

35. 34 and 18

36. randomized controlled trial.pt.

37. controlled clinical trial.pt.

38. randomized.ab.

39. placebo.ab.

40. drug therapy.fs.

41. randomly.ab.

42. trial.ab.

43. groups.ab.

44. 36 or 37 or 38 or 39 or 40 or 41 or 42 or 43

45. exp animals/ not humans.sh.

46. 44 not 45

47.35 and 46

48. $\left(2008121^{\star}\right.$ or $2008122^{\star}$ or $2008123^{\star}$ or $2009^{\star}$ or $2010^{\star}$ or $\left.2011^{\star}\right)$.ed.

49. 47 and 48

EMBASE (OVID)

1. thorax pain/

2. Syndrome X/

3. "syndrome $x$ ".tw.

4. microvascular angina.tw.

5. cardiac syndrome ${ }^{\star}$.tw.

6. chest pain ${ }^{\star}$.tw.

7. ((thorax or thoracic) adj1 pain $\left.{ }^{\star}\right)$.tw.

8. cardiac syndrome ${ }^{\star}$.tw.

9. or/1-8

10. angina pectoris/

11. angina.tw.

12. (normal adj5 coronary).tw.

13. (normal adj5 angiogram ${ }^{\star}$ ).tw.

14. (normal adj5 anatomy).tw.

15. or/12-14

16. 10 or 11

17. 15 and 16

18. 9 or 17

19. exp psychiatric treatment/

20. exp counseling/

21. psychotherap*.tw.

22. counsel ${ }^{\star}$.tw.

23. psychodynamic ${ }^{\star}$.tw.

24. (behavio* adj3 therap*).tw.

25. (cognitiv ${ }^{\star}$ adj3 therap $\left.{ }^{\star}\right)$.tw.

26. psychologic ${ }^{\star}$. tw.

27. (relaxation adj5 (treat ${ }^{\star}$ or therap* or technique $\left.\left.^{\star}\right)\right)$.tw.

28. cbt.tw.

29. guided imagery.tw.

Psychological interventions for symptomatic management of non-specific chest pain in patients with normal coronary anatomy (Review) 
30. (hyperventilat ${ }^{\star}$ adj3 control*).tw.

31. (hyperventilat ${ }^{\star}$ adj5 (treat ${ }^{\star}$ or therap ${ }^{\star}$ or technique $\left.{ }^{\star}\right)$ ).tw.

32. $\left(\right.$ talk $^{\star} \operatorname{adj} 3$ (therap* or treat $\left.\left.{ }^{\star}\right)\right)$.tw.

33. or/19-32

34. 33 and 18

35. random\$.tw.

36. factorial\$.tw.

37. crossover\$.tw.

38. cross over\$.tw.

39. cross-over\$.tw.

40. placebo\$.tw.

41. (doubl\$ adj blind\$).tw.

42. (singl\$ adj blind\$).tw.

43. assign\$.tw.

44. allocat\$.tw.

45. volunteer\$.tw.

46. crossover procedure/

47. double blind procedure/

48. randomized controlled trial/

49. single blind procedure/

50.35 or 36 or 37 or 38 or 39 or 40 or 41 or 42 or 43 or 44 or 45 or 46 or 47 or 48 or 49

51. (animal/or nonhuman/) not human/

52.50 not 51

53.34 and 52

54. limit 53 to embase

55. $\left(2008121^{\star}\right.$ or $2008122^{\star}$ or $2008123^{\star}$ or $2009^{\star}$ or $2010^{\star}$ or $\left.2011^{\star}\right)$.dd.

56.54 and 55

\section{PsycINFO (OVID)}

The RCT filter has been amended as an adaption of the Cochrane RCT filters used for MEDLINE and EMBASE.

\section{Thorax/}

2. Pain/

3. 1 and 2

4. "syndrome x".tw.

5. microvascular angina.tw.

6. cardiac syndrome ${ }^{\star}$.tw.

7. chest pain ${ }^{\star} . t w$.

8. ((thorax or thoracic) adj1 pain $\left.{ }^{\star}\right)$.tw.

9. or/3-8

10. Angina Pectoris/

11. angina.tw.

12. (normal adj5 coronary).tw.

13. (normal adj5 angiogram*).tw.

14. (normal adj5 anatomy).tw.

15. or/12-14

16. 10 or 11

17. 15 and 16

18. 9 or 17

19. exp Psychotherapy/

20. exp Counseling/

21. psychotherap ${ }^{*}$.tw.

22. counsel ${ }^{\star}$. tw.

23. psychodynamic ${ }^{\star}$.tw.

24. (behavio* adj3 therap $\left.{ }^{\star}\right)$.tw.

25. (cognitiv ${ }^{\star}$ adj3 therap $\left.{ }^{\star}\right)$.tw.

26. psychologic ${ }^{\star}$.tw.

27. (relaxation adj5 (treat ${ }^{\star}$ or therap ${ }^{\star}$ or technique $\left.{ }^{\star}\right)$ ).tw.

28. cbt.tw.

29. guided imagery.tw.

30. (hyperventilat ${ }^{\star}$ adj 3 control $\left.^{\star}\right)$.tw.

31. (hyperventilat ${ }^{\star}$ adj5 (treat* or therap* or technique*)).tw.

Psychological interventions for symptomatic management of non-specific chest pain in patients with normal coronary anatomy (Review) 
32. $\left(\right.$ talk $^{\star}$ adj3 (therap ${ }^{\star}$ or treat $\left.\left.{ }^{\star}\right)\right)$. tw.

33. or/19-32

34. 33 and 18

35. random $\$$.tw.

36. factorial\$.tw.

37. crossover\$.tw.

38. cross-over\$.tw.

39. placebo $\$$.tw.

40. (doubl\$ adj blind\$).tw.

41. (singl\$ adj blind\$).tw.

42. assign\$.tw.

43. allocat\$.tw.

44. volunteer\$.tw.

45. control*.tw.

46. "2000".md.

47. or/35-46

48. 34 and 47

49. $\left(2008121^{\star}\right.$ or $2008122^{\star}$ or $2008123^{\star}$ or $2009^{\star}$ or $2010^{\star}$ or $\left.2011^{\star}\right)$.up.

50.48 and 49

CINAHL Plus (EBSCO)

CS17 S15 and S16

S16 EM 20081210-20110909

S15 S11 and S14

S14 S12 or S13

S13 (random* or rct or groups or trial or "clinical study")

S12 (MH "Clinical Trials+")

S11 S5 and S10

$\mathrm{S} 10 \mathrm{~S} 6$ or $\mathrm{S} 7$ or $\mathrm{S} 8$ or $\mathrm{S} 9$

S9 AB (psychol* or counsel* or talk* or relaxation or hyperventilat* or CBT or cognitive or behavio*)

S8 TI (psychol* or counsel* or talk* or relaxation or hyperventilat* or CBT or cognitive or behavio*)

S7 (MH "Psychotherapy+")

S6 (MH "Psychology, Applied+")

S5 S1 or S2 or S3 or S4

S4 (TI "microvascular angina") or (AB "microvascular angina")

S3 (TI "chest pain") or (AB "chest pain")

S2 (MH "Chest Pain")

S1 (MH "Syndrome X")

\section{BIOSIS (ISI Web of Knowledge)}

\#6 \#5 AND \#4 AND \#3

\#5 TS=(random ${ }^{\star}$ or trial or RCT or groups or controlled or (double same blind) or (single same blind))

\#4 TS=(angina and ((normal same angiogram $\left.{ }^{\star}\right)$ or (normal same coronary) or (normal same anatomy)))

\#3 \#2 AND \#1

\#2 TS=(psychotherap* ${ }^{\star}$ or counsel ${ }^{\star}$ or psychologic ${ }^{\star}$ or psychodynamic ${ }^{\star}$ or talk or talking or (behavio* same therap ${ }^{\star}$ ) or (cognitive same therap ${ }^{\star}$ ) or CBT or hyperventilat $\left.{ }^{\star}\right)$

\#1 TS=(chest or angina or thora*)

\section{Appendix 4. 2014 search strategies}

\section{CENTRAL and DARE}

\#1MeSH descriptor Chest Pain, this term only

\#2chest next pain

\#3thorax next pain

\#4thoracic next pain

\#5MeSH descriptor Microvascular Angina, this term only

\#6cardiac next syndrome*

\#7microvascular next angina

\#8(\#1 OR \#2 OR \#3 OR \#4 OR \#5 OR \#6 OR \#7)

\#9angina

\#10normal near/6 coronary

Psychological interventions for symptomatic management of non-specific chest pain in patients with normal coronary anatomy (Review) 
\#11normal near/6 coronary

\#12normal near/6 anatomy

\#13(\#10 OR \#11 OR \#12)

\#14(\#9 AND \#13)

\#15(\#8 OR \#14)

\#16MeSH descriptor Psychotherapy explode all trees

\#17psychotherap*

\#18cognitive near/6 therap*

\#19behaviour* near/6 therap*

\#20behavior ${ }^{\star}$ near/6 therap*

\#21MeSH descriptor Counseling explode all trees

\#22 counsel ${ }^{*}$

\#23psychodynamic ${ }^{\star}$

\#24relax* near/6 therap*

\#25psychologic*

\#26hyperventilation

\#27breath* near/6 control ${ }^{*}$

\#28(\#16 OR \#17 OR \#18 OR \#19 OR \#20 OR \#21 OR \#22 OR \#23 OR \#24 OR \#25 OR \#26 OR \#27)

\#29(\#15 AND \#28)

\section{MEDLINE OVID}

1. Chest Pain/

2. exp Microvascular Angina/

3. "syndrome $x " . t w$.

4. microvascular angina.tw.

5. cardiac syndrome*.tw.

6. chest pain ${ }^{\star}$.tw.

7. ((thorax or thoracic) adj1 pain*).tw.

8. cardiac syndrome*.tw.

9. or/1-8

10. Angina Pectoris/

11. angina.tw.

12. (normal adj5 coronary).tw.

13. (normal adj5 angiogram ${ }^{\star}$ ).tw.

14. (normal adj5 anatomy).tw.

15. or/12-14

16. 10 or 11

17.15 and 16

18. 9 or 17

19. exp Psychotherapy/

20. exp Counseling/

21. psychotherap ${ }^{\star}$. tw.

22. counsel*.tw.

23. psychodynamic ${ }^{\star}$.tw.

24. (behavio* adj3 therap*).tw.

25. (cognitiv ${ }^{\star}$ adj3 therap $\left.{ }^{\star}\right)$.tw.

26. psychologic ${ }^{\star} . t w$.

27. exp Mind-Body Therapies/

28. (relaxation adj5 (treat* ${ }^{\star}$ or therap ${ }^{\star}$ or technique $\left.{ }^{\star}\right)$ ).tw.

29. cbt.tw.

30. guided imagery.tw.

31. (hyperventilate* $\operatorname{adj}$ control $\left.^{\star}\right)$.tw.

32. (hyperventilate ${ }^{\star}$ adj5 (treat ${ }^{\star}$ or therap* ${ }^{\star}$ or technique $\left.{ }^{\star}\right)$ ).tw.

33. (talk* adj3 (therap ${ }^{\star}$ or treat $\left.\left.{ }^{\star}\right)\right)$.tw.

34. or/19-33

35. 34 and 18

36. randomized controlled trial.pt.

37. controlled clinical trial.pt.

38. randomized.ab.

39. placebo.ab.

40. drug therapy.fs.

Psychological interventions for symptomatic management of non-specific chest pain in patients with normal coronary anatomy (Review) 
41. randomly.ab.

42. trial.ab.

43. groups.ab.

44.36 or 37 or 38 or 39 or 40 or 41 or 42 or 43

45. exp animals/ not humans.sh.

46. 44 not 45

47.35 and 46

$48 .\left(201108^{\star}\right.$ or $201109^{\star}$ or $201110^{\star}$ or $201111^{\star}$ or $201112^{\star}$ or $2012^{\star}$ or $2013^{\star}$ or $\left.2014^{\star}\right)$.ed.

49.47 and 48

\section{EMBASE OVID}

1. thorax pain/

2. Syndrome X/

3. "syndrome x".tw.

4. microvascular angina.tw.

5. cardiac syndrome ${ }^{\star}$.tw.

6. chest pain ${ }^{\star}$. tw.

7. ((thorax or thoracic) adj1 pain*).tw.

8. cardiac syndrome ${ }^{\star}$.tw.

9. or/1-8

10. angina pectoris/

11. angina.tw.

12. (normal adj5 coronary).tw.

13. (normal adj5 angiogram*).tw.

14. (normal adj5 anatomy).tw.

15. or/12-14

16. 10 or 11

17. 15 and 16

18. 9 or 17

19. exp psychiatric treatment/

20. exp counseling/

21. psychotherap ${ }^{\star}$.tw.

22. counsel $^{\star}$.tw.

23. psychodynamic*.tw.

24. (behavio* adj3 therap*).tw.

25. $\left(\right.$ cognitiv $^{\star}$ adj3 therap $\left.{ }^{\star}\right)$.tw.

26. psychologic ${ }^{\star}$.tw.

27. (relaxation adj5 (treat ${ }^{\star}$ or therap ${ }^{\star}$ or technique $\left.\left.{ }^{\star}\right)\right)$.tw.

28. cbt.tw.

29. guided imagery.tw.

30. (hyperventilat ${ }^{\star}$ adj3 control $\left.^{\star}\right)$.tw.

31. (hyperventilat* adj5 (treat ${ }^{\star}$ or therap ${ }^{\star}$ or technique $\left.{ }^{\star}\right)$ ).tw.

32. $\left(\right.$ talk $^{\star}$ adj3 $\left(\right.$ therap $^{\star}$ or treat $\left.\left.{ }^{\star}\right)\right)$.tw.

33. or/19-32

34. 33 and 18

35. random\$.tw.

36. factorial\$.tw.

37. crossover\$.tw.

38. cross over\$.tw.

39. cross-over\$.tw.

40. placebo\$.tw.

41. (doubl\$ adj blind\$).tw.

42. (singl\$ adj blind\$).tw.

43. assign\$.tw.

44. allocat $\$$.tw.

45. volunteer\$.tw.

46. crossover procedure/

47. double blind procedure/

48. randomized controlled trial/

49. single blind procedure/

50.35 or 36 or 37 or 38 or 39 or 40 or 41 or 42 or 43 or 44 or 45 or 46 or 47 or 48 or 49

Psychological interventions for symptomatic management of non-specific chest pain in patients with normal coronary anatomy (Review) 
51. (animal/ or nonhuman/) not human/

52. 50 not 51

53.34 and 52

54. limit 53 to embase

55. $\left(201108^{\star}\right.$ or $201109^{\star}$ or $201110^{\star}$ or $201111^{\star}$ or $201112^{\star}$ or $2012^{\star}$ or $2013^{\star}$ or $\left.2014^{\star}\right)$.dd.

56.54 and 55

\section{PsycINFO OVID}

1. Thorax/

2. Pain/

3. 1 and 2

4. "syndrome $x " . t w$.

5. microvascular angina.tw.

6. cardiac syndrome ${ }^{\star}$.tw.

7. chest pain*.tw.

8. ((thorax or thoracic) adj1 pain $\left.{ }^{\star}\right)$.tw.

9. or/3-8

10. Angina Pectoris/

11. angina.tw.

12. (normal adj5 coronary).tw.

13. (normal adj5 angiogram $\left.{ }^{\star}\right)$.tw.

14. (normal adj5 anatomy).tw.

15. or/12-14

16. 10 or 11

17.15 and 16

18. 9 or 17

19. exp Psychotherapy/

20. exp Counseling/

21. psychotherap*.tw.

22. counsel ${ }^{\star}$. tw.

23. psychodynamic*.tw.

24. (behavio* adj3 therap*).tw.

25. (cognitiv ${ }^{\star}$ adj 3 therap $\left.{ }^{\star}\right)$.tw.

26. psychologic ${ }^{\star}$. tw.

27. (relaxation adj5 (treat ${ }^{\star}$ or therap ${ }^{\star}$ or technique $\left.\left.{ }^{\star}\right)\right)$.tw.

28. cbt.tw.

29. guided imagery.tw.

30. (hyperventilat ${ }^{\star}$ adj3 control $\left.^{\star}\right)$.tw.

31. (hyperventilat* adj5 (treat ${ }^{\star}$ or therap* ${ }^{\star}$ or technique $\left.{ }^{\star}\right)$ ).tw.

32. (talk* adj3 (therap* or treat $\left.\left.^{\star}\right)\right)$. tw.

33. or/19-32

34.33 and 18

35. random\$.tw.

36. factorial\$.tw.

37. crossover\$.tw.

38. cross-over\$.tw.

39. placebo\$.tw.

40. (doubl\$ adj blind\$).tw.

41. (singl\$ adj blind\$).tw.

42. assign\$.tw.

43. allocat\$.tw.

44. volunteer\$.tw.

45. control*.tw.

46. "2000".md.

47. or/35-46

48. 34 and 47

49. $\left(201108^{\star}\right.$ or $201109^{\star}$ or $201110^{\star}$ or $201111^{\star}$ or $201112^{\star}$ or $2012^{\star}$ or $2013^{\star}$ or $\left.2014^{\star}\right)$.up.

50.48 and 49

\section{CINAHL Plus EBSCO}

\section{S17 S15 and S16}

Psychological interventions for symptomatic management of non-specific chest pain in patients with normal coronary anatomy (Review) 
S16 EM 20110901-20140506

S15 S11 and S14

S14 S12 or S13

S13 (random* or rct or groups or trial or "clinical study")

S12 (MH "Clinical Trials+")

S11 S5 and S10

$\mathrm{S} 10 \mathrm{~S} 6$ or $\mathrm{S} 7$ or $\mathrm{S} 8$ or $\mathrm{S} 9$

S9 AB (psychol* or counsel* or talk* or relaxation or hyperventilat* or CBT or cognitive or behavio*)

S8 TI (psychol ${ }^{\star}$ or counsel* or talk* or relaxation or hyperventilat ${ }^{\star}$ or CBT or cognitive or behavio*)

S7 (MH "Psychotherapy+")

S6 (MH "Psychology, Applied+")

$\mathrm{S} 5 \mathrm{~S} 1$ or $\mathrm{S} 2$ or $\mathrm{S} 3$ or $\mathrm{S} 4$

S4 (TI "microvascular angina") or (AB "microvascular angina")

S3 (TI "chest pain") or (AB "chest pain")

S2 (MH "Chest Pain")

S1 (MH "Syndrome X")

\section{BIOSIS}

\#6 \#5 AND \#4 AND \#3 Timespan=2011-2014

\#5 TS=(random* or trial or RCT or groups or controlled or (double same blind) or (single same blind))

\#4 TS=(angina and ((normal same angiogram $\left.{ }^{\star}\right)$ or (normal same coronary) or (normal same anatomy)))

\#3 \#2 AND \#1

\#2 TS=(psychotherap* ${ }^{\star}$ or counsel* or psychologic ${ }^{\star}$ or psychodynamic ${ }^{\star}$ or talk or talking or (behavio* same therap ${ }^{\star}$ ) or (cognitive same therap ${ }^{\star}$ ) or CBT or hyperventilat*)

\#1 TS=(chest or angina or thora*)

\section{WHAT'S NEW}

\begin{tabular}{lll}
\hline Date & Event & Description \\
\hline 26 March 2021 & Review declared as stable & $\begin{array}{l}\text { The evidence is current to 6 May 2014. Conclusions have not } \\
\text { changed since publication in 2005 despite adding nine more } \\
\text { studies. }\end{array}$ \\
\hline
\end{tabular}

\section{H I S T O R Y}

Protocol first published: Issue 1, 2003

Review first published: Issue 1, 2005

\begin{tabular}{lll}
\hline Date & Event & Description \\
\hline 9 July 2014 & $\begin{array}{l}\text { New citation required but conclusions } \\
\text { have not changed }\end{array}$ & The review conclusions have not changed. \\
\hline 21 May 2014 & New search has been performed & $\begin{array}{l}\text { We updated search strategies and performed literature searches } \\
\text { up to 06 May 2014. We included one new study and an additional } \\
\text { paper to an already included study. }\end{array}$ \\
\hline
\end{tabular}

30 November $2011 \quad$ New search has been performed

We updated search strategies and performed literature searches up to September 2011. We included five new studies and an additional paper to an already included study. The conclusions were essentially unchanged.

21 September $2009 \quad$ New search has been performed

We updated search strategies and reran searches up to December 2008. We included two new studies and an additional paper to an already included study. We assessed 21 new studies in de- 


\begin{tabular}{lll}
\hline Date & Event & Description \\
\hline & & $\begin{array}{l}\text { tail and excluded them. The review conclusions were essentially } \\
\text { unchanged. }\end{array}$ \\
\hline 21 September 2009 & $\begin{array}{l}\text { New citation required but conclusions } \\
\text { have not changed }\end{array}$ & We added a new review author. \\
\hline 9 September 2008 & Amended & We converted to a new review format. \\
\hline 1 November 2004 & New citation required and conclusions & First version of the review was published. \\
& have changed &
\end{tabular}

\section{CONTRIBUTIONS OF AUTHORS}

Two review authors (SK, LAC) independently selected suitable studies for inclusion in the original review (Kisely 2005).

SK and AP independently selected suitable studies for subsequent updates. Where the two review authors disagreed about inclusion of a study, we resolved disagreements by consensus of opinion, or we consulted a third and fourth review author (PS, MY) if necessary.

SK, LAC or AP extracted data from the included studies. Two review authors (SK and LAC or AP) independently entered data into RevMan 2014.

\section{DECLARATIONS OF INTEREST}

SK: None known.

LAC: This review was supported by a Nova Scotia Health Research Foundation Knowledge Programs Grant.

MY: None known.

AP: None known.

\section{SOURCES OF SUPPORT}

\section{Internal sources}

- Health Outcomes Unit, Capital District Health Authority, Halifax, Canada

- Dalhousie University, Halifax, Canada

- University of Western Australia, Australia

- Fremantle Hospital, Australia

- University of Queensland, School of Population Health, Australia

\section{External sources}

- No sources of support supplied

\section{DIFFERENCES BETWEEN PROTOCOLANDREVIEW}

In the protocol we stated that we would only include RCTs where $<20 \%$ of participants originally randomised were lost to follow-up. In view of the limited number of included trials, we relaxed these criteria to include studies that combined RCT and cross-over designs, and trials that had greater losses to follow-up. In each case, we performed sensitivity analyses to assess the effect of inclusion of these studies. Given the increase in the number of studies since publication of Kisely 2005, we have presented the results of random effects models in all the tables even where there was no evidence of statistical heterogeneity. This is because we could not definitely exclude other sources of between-study variation, such as clinical heterogeneity. 


\section{NDEX TERMS}

\section{Medical Subject Headings (MeSH)}

Behavior Therapy; Chest Pain [ ${ }^{\star}$ psychology] [therapy]; Cognitive Behavioral Therapy [ ${ }^{\star}$ methods]; Coronary Vessels [ ${ }^{\star}$ anatomy \& histology]; Hypnosis; Microvascular Angina [psychology] [therapy]; Psychotherapy [methods]; Randomized Controlled Trials as Topic; Recurrence; Treatment Outcome

\section{MeSH check words}

Humans 